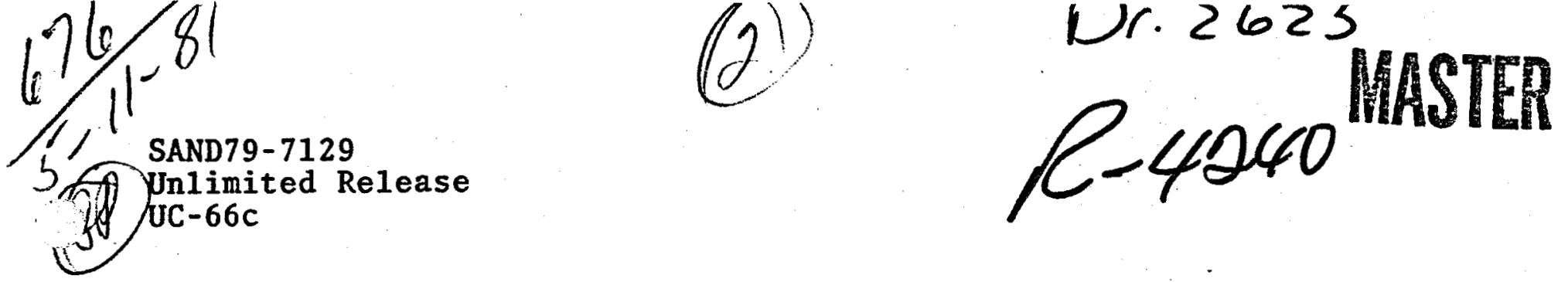

\title{
State-OF-THE-ART OF DRILLINg Thrusters
}

D. W. Dareing

Maurer Engineering, INC.

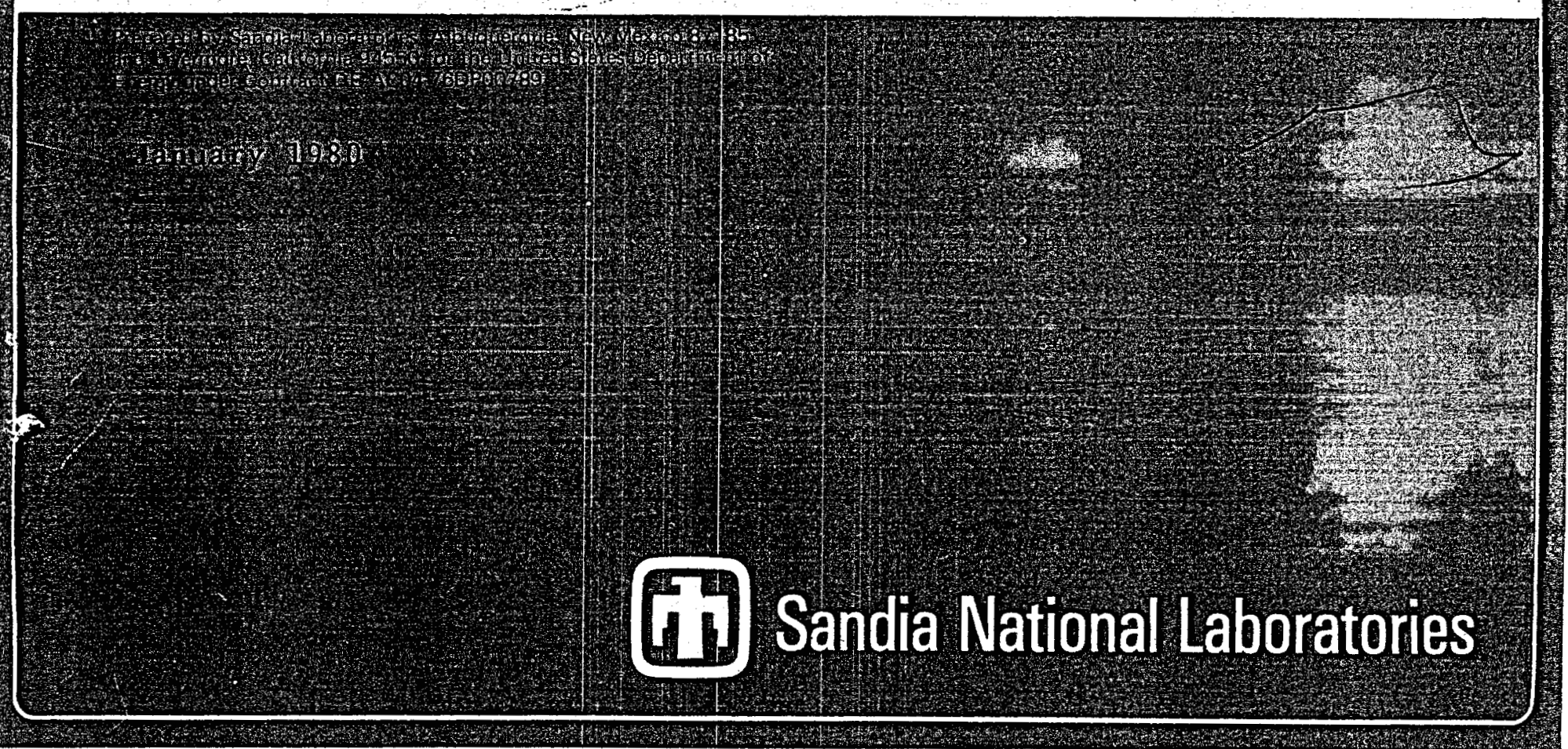

SF $2900-Q(3-80)$ 


\section{DISCLAIMER}

This report was prepared as an account of work sponsored by an agency of the United States Government. Neither the United States Government nor any agency Thereof, nor any of their employees, makes any warranty, express or implied, or assumes any legal liability or responsibility for the accuracy, completeness, or usefulness of any information, apparatus, product, or process disclosed, or represents that its use would not infringe privately owned rights. Reference herein to any specific commercial product, process, or service by trade name, trademark, manufacturer, or otherwise does not necessarily constitute or imply its endorsement, recommendation, or favoring by the United States Government or any agency thereof. The views and opinions of authors expressed herein do not necessarily state or reflect those of the United States Government or any agency thereof. 


\section{DISCLAIMER}

Portions of this document may be illegible in electronic image products. Images are produced from the best available original document. 
SAND79-7129

Unlimited Release

Printed January 1980

Category UC-66c

STATE-OF-THE-ART OF DRILLING THRUSTERS ${ }^{*}$

\author{
D. W. Dareing \\ Maurer Engineering \\ Houston, Texas
}

\begin{abstract}
Several different concepts for applying force or thrust to drill bits are identified. Recommendations for further studies of drilling thrusters are made.
\end{abstract}

\author{
Printed in the United States of America \\ Avatlable from: \\ National Technical Information Service \\ U. S. Department of Commerce \\ 5825 Port Royal Road \\ Springfield, VA 22161 \\ Price: Printed Copy \$6.75; Microfiche $\$ 3.00$
}

ॠork performed under Sandia Contract No. 13-5083; sponsored by the

Department of Energy, Division of Geothermal Energy. 
U

• 
Joe Cervik

U. S. BUREAU OF MINES

Cochran Mill Rd.

Bruceton, PA 15129 .

(412) $67.5-6400$

Maurice. Deuhl

U. S. BUREAU OF MINES

Cochran Mill Rd.

Bruceton, PA 15129

(412) $675-6400$

Pat Diamond

U. S. BUREAU OF MINES

Cochran Mill Rd.

Bruceton, PA 15129

(412) $675-6400$

Gerald Finfinger

U. S. BUREAU OF MINES

Cochran Mill Rd.

Bruceton, PA 15129

(412) 675-6400

\section{Bill Garrett}

DRILCO

(16740 Hardy St. Rd.)

P. 0. Box 60068

Houston, TX 77205

(713) $443-3370$
Jackson M. Kellner

DRILCO INDUSTRIAL

P. 0. Box 3135

Midland, TX 79702

(915) $683-5431$

David Oyler

U. S. BUREAU OF MINES

Cochran Mill Rd.

Bructeon, PA 15129

(412) $675-6400$

Joe Pasini

SCIENCE APPLICATIONS INC.

Chestnut Ridge Professional Bldg., Suite 8 Morgantown, WV 26505

(304) 599-9696

Dr. Pramod C. Thakur

CONTINENTAL OIL COMPANY

P. O. Box 4294

Morgantown, WV 26505

(304) 983-2251

Dr. Hi Imar von Schoenfeld

ISLAND CREEK COAL COMPANY

(2355 Harrodsburg Rd.)

P. 0. Box 11430

Lexington, KY 40511

(606) 276-1525 
$\mathcal{U}$

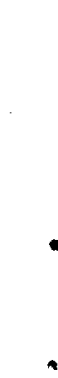

. 


\section{SUMMARY}

This study identifies several different concepts for applying force or thrust to drill bits. Some are fully developed and operational. Most are not. Present day directional wells are being successfully drilled using drill collars, stabilizers, and bent subs. As measurements-whiledrilling technology advances it will be desirable to have more direct control of axial and transverse bit force components, which can be controlled at the surface. Hydraulic bit thrusters are a prime candidate for futuristic downhole directional drilling assemblies. While they are not commonly used today, they are fully developed based on twenty years of engineering and field testing.

The selection of drilling thruster type depends on performance requirements and compatibility with other bottomhole equipment. Future directional drilling assemblies will no doubt include downhole monitoring and telemetry subsystems giving instantaneous feedback to the driller. Future drilling thrusters should therefore be controllable from the surface to allow the driller to change the course of the drill bit as downhole information is transmitted to the rig.

Further studies on drilling thrusters should be combined with design studies of bottomhole drilling assemblies which utilize recent advances in downhole monitoring and telemetry. 
$\omega$

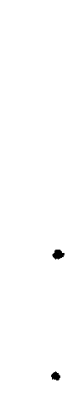




\section{CONTENTS}

INTRODUCTION

$\underline{\text { Page }}$

PERFORMANCE REQUIREMENTS

STATE-OF-THE-ART

0 il and Gas Production

17

Horizontal Drilling into Coal Seams

17

Shallow Horizontal Holes for Utility Lines and Site Investigation

Cluster Drilling 54

Underground Mining 61

CONCLUSIONS

RECOMMENDED FUTURE WORK

REFERENCES

APPENDIX -- DRILLING THRUSTER PATENTS

$0 i 1$ and Gas Production

75

Horizontal Drilling into Coal Seams

105

Shallow Horizontal Holes for Utility Lines and Site Investigation

117

Cluster Drilling

127

Underground Mining

138 
• 
INTRODUCTION

Directional drilling is important in recovering energy to meet world-wide energy demands. For example, present offshore production practices require as many as 25-30 directional wells to be drilled from one platform. Drilling multiple wells from one location allows development of offshore oil and gas fields that would otherwise be uneconomical.

Special hardware has been developed by the petroleum industry to control the path of wellbores to hit desired targets. Recently, other applications for directional drilling have emerged. They are, for example, horizontal and slanthole drilling into coal seams for drainage and recovery of methane, vertical to horizontal drilling for in situ coal gasification processes and mineral leaching, drilling curved holes for utility lines, and geothermal applications. These and other directional drilling applications will require extension of present drilling technology and hardware (1).

Present directional driling is time consuming and costly because hole monitoring or surveys and drill bit directional control is required intermittently with drilling. Drilling is stopped while surveys are being made. The ideal directional drilling system should allow continuous hole monitoring and directional control while drilling. Advances are being made in sensing and telmetering downhole information while drilling. Bit thruster hardware will be needed to give instantaneous directional control and to utilize new downhole monitoring technology.

In order to advance directional drilling technology, the Department of Energy contracted Sandia Laboratories to assess all phases of directional drilling as they currently apply to 
the fossil resource recovery and evaluate present directional drilling capabilities, hardware, and specialized designs. This information will be useful for planning future research and development.

Our report covers one phase of the total project and is therefore part of a broader study being conducted by Sandia Laboratories. Specifically, the report assesses hardware and techniques for applying force to the drill bit. The work was .conducted by Maurer Engineering Inc. as a subcontractor to Sandia Laboratories. The "Statement of Work" for this subcontracted study is:

1. "Perform a comprehensive review of existing patents that concern directional drilling thrusters. Special emphasis should be given to nonconventional techniques and equipment. other aspects such as kick-off procedures and special rigs sbould be considered. All applications are relevant and directional drilling for methane drainage from coal should be addressed."

2. "Issue a final report that details the findings in the above described review. This report should contain a description of the state-of-the-art including capabilities, deficiencies, and recommendations for solutions."

Our study began with a survey of $U$. S. and foreign patents that relate to directional drilling. From these patents, we filtered out the ones that included concepts for applying force to drill bits. A drawing from each thruster patent is given in the Appendix. Some of the patents deal with only the axial force component while others deal with the transverse force component. Both components are important in directional drilling as the bit tends to drill in the direction of the resultant bit force. The transverse force component affects directional change 
while the axial force component affects rate of penetration along the axis of the drill bit. The term "thruster" as used in this report will refer to any device or means for generating either transverse or axial bit force components.

Another source for developing our information or data base for this study was personal discussions with engineers and scientists developing bit thrusters or using them in the field. These personal discussions helped indentify thruster concepts that have reached advanced development stages. We gratefully. acknowledge the individuals who made direct input to this study. 
C

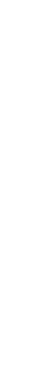

$\checkmark$ 


\section{PERFORMANCE REQUIREMENTS}

Performance requirements state specifically what is required of a given piece of hardware or equipment. They become the baseline or reference for the design. Most of the thruster ideas we reviewed are conceptual only and have never reached the design stage. None the less, it is useful to identify a few general performance requirements for use in evaluating the various thruster concepts:

- Develop adequate bit force vector for directional control.

- Develop adequate bit force magnitude to achieve acceptable drilling rate.

- Operate in an abrasive environment.

- Keep up with drilling rate.

- Permit adequate hole cleaning.

- Be rugged and simple for maintainability and ease of operation.

- Not damage the wellbore.

- Be controllable from the surface.

- Be compatible with total directional drilling assembly.

A basic requirement of any drill bit thruster is that it be rugged, mechanically uncomplicated, and simple to operate. While most of the patented concepts work in theory, they do not satisfy this fundamental requirement. 
Future directional drilling systems will monitor and control hole direction simultaneously with drilling. Important performance requirements of future drilling thrusters are:

\footnotetext{
- Control bit thrust vector (axially and transverse force components) while drilling.

- Be compatible with future downhole directional drilling assemblies.
} 
The patent survey indicated that many devices have been conceived for developing forces at drill bits. Most thruster inventions are conceptual only and few have been engineered and developed for field operation. Drawings from each patent (See Appendix) illustrate the various concepts and outline the history of drilling thruster activity. We give a brief discussion in the text of only a few patents in order to emphasize the thruster concepts that have been engineered, developed, and undergone field testing.

Drilling thruster can be divided into five major types of dilling operations:
1. 0 il and Gas Production.
2. Methane Drainage.
3. Utility Line Installation.
4. Cluster Holes from Vertical Wellbore.
5. Underground Mining.

The following sections summarize our findings and give the state-of-the-art of thrusters for each type of drilling operation.

\section{0il and Gas Production}

Since the early days of rotary drilling, bit force or bit weight has been generated by gravity (e.g., drill collar weight). Drill collars are heavy walled tubulars located directly above the drili bit and apply their weight to the drill bit when 
tension support at the top of the drill string is reduced. Drill collars are simple and rugged. Their length is designed to generate the desired bit weight while keeping the neutral point within the collars. This keeps the drill pipe from buckling.

The use of drill collars has not been completely satisfactory. Drill collars are much heavier than drill pipe and thus increase hoisting and rig floor handing requirements. In addition, drill collars deflect laterally due to their weight and this deflection changes the orientation of the drill bit and causes the borehole to deviate. Stuck drill strings in the borehole are often attributed to the presence of drill collars; however, this problem is alleviated by using spiraldrill collars. Also, the length of drill collars frequently prevents their use in drilling through hard formations lying very close to the earth's surface.

Downhole wall anchors are an alternative to drill collars, but they are not regularly used by the petroleum industry. They fit into the drill string directly above or near the bit and derive their downward force by fluid pressure acting on cylinders. The magnitude of the downward thrust force depends on the pressure drop across the drill bit and on the cylinder pressure area. Multiple cylinders can increase the total pressure area and thus bit force magnitude. The reaction thrust is taken by grippers that expand against the walls of the wellbore. Gripping capacity is an important design consideration because it must be as great as the downward bit thrust. 
A. P. Roberts invented a wall anchor tool in the late $1950 \mathrm{~s}$. This Exxon Production Research Co. patent $(3,225,844)$ stimulated a number of wall anchor patents including:
Kellner
$3,088,532$
Kellner
$3,105,561$
Kellner, Reed, Hildebrandt
$3,180,436$
Kellner, Allen
$3,180,437$
Ortloff, Howe
$3,225,843$

One disadvantage of $3,225,844$ is that drilling has to be stopped and pump pressure lowered to disengage the anchor blocks so that the tool can be reset for the next drilling interval. This disadvantage is overcome by other Exxon patents that followed as they allow for automatic reset. A prototype of 3,105,561 was built and tested and has worked for 17 automatic resets (2) (see Figure 1).

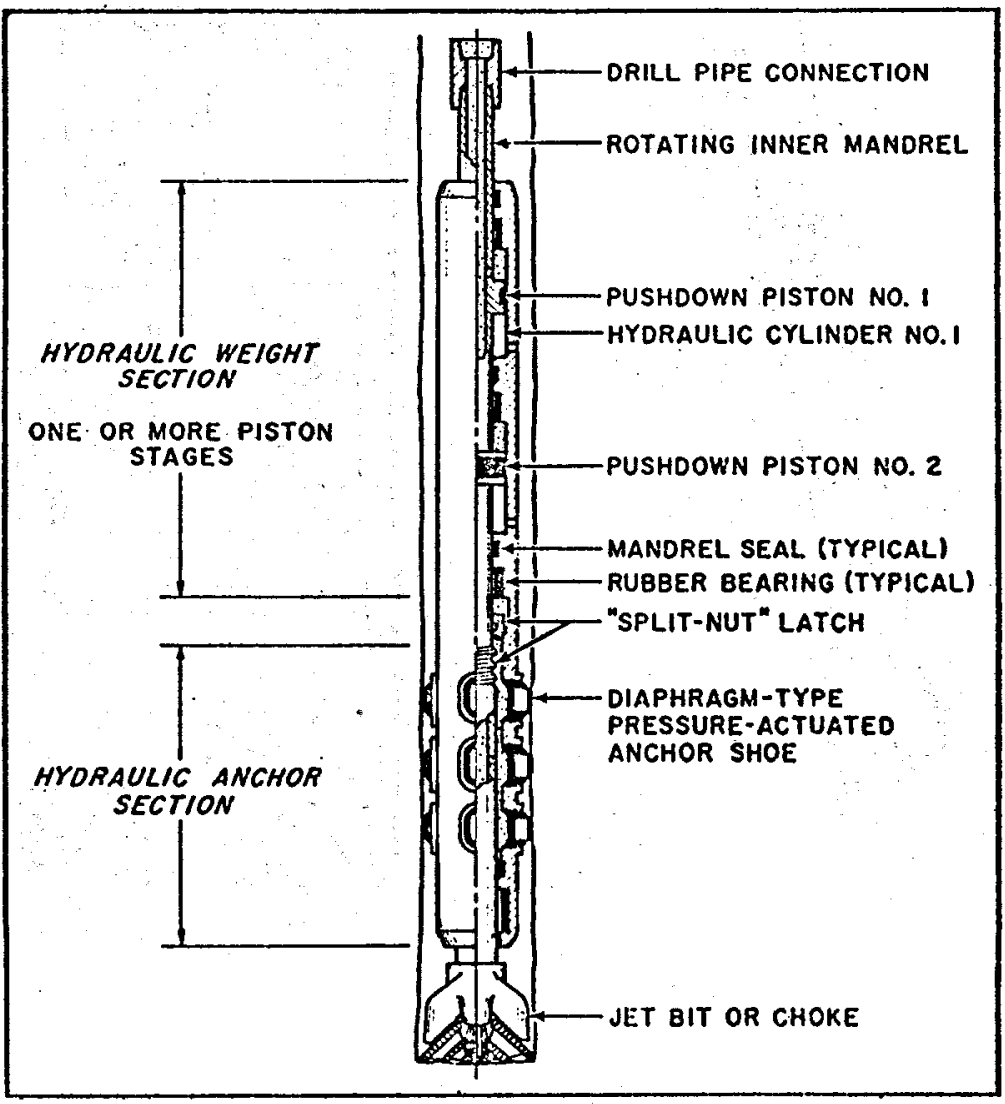

Figure 1 
Another type of thruster is described in 4,060,141 and is part of a self-propelled turbine drilling system (Figure 2). This thruster is made up of expandable "clam shells" which grip the borehole, an axial turbine propulsion unit, and a screw drive. The downward thrust, or bit force, is generated by a turbine which operates essentially at stalled torque conditions, advancing the drill bit and a separate drill turbine via the screw drive; thrust reaction is transmitted to the borehole walls by the "clam shells." When the screw drive reaches the end of its travel, the thrust turbine is reversed allowing the thrusting device to follow the cutter head.
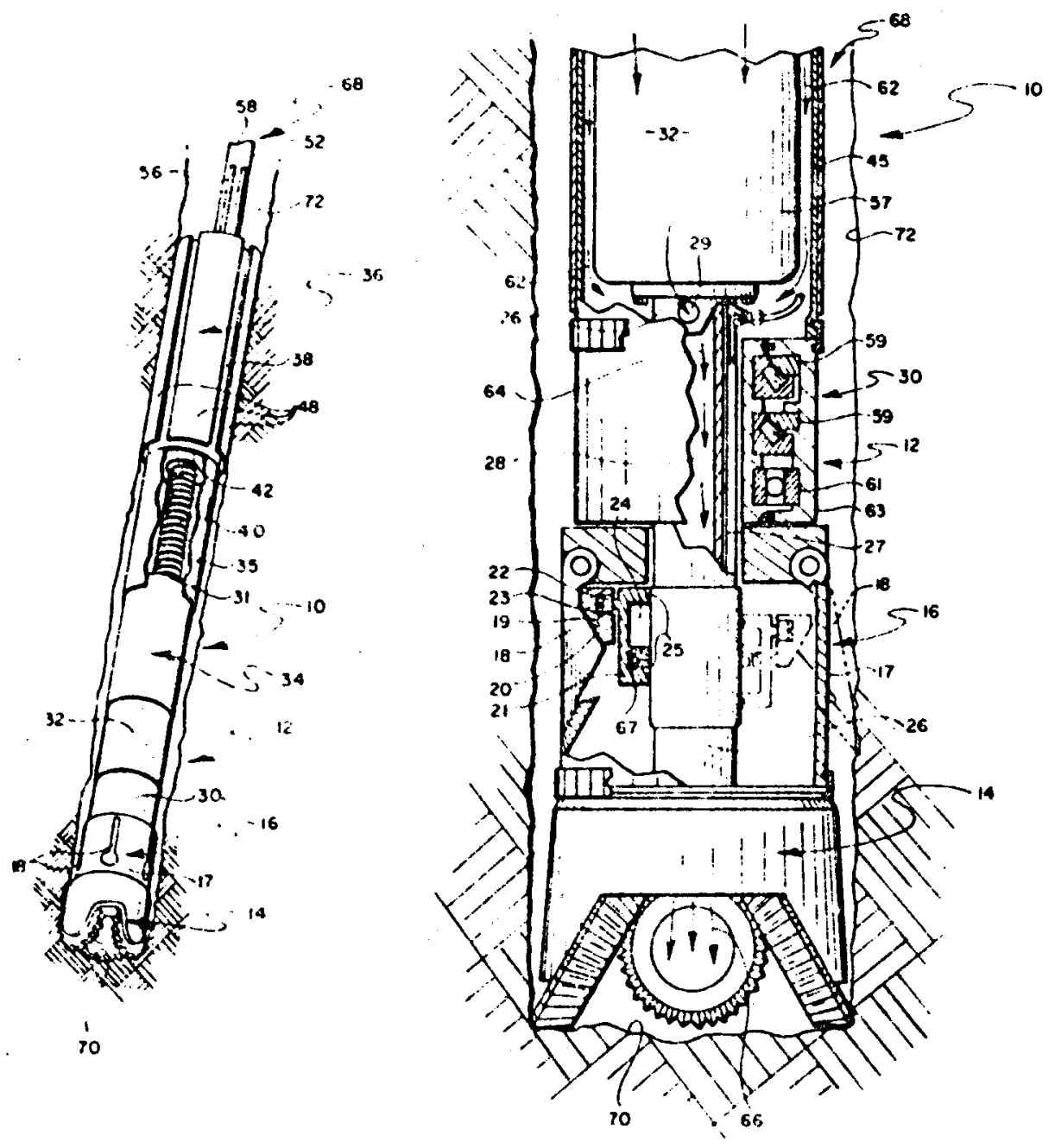

Figure 2 
Carey E. Murphy, Jr., of Shell oil Company patented $(3,706,348)$ a heavy metal collar concept and analytically showed that his idea would improvedrilling practices by providing more well deviation control in difficult formations (see figure 3 ). By using depleted uranium or tungsten as drill collar material, the collar section would be stiffer, heavier, and shorter than normal steel collars ( 3 ).

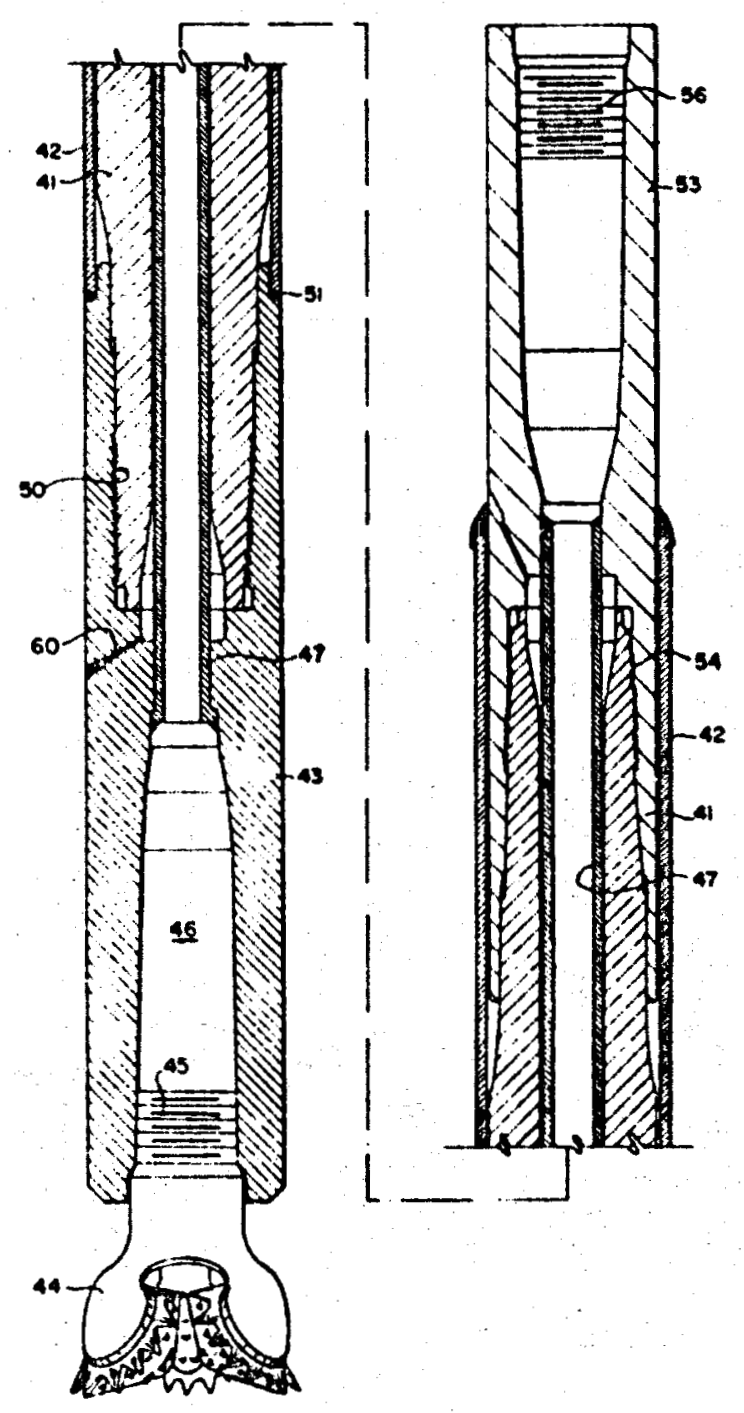

Figure 3 
The thruster types mentioned so far generate static bit forces. A. G. Bodine, Jr. obtained a patent $(2,554,005)$ which covers dynamic force generators for developing dynamic forces at the drill bit (Figure 4). This patent describes various types of mechanical devices for exciting the longitudinal vibration modes of drill strings in order to generate dynamic forces at drill bits. Experiments showed drilling rates of 6 inches per minute in granite with the Bodine apparatus compared to one inch per minute with conventional rotary drilling methods.

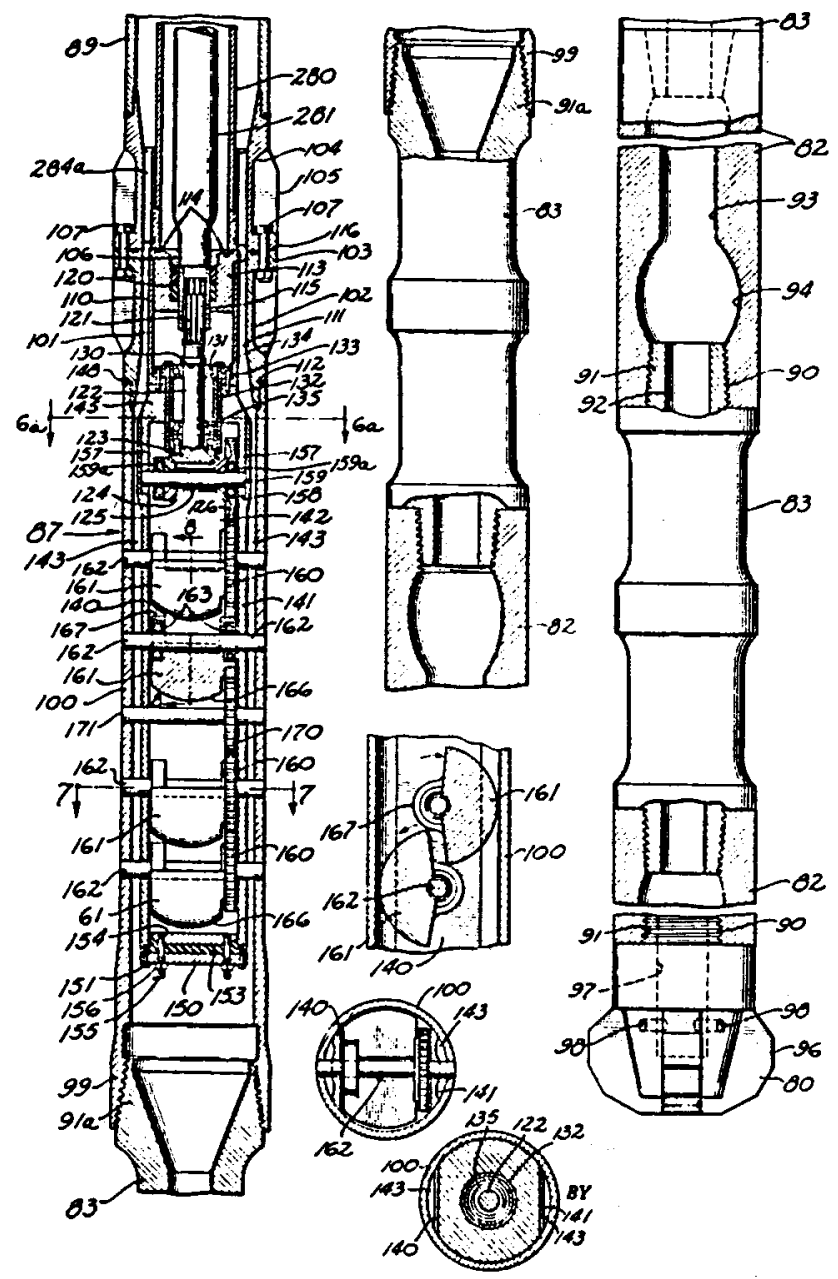

Figure 4 
The patent $(2,684,835)$ of $T$. V. Moore illustrates simply how pressure drop across drill bits can generate an axial thrust force (Figure 5). The magnitude of the thrust force is equal to the product of the pressure drop across the bit and area of the piston. In this patent, rotary power is transmitted from the surface through the drill string. In order to rotate the drill bit and allow the piston rod to slide within the cylindrical element, the piston rod must be splined as shown in this patent.

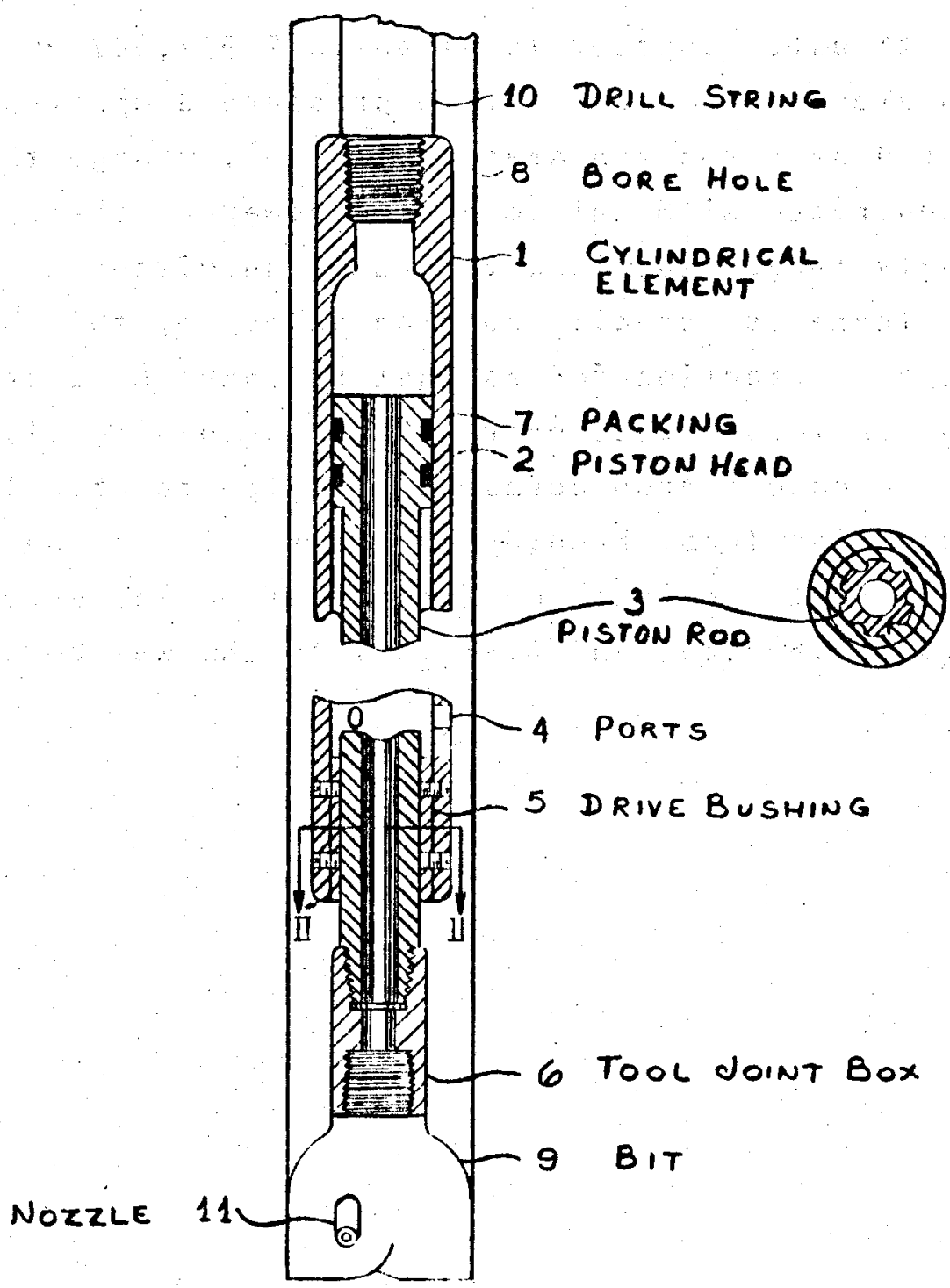

Figure 5 
If the inside area of the drill string is the same as the total area of the piston head, there will be no upward reaction in the drill string. However, if the total area of the piston head is greater than the inside area of the drill string, an upward reactionary force will be imparted to the drill string. This patent is mentioned to show that bit thrust reaction can be taken completely by pump pressure provided piston area is the same as drill pipe bore area. However, this is probably not the intent of $2,684,935$.

A similar thruster concept is given in $2,937,007$ by F. Whittle who elected to use multiple pressure drop areas; the spline is located near the top area (Figure 6). Large thrust loads can be generated with this concept, however, there will be a correspondingly large reactionary force transmitted to the drill string. There is actually nothing gained by this particular thruster concept as reaction forces must be taken by a drill collar section. A large reactionary force taken directly by drill pipe along with pressure drop across drill pipe can buckle drill pipe and produce high local bending stresses. It is therefore desirable to transmit the reaction force that would be generated by the inventions $2,684,835$ and $2,937,007$ to the wellbore by means of a wall anchor. 


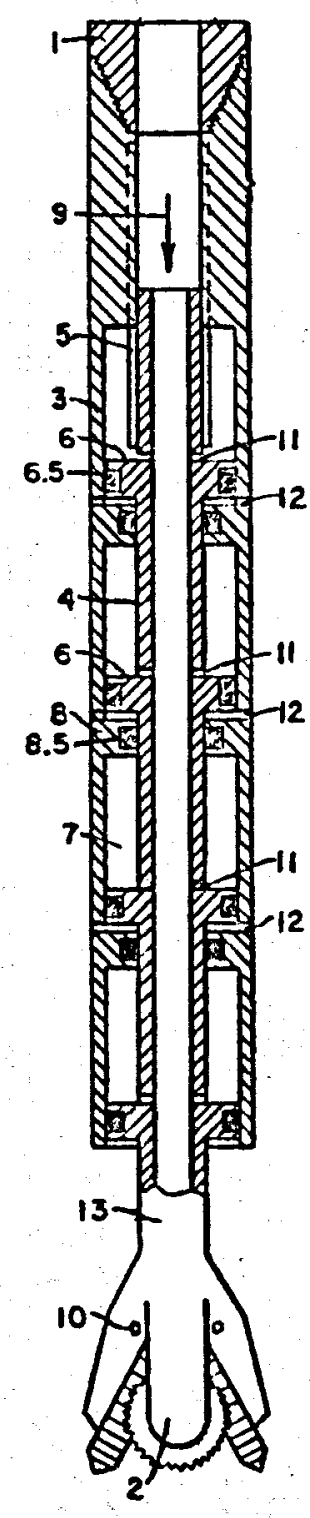

Figure 6

One of the earliest wall anchor inventions is given in 1,983,287 (Figure 7). The wall anchors are engaged by a clutch mechanism that is activated mechanically by moving the drill pipe or pneumatically by air pressure delivered through a hose. This particular patent is directed primarily at a "sub-circulation" drilling system. 


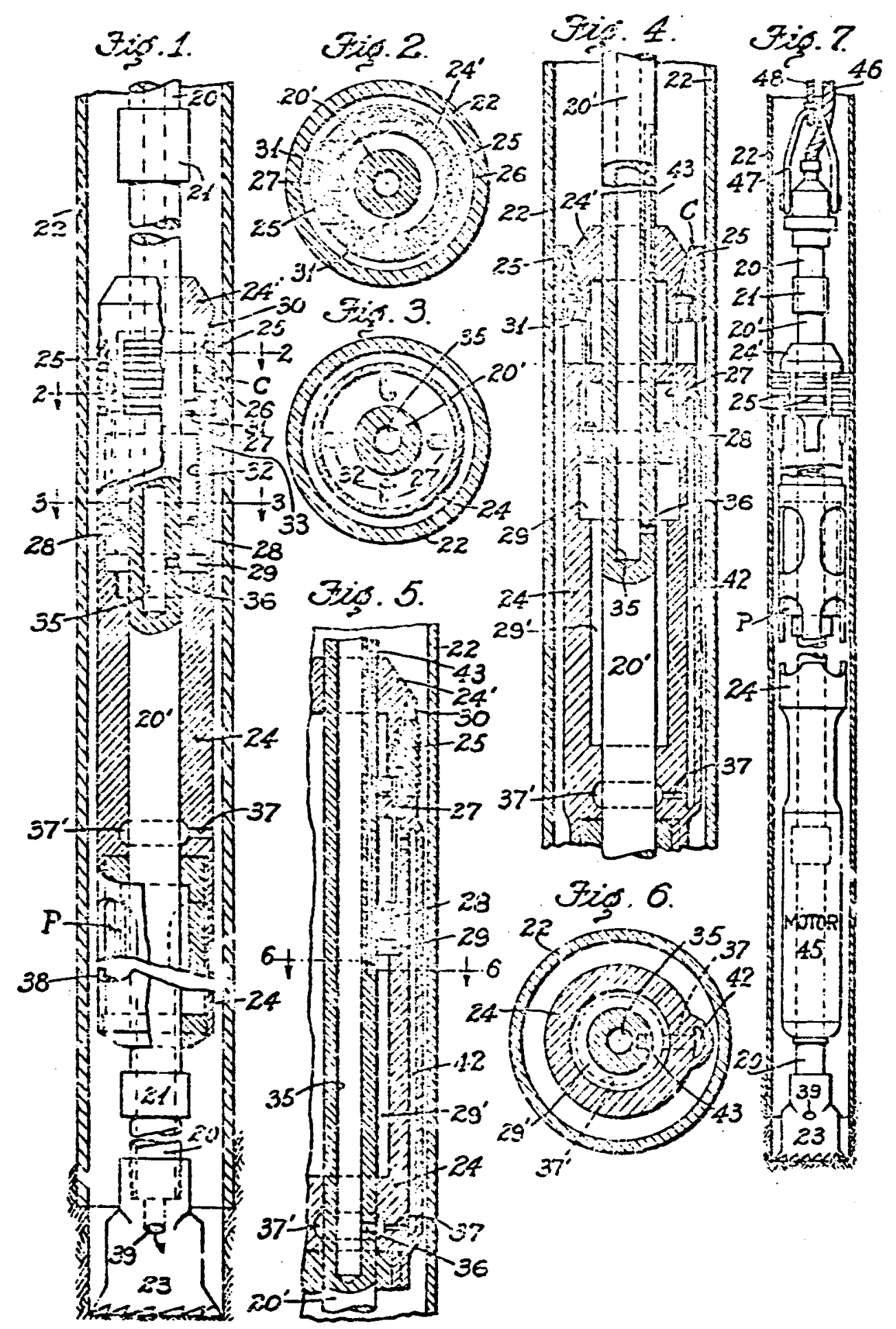

Figure 7 
Let us now consider thruster hardware for pushing the drill bit sideways or transverse thrusters. These types of thrusters are important in directional control either for keeping the wellbore near vertical or intentionally building hole angle to direct the drill bit toward a lateral target. Usually, it is desirable to drill a vertical hole but recognizing that the bit will wander away from a straight path as a result of drill collar bending and formation changes. That is why directional surveys are taken periodically to check for high rates of angle build-up. If the hole is wandering off course, various techniques and tools can be applied to bring the hole back.

In other cases, it may be desirable to intentionally drill a directional hole to hit a target some lateral distance away from the vertical. For example, it is common practice to drill some 20 to 25 directional walls from a single offshore platform to economically produce an oil or gas reservoir. When all directional wells are completed, they fan out over a large area of the reservoir covering approximately a mile radius from the platform. Di,rection drilling is sometimes required to kill a blowout. In this case, an offset well or relief well is directional drilled to interact the uncontrolled well so that cement can be pumped into the uncontrolled well.

The theory of controlling hole direction with drill collar bending was developed by A. Lubinski (4). He recognized that drill collars buckle due to their own weight and bend within the confines of the wellbore. This bending causes the bit to be . oriented away from the vertical and at the same time produces transverse and axial bjt force component. If this bending goes uncontrolled, hole angle can build up sharply and wellbore control is lost. These same forces, however, can be used by the driller to control hole direction. 
It is believed that the main forces acting on the bit are pendulum forces of gravity, levered forces of the drill string, the wedging or refraction effect of formation changes and the walking effect of rotation, especially of the tricone bit (5).

These forces are controlled by:

1. Adjusting bit weight - Lighter bit weights encourages the bit to drill in the direction it is pointing. High bit weight turns the hole and helps build hole angle. Very light bit weight produces low penetration rate but makes it easy to control the direction of the well.

2. Using large drill collars or square drill collars - The stiffness of a pipe is proportional to the fourth power of the diameter. So stiffening drill collars by increasing their diameter is very significant. Squaredrill collars are often used to get the stiffness factor yet still allow room for fluid circulation (Figure 8).

3. Placing stabilizers in the collar string Stabilizers can be placed to control the action of the lower part of the drill string according to either pendulum or lever principles. Two stabilizers are used as shown in Figure 9 to maintain hole direction; the bottom stabilizer relieves the transverse bit force component. 


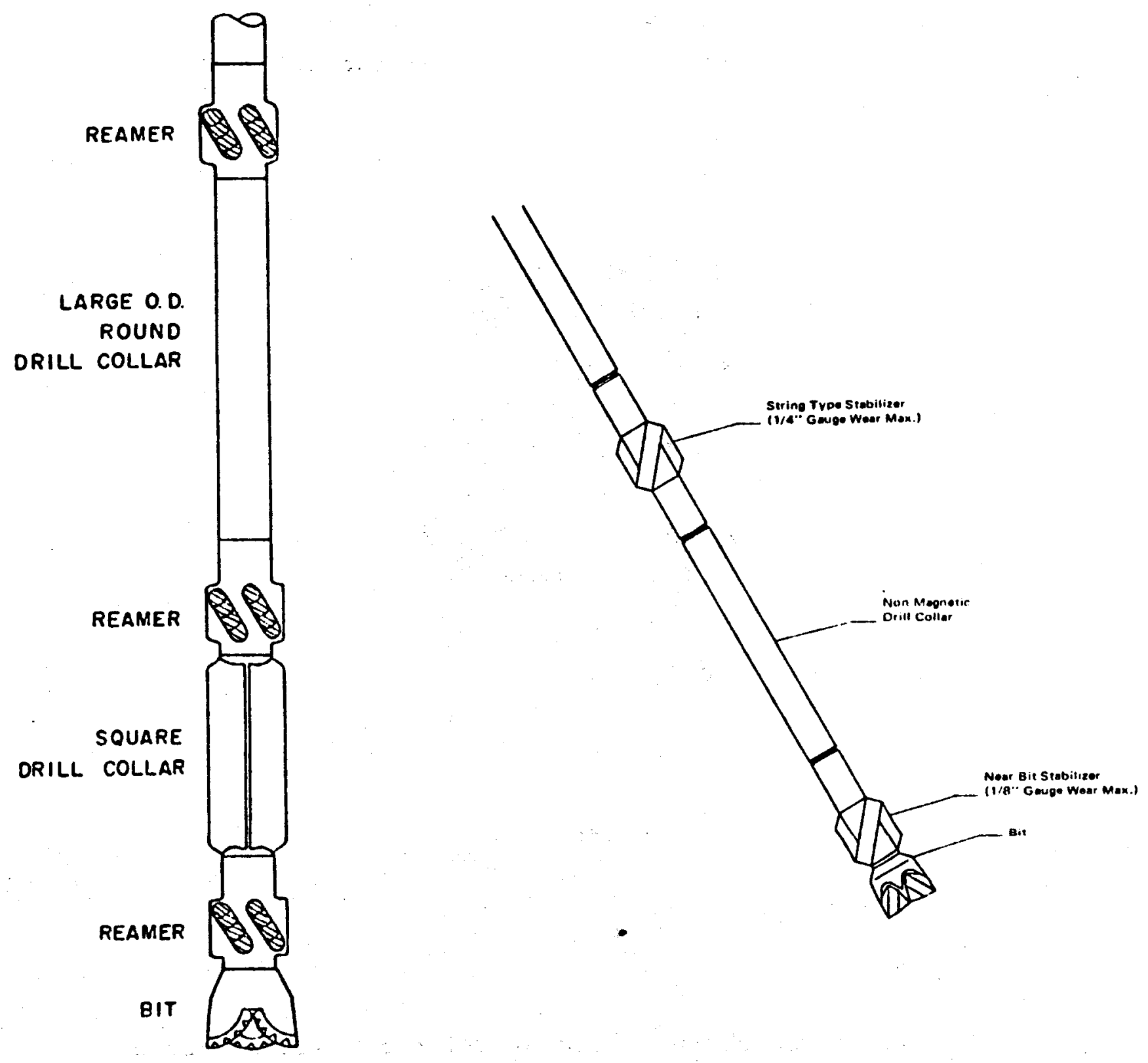

Figure 8

Figure 9 
One stabilizer directly above the bit is used to build hole angle. This method of building hole angle is based on the fulcrum principle as shown in Figure 10 and requires adjustment in bit weight to tilt or lever the drill bit about the fulcrum point.

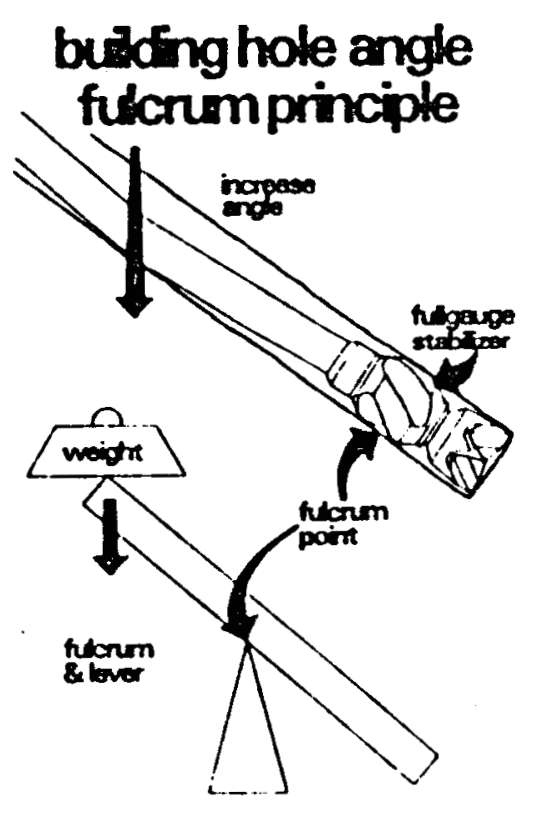

Figure 10

Hole angle can be decreased by using one stabilizer as shown in Figure 11. This stabilizer acts as a pivot point for a drill collar pendulum. Restoring bit forces are generated by drill collar gravity loads which tend to swing the collars and bit back to the vertical position. 


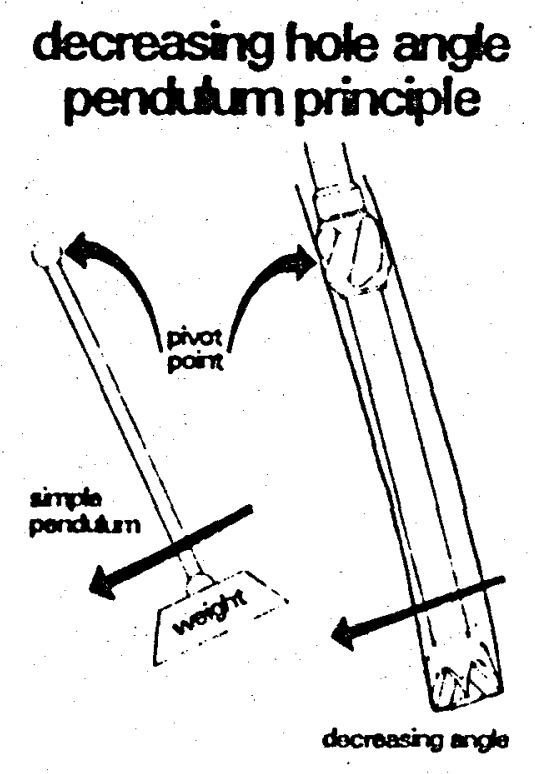

Figure 11

The bent sub is a preferred directional tool wherever it can be employed. The bent sub, which may be in some cases a bent downhole motor housing, when used with the proper collars and stabilizers can thrust the bit off at an angle (Figure 12). orientation of a bent sub can give $360^{\circ}$ of azimuth change by indexing the drill pipe or as a function of continual change in direction. It can also give an angle change or a combination of angle and direction. Bent subs normally are made up in $1 / 2$ degree angles up to four or five degrees. 


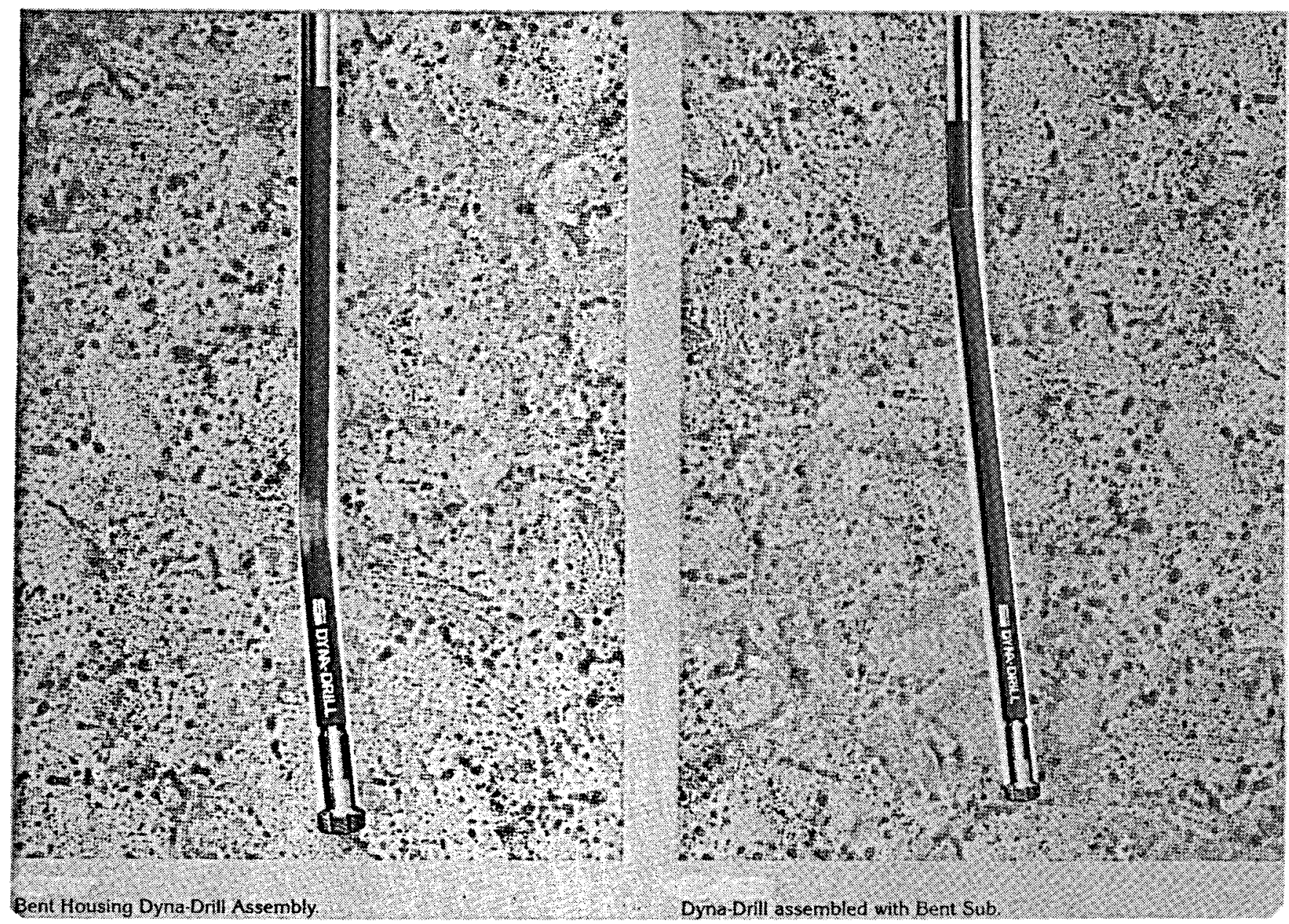

Figure 12

The bent sub technique is limited to drilling when using a downhole motor because the obvious advantages of the bent sub are lost if the drill pipe must be rotated. The bent sub does not provide enough directional/side thrust to drill out of casing when sidetracking a hole or to change direction across the grain of a hard rock with very strong anisotropic properties. 
The Dyna-Drill Division of Smith Industries markets a variable sub (Figure 13). It is wireline actuated and cannot be used when a mule shoe orientation collar is in use. This severely limits its use. The development of a variable sub that can be used with steering tools could reduce directional drilling costs by $25 \%$ by eliminating extra trips.

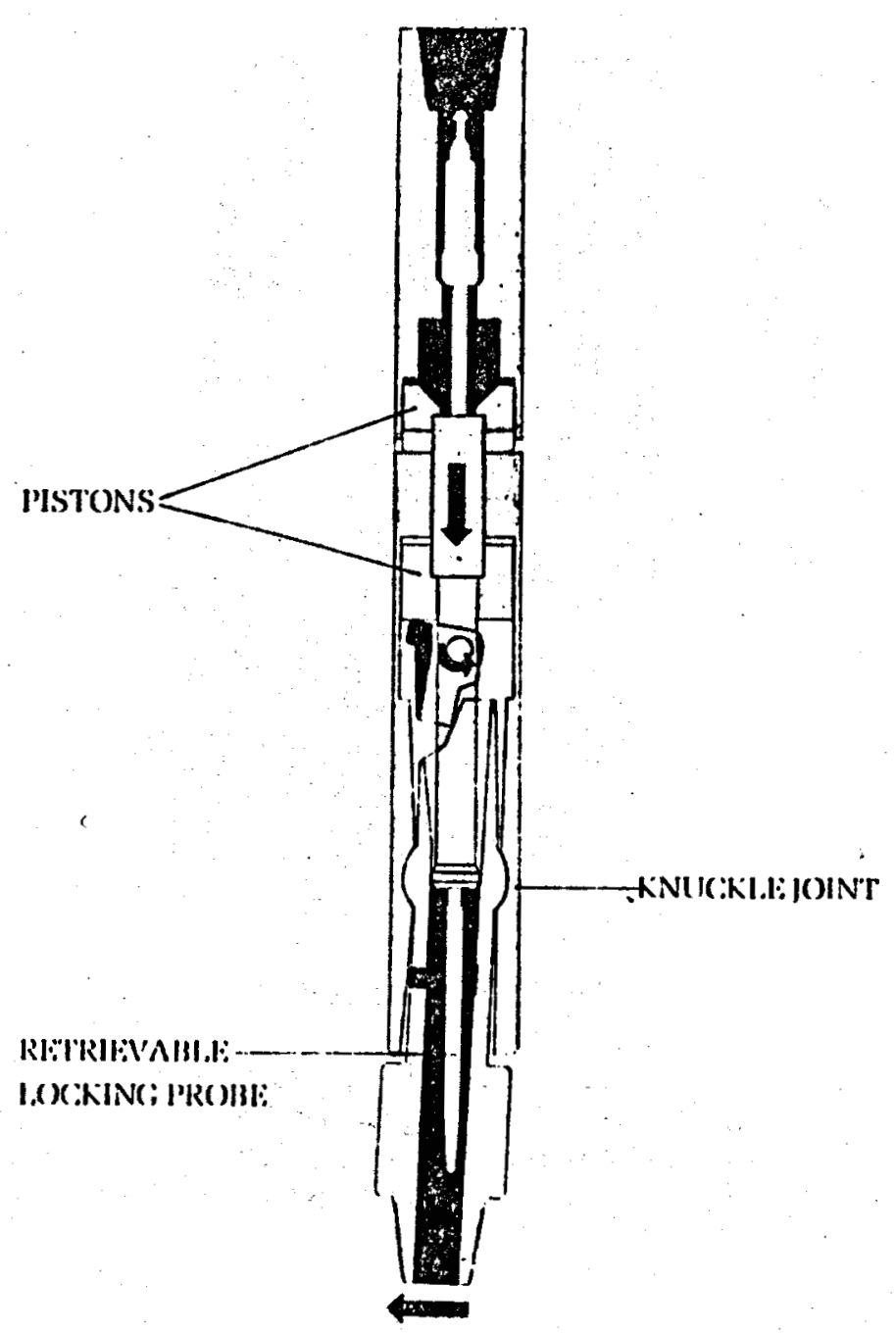

WYNATIILX

Figure 13 
The directional drilling service business was founded on the whipstock (Figure 14). It is a rugged and reliable tool, but very consumptive of rig time. The tool is a wedge-shaped steel casting with a tapered concaved guide channel for the bit.

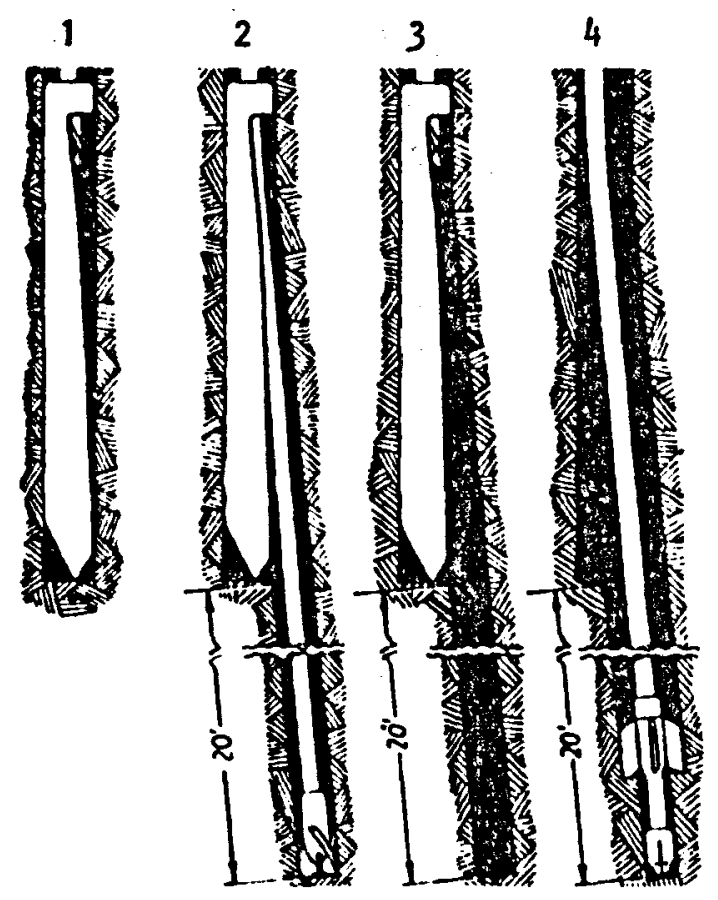

Whipstock Steps

1. Set the Whipstock

2. Drill Pilot Hole

3. Remove Whipstock

4. Ream Pilot Hole

Figure 14 
The drill pipe or a small drill collar is lowered through the ring of the stock and a small diameter bit made up on the bottom of the pipe. The bit is then positioned and attached to the whipstock by means of a shear pin. The whipstock is lowered to the bottom of the hole, orientated to turn the face in the desired direction and the weight of the string is applied to force the chisel point into the formation to hold the whipstock in place. The shear pin is then sheared by applying additional weight to the bit. The bit is rotated slowly as it drills down the face of the whipstock which forces it to drill outward into the formation. After 20 feet of hole is drilled, the bit is pulled back up the face of the whipstock until it contacts the ring thus withdrawing the whipstock as the pipe is pulled out of the hole. A round trip is made with a pilot bit to ream the pilot hole to gauge. A short hook-up is then run and from 30 to 60 feet of hole drilled and surveyed. If the results are favorable on the survey, a short string of drill collars are run and drilling proceeds. If the results of the survey are unfavorable, the whole process of rerunning the whipstock is repeated over again. Additional conditioning trips are occasionally necessary in unstable holes when it is not possible to get the whipstock to bottom due to bridging, tight spots in the hole, or fill up on bottom. The use of the whipstock requires many round-trips for only a small amount of hole obtained, thus are usually much more expensive than the jetting and Dyna-Drill techniques. The whipstock thus should only be used in situations where the other two techniques cannot be employed.

The use of a bit or jet sub with a directional jet is one of the quickest and hence more economical ways of changing the direction of a hole (Figure 15). It is particularly attractive 
because so little extra equipment is needed, and the same bit that jets can be used to drill ahead. However, it only works in very soft sediments.

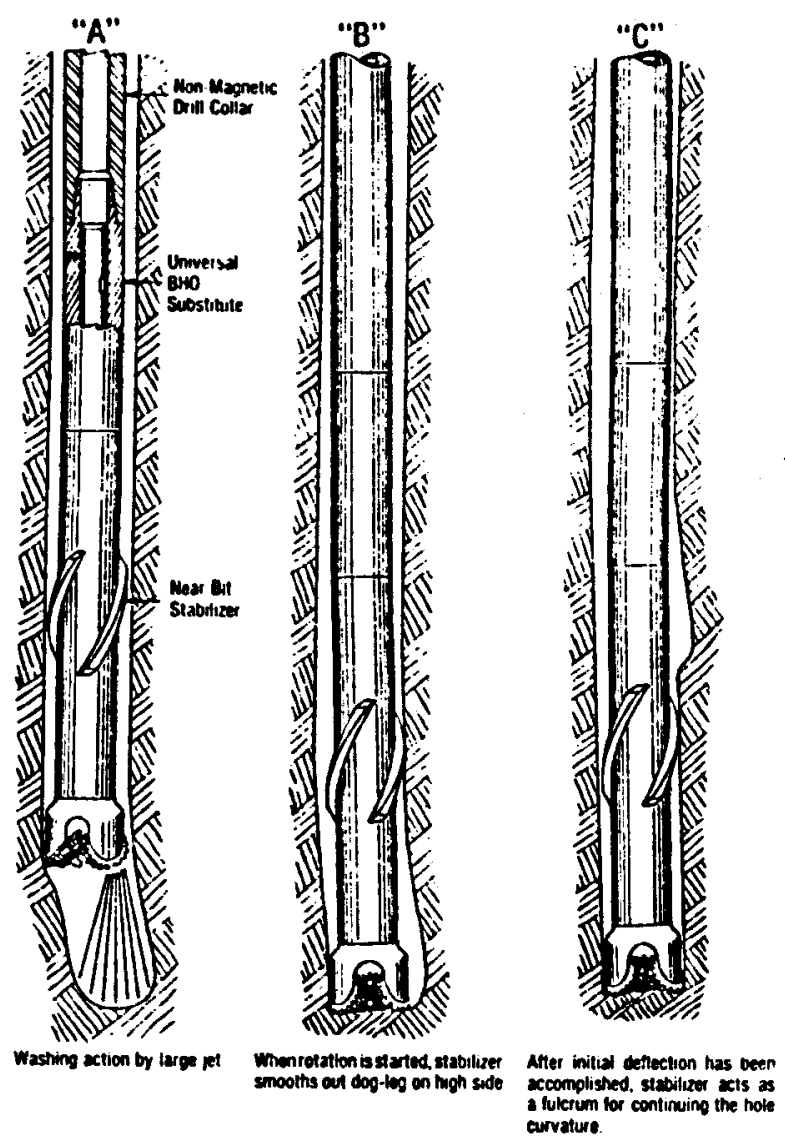

Figure 15

Our patent survey uncovered several downhole tool concepts for generating side thrust loads on drill bits. In nearly all cases, side loads are generated by activating a guide shoe which would extend from the tool, located near the drill bit, and push against the wellbore wall. 
W. H. Etherington's patent $(3,023,821)$ was one of the first side thrusters of this type; this patent is uncomplicated and shows basically how this type of tool works (Figure 16). His drawings show a single guide shoe which is initially oriented within the wellbore. The guide shoe is set by pump pressure, forcing the outer cylinder against the wellbore. An inner pipe, which is in tandum with the drill collars and drill bit, is free to rotate and advance down the wellbore as drilling progresses. The tool has to be reset each time the drilling advancement equals the stroke limits of the tool.

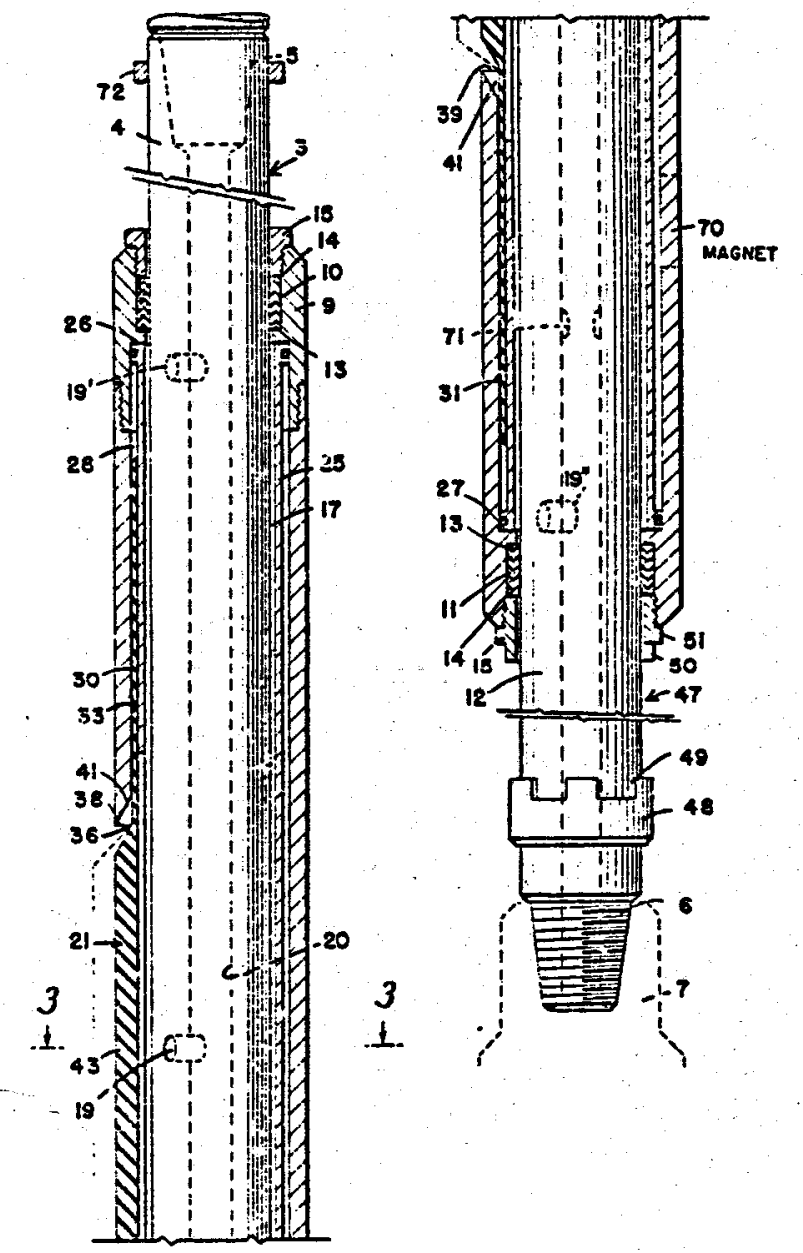

Figure 16 
Another side thruster invented by J. S. Page, Sr., et al $(2,891,769)$, utilizes two sets of guide shoes, one at each of two longitudinal locations (Figure 17). Each shoe is individually activated hydraulically so as to achieve a large angular or directional control of the drill bit. Unlike Etherington's tool, the Page tool would advance downhole as the drill bit penetrates into the formation. It does permit relative rotation with respect to the anchored cylinder.

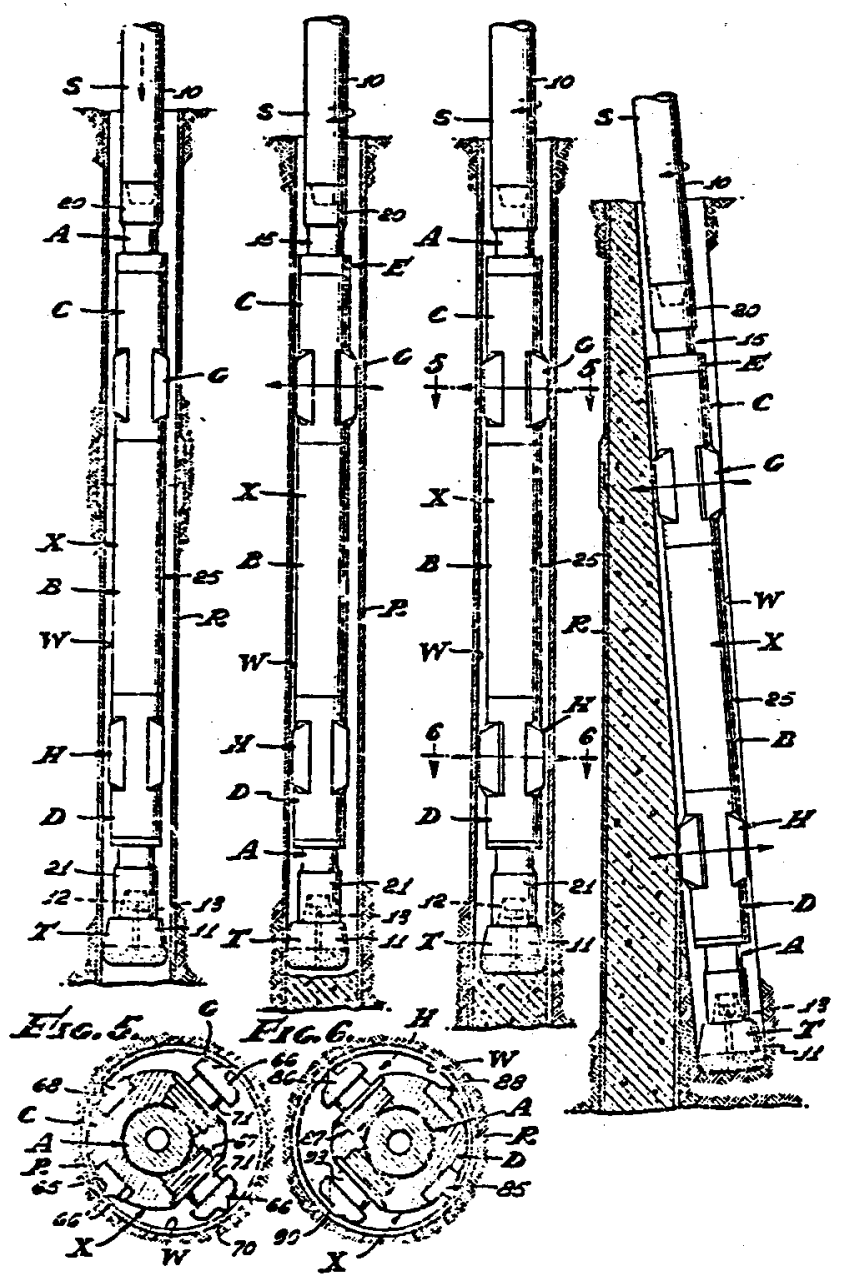

Figure 17 
The stabilizer and deflecting tool by W. H. Antle $(3,370,657)$ contains guide shoes that are activated by drill collar weight (Figure 18). A linkage mechanism generates high lateral forces between the guide shoes and wellbore wall. When the tool is being withdrawn, an internal spring deactivates the guide shoe. The tool progresses downhole with the drill bit. The outer cylinder does not rotate. The inner pipe rotates with drill collars and bit.
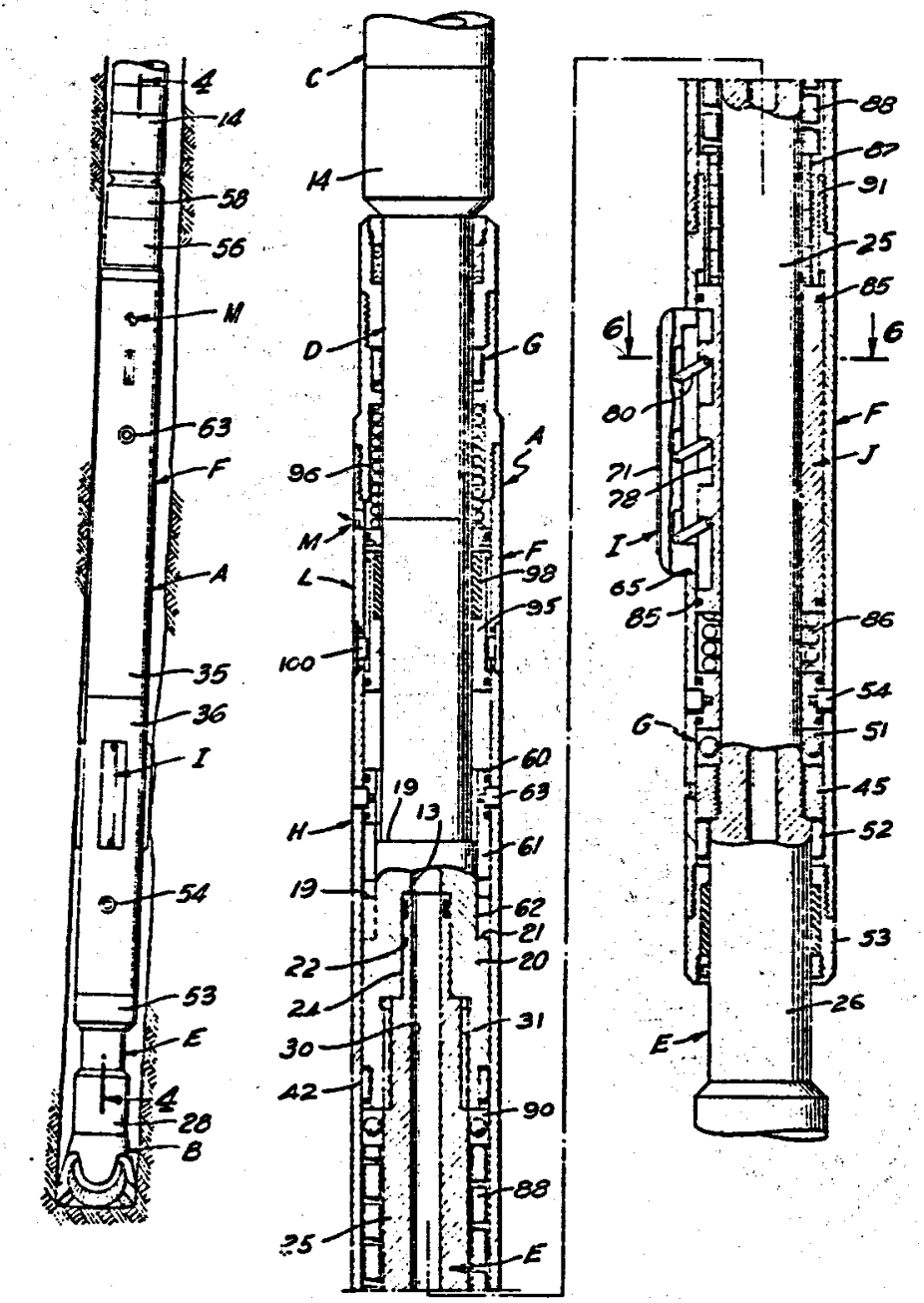

Figure 18 
The patent by J. L. Blake, Jr. $(3,974,886)$, shows how guide shoes can be activated by siliding cams (Figure 19). According to this patent, a symmetrical array of guide shoes are activated simulataneously to produce a stabilizer for pendulum fulcrum type directional control methods. The guide shoes are activated by a wireline tool. The advantage of this tool is that stabilizers can be created near the bit without withdrawing the drill string.

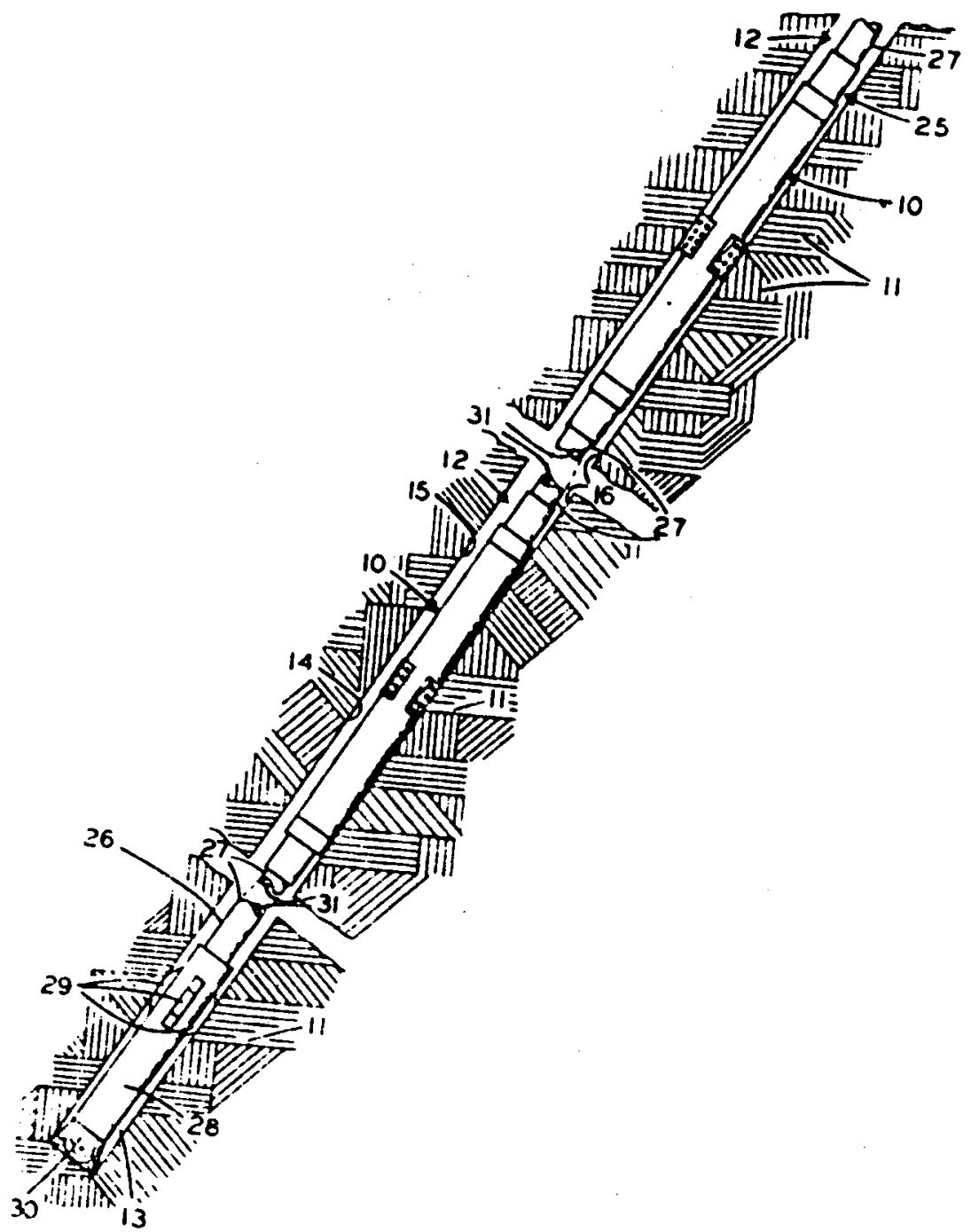

Figure 19 
Drilco developed a downhole thruster tool called a "Bit Boss" which has the capability of generating both transverse and axial bit forces (See U.S. Patent 3,298,449). The tool can be used either as a directional drilling tool by forcing the drill string laterally against the wellbore or it can be used as a wall anchor for applying axial thrust to the drill bit. The positioning members or guide shoes are activated hydraulically by removing a valve by wireline. Drill collar weight is needed for drilling until the too'l is activated by retrieving the valve. Drilco's Bit Boss is covered under the following patents:

$\begin{array}{lr}\text { Bachman, Moore, Rollins, Garrett } & 3,298,449 \\ \text { Garrett, Nixon } & 3,326,305 \\ \text { Garrett } & 3,460,639\end{array}$

A single pressure source is common to all positioning members. The positioning members in their directional tool are in a nonsymmetrical pattern which is oriented within the wellbore to produce the desired transverse movement against the wellbore. The anchoring cylinder is stationary within the wellbore and the inner pipe rotates and advances with the drill bit.

Positioning members in Drilco's wall anchor tool are symmetrical and centralize the tool within the borehole. Downward bit thrust is developed by pump pressure acting on internally exposed shoulders. The inner pipe rotaies and advances with the drill bit. These tools are fully developed and commercially available. 


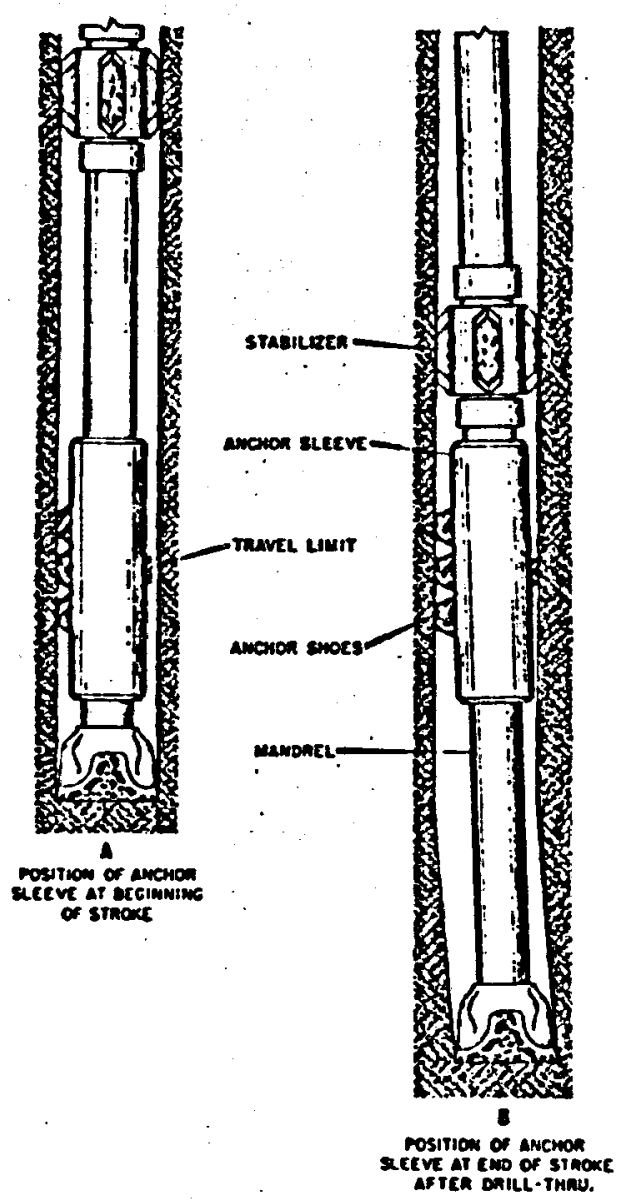

-Basic concept of the new tool is the hydraulic jack effect of the anchor shoes when drilling.

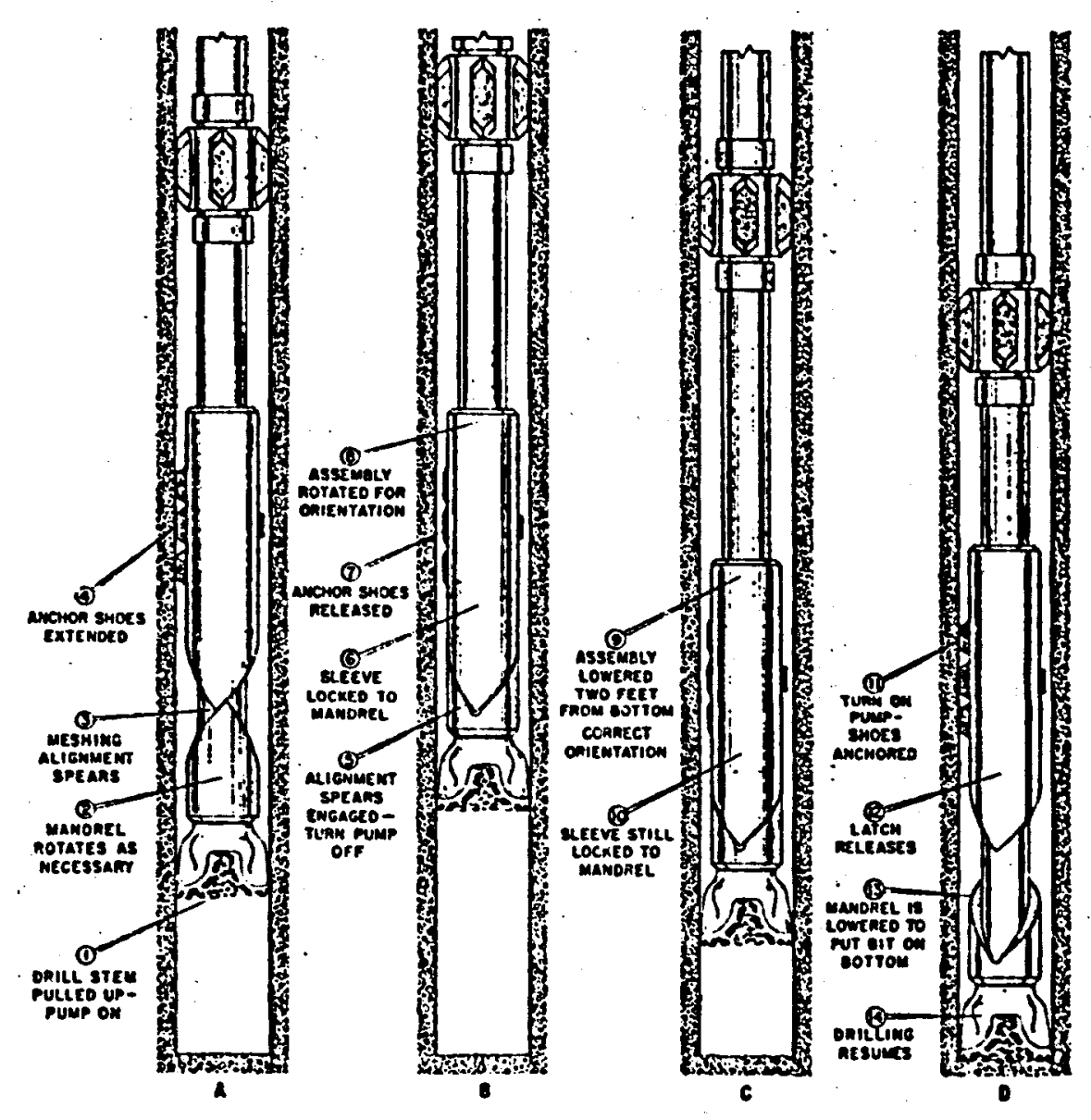

-Detailed operation of the new dircctional control tool is shown above in sequence views $A, B, C$ and $D$.

Figure 20

During the early 1960's, Drilco built and tested a side thruster for use in deviation control $(6,7)$. Their thruster was marketed and used during a short period of time. Operational 
steps are illustrated in Figure 20. Field experiences obtained with this tool are (6):

- "The tool hás been operated to depths as great as 10,000 feet. Conditions creating unusual torque or drag on the drillstem tend to limit the depth at which the tool can be run with best results."

- "No difficulty has been experienced with oversize hole preventing the shoes from engaging the hole wall. Apparently, there is not substantial hole enlargement just above the bit even in very soft formation.".

- "Extra rig time required to operate the tool including running surveys, setting the sleeve and replacing worn parts has varied from one to four hours per day."

"Although this tool is believed to be of general utility for all drilling fluids, including air and gas as well as water and oil base muds, the particular design herein described was built specifically to operate in a hole drilled with normal drilling liquids."

"A full time operator is required to supervise the drilling crew in use of the tool and to provide local inspection and maintenance of the tool." 
Horizontal Drilling Into Coal Seams

The previous section dealt with oil and gas drilling which reaches a depth of around $10,000 \mathrm{ft}$. This section covers horizontal drilling into cool seams which is a much shallower type drilling. Bit thruster requirements are slightly different because the borehole is horizontal and gravity is not a significant bit loading source.

The main reason for drilling into coal beds is to drain methane gas in advance of mining to improve the safety of underground coal mining. The U. S. Bureau of Mines is one of the leaders in advancing technology in this area $(8,10)$. There are, however, other applications. Techniques for surveying coal seams from horizontal holes are being developed and will give miners useful information for planning their mining program. The economic incentive for producing methane for commercial use is marginal at present but this could change with the rapid rise of energy costs. In addition, in situ coal gasification schemes, such as the Longwall generator shown in Figure 21 , will require slant hole drilling into coal seams.

Four methods for drilling horizontally into coal beds are:

1. Horizontal Drilling at the Coal Face

2. Slant Hole Drilling from the Surface into the Coal Seam

3. Horizontal Drilling from a Vertical Shaft

4. Hydraulic Fracturing

Since hydraulic fracturing is not within the scope of this study, we evaluated patents and hardware that related to horizontal drilling at the coal face and slant hole drilling from the surface. 


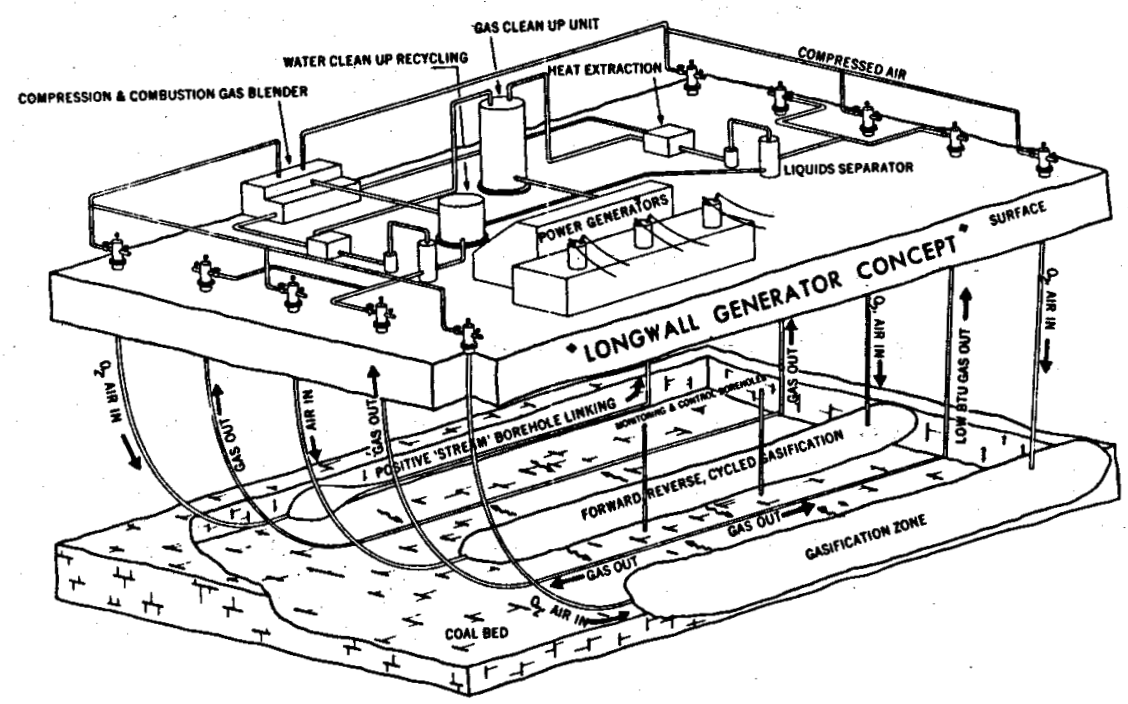

Figure 21

A review of the patents and discussions with mining engineers indicate that horizontal drilling into coal seams is relatively new. The first drilling of this type was first conducted in the United States in the early 1950s. In the early 1970s, Consolidation Coal Company began an intensive research effort to develop a drilling system which would drill into coal seams, monitor the location of the bit, and guide the drill bit within the coal seam. The technique for loading the drill bit was only-one aspect of their total drilling research program. Continental Mining Research has stimulated much of the hardware development discussed below. 
One innovative systems for drilling horizontally into coal seams was developed by Jack Kellner of Drilco. This system, sometimes called the "Kreepie-Krawler," is made up of a downhole Dyna-Drill fluid motor and a downhole mechanical thruster. The thruster unit has the capability to

1. Apply axial force to the drill bit

2. Grip the walls of the hole

3. Walk the downhole unit either forward or backwards

4. Apply lateral force to the drill bit for directional hole control

The "Kreepie-Krawler" unit is powered and controlled hydraulically through a bundle of hoses which serves as an umbilical to a power source outside the hole (Figure 22).

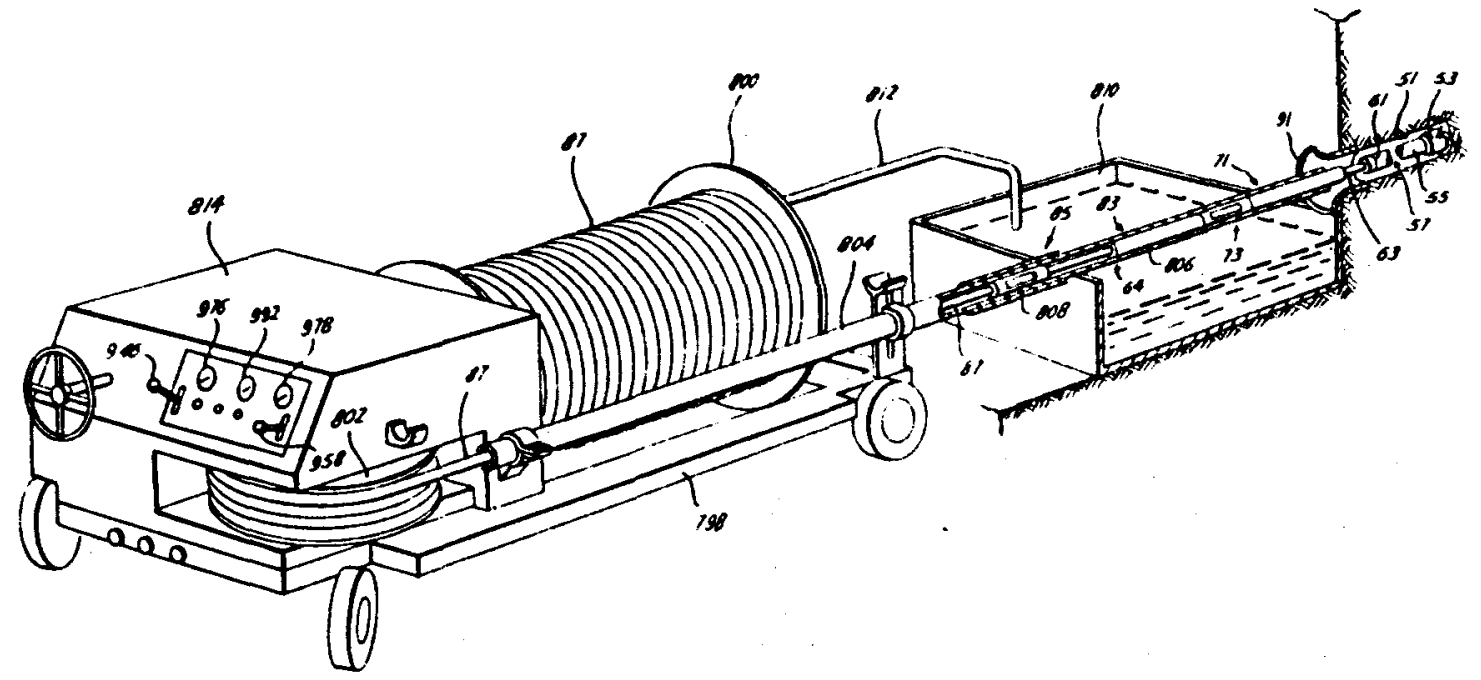

Figure 22 
The design philosophy behind the Kreepie Krawler was an omni directional drilling system which would be compatable with automation. A hose bundle is more amenable to automation than drill pipe. Hydraulic thrusters near the bit give more direct control of the drill bit than do stabilizers or bent subs.
"Basically, the Drilco thruster is a double-acting cylinder having a hollow piston rod running through both ends. Attached to the bit end of the cylinder is an extension containing a set of radially-operable pistons, spring-loaded inward and called the Cylinder Anchor, a spline between the rod and anchor cylinder prevents rotation. Attached to the outer end of the piston rod are similar anchors called the Piston-Rod Anchor. Each function is powered hydraulically through a hose extending outside the hole to the power unit shown. In operation, pressure is first applied to the cylinder anchor to couple it to the hole wall. Next, pressure is applied to the "cut-hole" piston side and thereby provides forward thrust to the drill-motor as it advances in hole. As you can see, this advance is limited to the pistons stroke at the end of which the cylinder must be reset. This step is accomplished by first applying pressure to the hole-wall. Next, the pressure is released from the cylinder anchors which retract. Pressure is then applied to the opposite or "inside" side of the piston forcing the cylinder in-hole one stroke length. The cylinder anchor is again engaged while the piston anchor is retracted and the whole process repeated. The hydraulic power unit is designed so that the resetting operating is done automatically and requires about 10-15 seconds."
"By sequencing the anchors differently, the device can also pull itself out of the hole as well as advance inward. This latter feature is intended to be used should the entire assembly become stuck as ordinarily, the in-hole equipment would be removed by pulling on the hoses. These members are generally one piece of a length equal to the hole depth to be drilled; they can be mounted on a powered drum as shown in our patents. "1*

The Drilco horizontal drilling system is covered under the following patents:

$\begin{array}{ll}\text { Kellner, Alther } & 3,797,589 \\ \text { Kellner } & 3,799,277 \\ \text { Kellner } & 3,997,008 \\ \text { Kellner } & 4,040,494 \\ \text { Kellner, Garrett } & 4,040,495\end{array}$

ॠPersonal communication with Jack Kellner, Drilco 
Drilco developed two different thruster size; a 5-3/4" OD tool and a 2-3/4" OD tool. Both have been used to drill several thousand feet into coal beds. The maximum length for a single hole (6" diameter) was in excess of $700 \mathrm{ft}$. Some of the characteristics of the 5-3/4" tool are:

$\begin{array}{lc}\text { Outside Diameter } & 5-3 / 4 " \prime \\ \text { Length } & 128 " \prime \\ \text { Stroke } & 30^{\prime \prime} \\ \text { Power Required } & 5 \mathrm{hp} \\ \text { Maximum Axial Thrust } & 7,000-8,000 \mathrm{lbs} \\ \text { Normal Drill Thrust } & 1,000-4,000 \mathrm{lbs} \\ \text { Normal Drilling Rate } & 200 \mathrm{ft} / \mathrm{hr} \\ & \text { (occasionally } 1,000 \mathrm{ft} / \mathrm{hr} \text { ) }\end{array}$

Operational concerns with the Kreepie-Krawler are: the hose spool is cumbersome and there may not be enough room in a 5-foot coal seam for, say, $2,000-3,000 \mathrm{ft}$ of 3 -inch hose bundle.

Another drilling system for drilling horizontal hole at the coal face was developed by Acker Drill Company, Inc. of Scranton, Pennsylvania (Figure 23). This system, which Acker labels "Big John, uses drill pipe to transmit rotation and axial thrust force to the drill bit. It has the capacity to drill horizontally to a depth of 3,000 to 5,000 feet. Downhole motors can be used in their drilling system, however, rotary power usually is delivered from outside the borehole.

Another underground mobile drilling rig was designed by Continental $0 i l$ Company and fabricated by J. H. Fletcher and Company of Huntington, West Virginia. Thrust is developed outside the wellbore and transmitted to the bit by drill pipe. 


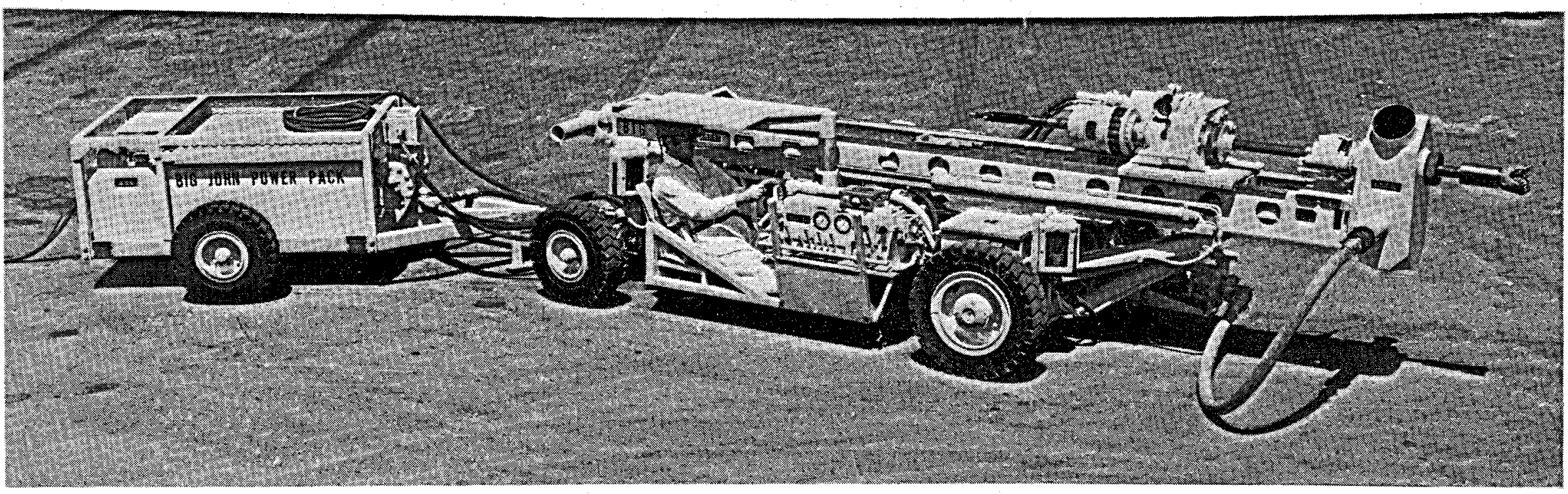

Figure 23

(Courtesy of Acker Drill Company, Inc.) 
Other horizontal drilling inventions by Conoco are disclosed in the following patents:

$\begin{array}{ll}\text { Edmond } & 3,827,512 \\ \text { Dahl, Edmond } & 3,853,182 \\ \text { Bourne, Schroeder } & 3,888,319 \\ \text { Dahl, Edmond } & 3,907,045 \\ \text { Schroeder } & 3,978,930\end{array}$

Two of the first horizontal drilling machines built for coal mine operations were fabricated by the Longyear company of Minneapolis and Sprage and Henwood of Scranton, Pennsylvania. Both are still in operation today.

Controlling hole direction is a major problem in drilling horizontally into coal seams. Coal is soft and side loads on the bit can easily build hole angle. When bit thrust is generated outside the borehole and transmitted through drill pipe, the entire drill pipe will buckle as an Euler column within the confines of the borehole. Stabilizers and drill collars are therefore required near the drill bit to eliminate pipe buckling near the drill bit and to controldrilling direction.

There are two types of bottom-hole assemblies being used with underground mobile drilling rigs which use drill pipe to transmit axial force to drill bits. One is called the rotary borehole assembly. The other is called the nonrotary borehole as sembly.

The rotary borehole assembly contains two stabilizers separated by a 20-foot drill collar section; the drill bit is adjacent to the bottom stabilizer. The entire assembly rotates 
with the drill pipe. The purpose of the two stabilizers and drill collar is to control hole direction. If a directional survey indicates the borehole needs to be turned up, the back stabilizer is removed and bit weight is increased to about 2,500 lbs. To turn the bit down, the back stabilizer is replaced, the front stabilizer removed, and bit weight is reduced to about 1,000 lbs. Normally both stabilizers are used with a bit weight of about 1,500 to 1,700 lbs applied through the drill pipe.

The nonrotary borehole assembly as proposed by Continental oil Company includes a drill bit, deflection device or side thruster, downhole motor and stabilizer (9).
"The deflection device is a spring-loaded, eccentric sub which exerts a constant force on the side of the bit. The direction of this applied force depends on the orientation of the device and determines whether the bit will be deflected up, down, left, or right. The magnitude of this force and hence the rate of angle build is controlled by the size of the spring."

The advantage of this assembly is it allows more directional control while drilling and provides nonrotating locations for downhole directional sensing instrumentation.

Slant hole drilling from the surface using direction drilling techniques is being evaluated by the $U$. S. Bureau of Mines as an alternate method for drilling horizontally into coal seams. Drilling is conducted from the ground surface instead of at the coal face and requires accurate directional surveying and bit control to hit the coal seam at a near horizontal slope (see Figure 24). Their project includes drilling into the Pittsburg coalbed at the Emerald Mine near Waynesburg, Pennsylvania. A Detailed description of the USBM project is given in Reference 1:0. 


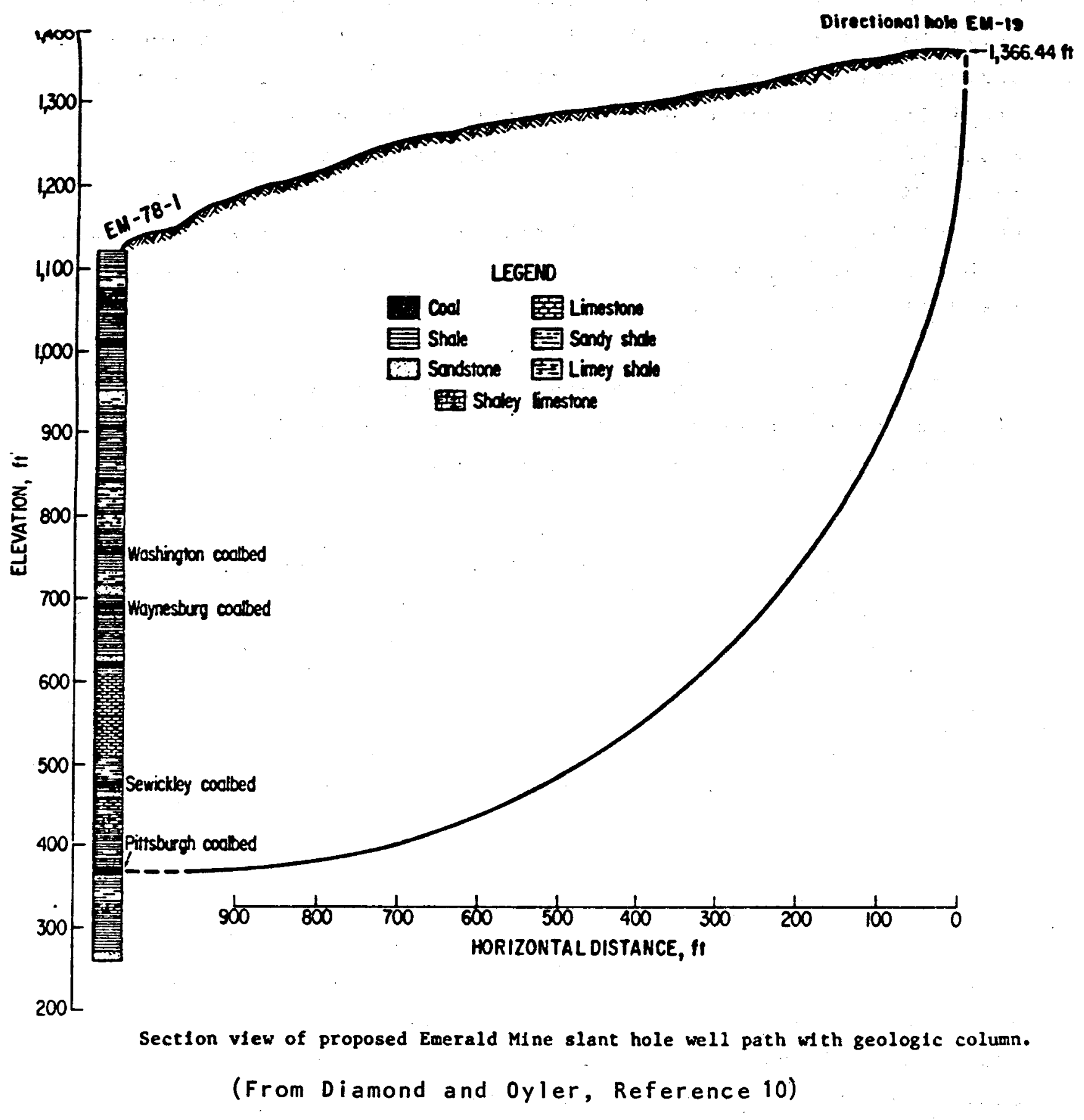

Figure 24 
One goal of the USBM project is to drill a circular arc directional well having a planar radius of about $1,000 \mathrm{ft}$ and then continue the drilling program with boreholes harizontally into a coal seam. The circular arc directional hole has already been successfully drilled and cased.

This unique wellbore is being drilled with a truck mounted drilling rig using a 2-3/8 inch Dyna-Drill having a bent housing. Accurate directional surveying, using Eastman. Whipstock magnetic singleshot equipment, was a key factor in the successfuldrilling of this hole.

Bit force was generated by hydraulic cylinders pushing down on the drill pipe at the surface. Part of this push down load was absorbed by friction and confining forces along the drill pipe so the magnitude of the bit force was not exactly known during the drilling. The axial bit force component, however, can be monitored reasonably well from the known pump pressure. The Dyna Drill is a positive displacement motor so pressure drop across the motor is a good indicator of output torque and thus bit thrust force. 
Shallow Horizontal Holes for Utility Lines and Site Investigation

There are several conventional methods for drilling shallow horizontal holes for installing utility lines. These methods are summarized in Reference 1.1. The simplest and most widely used method is spoil augering and is depicted in U. S. Patent 2,524,262 (Figure 25). According to this method, a pit is dug into the ground large enough to accomodate the augering tool and deep enough for the require hole depth. Drilling thrust is applied outside the hole. This method is limited to 500 feet long holes having small diameters or to $300^{\prime}$ long holes having diameters near 40 inches.
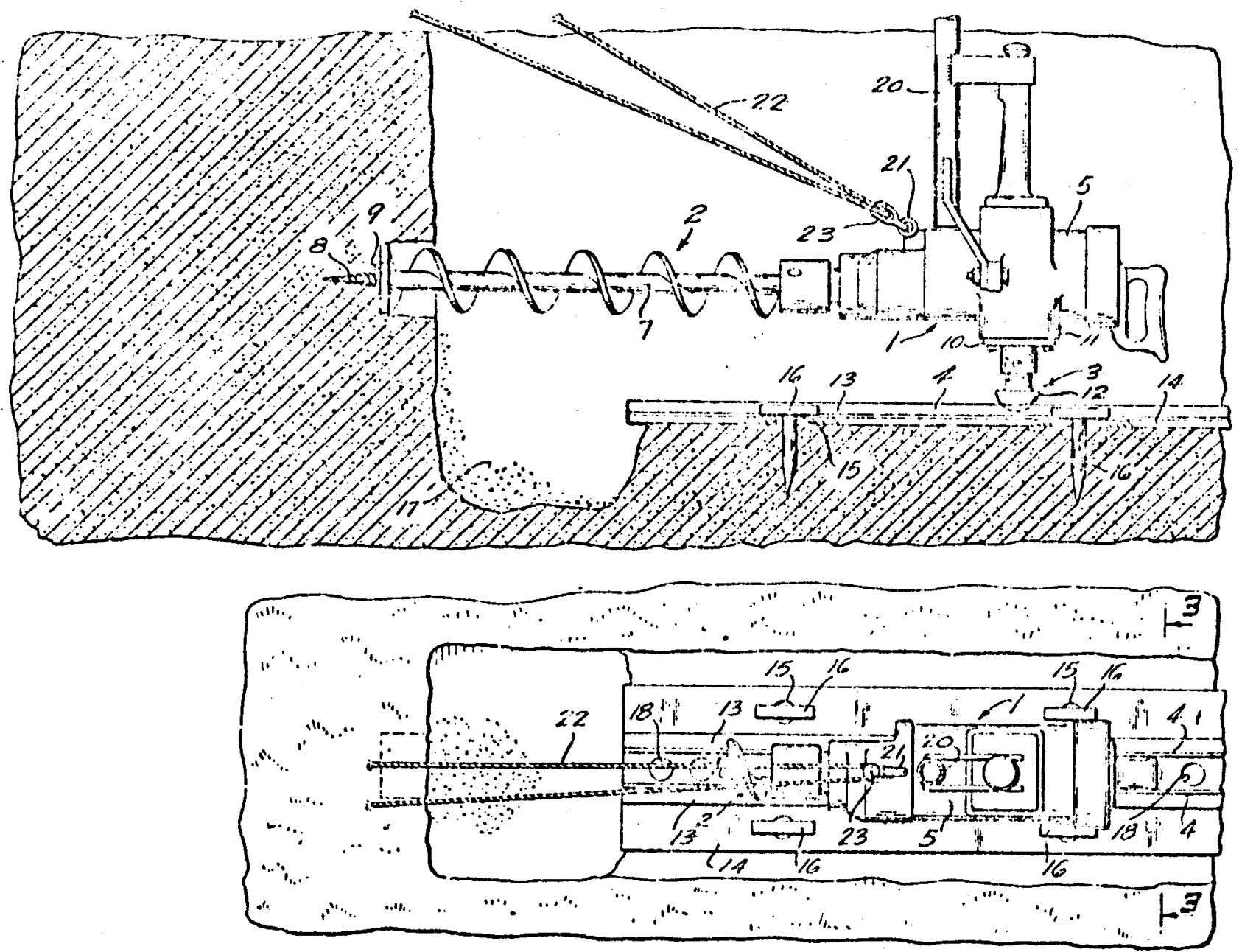

Figure 25 
In hard rock areas, rotary and percussion drilling is used. These methods derive their thrust from outside the borehole by hydraulic loading cylinders.

The "mechanical mole" is an air-driven impact tool containing a hammer and anvil encased in a bullet-shaped housing (Figure 26):

Steen

Cogne

Tupitsyn
$3,814,192 \ldots$ U.S.

$3,630,295$. U. S.

$1,170,167$ British

The tool is driven forward as the hammer impacts the anvil. The soil is not removed but instead is compacted and provides a temporary natural casing until the utility lines are installed.
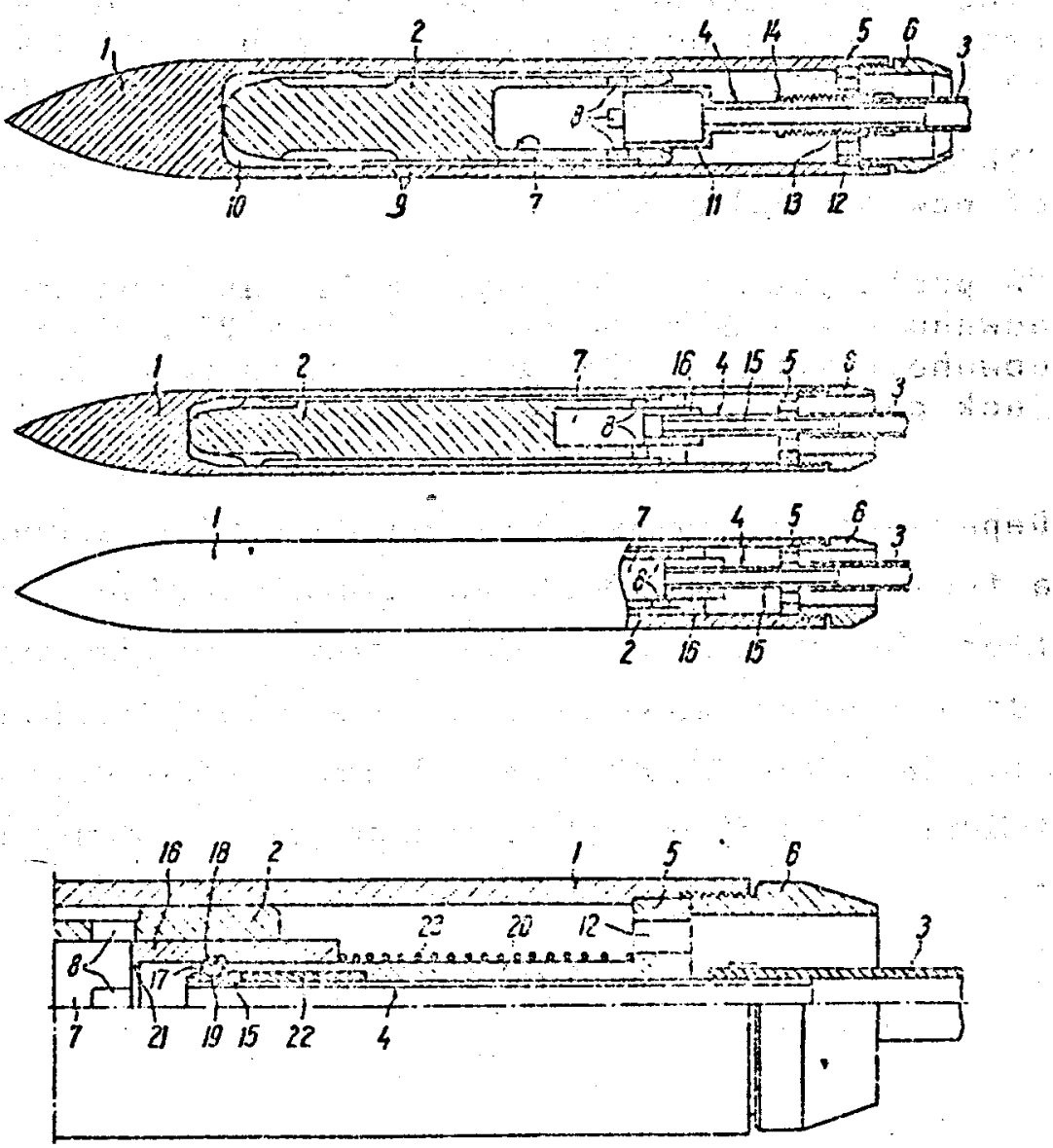

Figure 26 
Dr: Daniel Hettiaratchi (see Reference 12) at the University of Newcastle upon Tyne in England has developed a similar tool based on the mechanism by which roots grow in soil. Anchor pods in the bullet shaped tool expand radially first to crack the soil and then a nose cone is thrust forward. The tool is pneumatically powered.

Pipe pushing is another method for establishing shallow horizontal holes. Because of extreme forces required to push pipe through soil, this method is used only for short holes. The recent patent $(3,834,668)$ by Casey indicates there is still interest in this method.

A. Ciavatta (Reference 11) conciudes:

- "The installation of future utility lines will requiredrilling hardware that can drill 24 inch diameter holes horizontally out to $2,000 \mathrm{ft}$."

- "This can be done without the major development of new technology."

- "A preferred drilling system is based on the downhole assembly shown in Figure 27. The downhole assembly includes a percussion drill, jack pads for steering, and downhole thrusters."

The Department of Transportation recently issued a report covering a feasibility study of horizontal boring for site investigation (Reference 12). The report gives a comprehensive survey of drilling hardware that may have application for directionally drilling 5,000 feet of hole under rivers, etc. The report identifies five different downhole thruster applicators. 
They are:

- Drilco Thrust Applicator

- NURAT

- British Government Post Office Ductmotor

- U.S. Navy Polytoroidal Tunneling Thruster

- WORM TM

The Drilco Thrust Applicator is the same as the KreepieKrawler discussed earlier and NURAT is mechanical mole developed by Dr. Hettiaratchi of Newcastle, England.

The British Post office Ductmotor was designed to crawl through utility ducts. Its principle of operation is similar to Drilco's Kreepie-Krawler except air bags are used to grip the duct walls instead of anchor pads that are designed to grip the borehole walls.

The U.S. Navy Polytoroidal Tunneling Thruster derives its forward motion and thrust by vermiculating or earthworm like motions which traverses a contacting surface with a longitudinal wave: Sets of toroids cyclically expand and contract to provide the vermiculating motion (Figure 28 ).

WORM, an acronym for Wheel-less Orthogonal Reaction Motor, was invented by $W$. Still. This downhole assembly concept has been tested with a small model. It is an advanced form of the U.S. Navy Polytoroidal Tunneler and is being developed for oilfield type drilling.

The Department of Transportation Project included directionally drilling a curved borehole under the Cerritos Channel, 


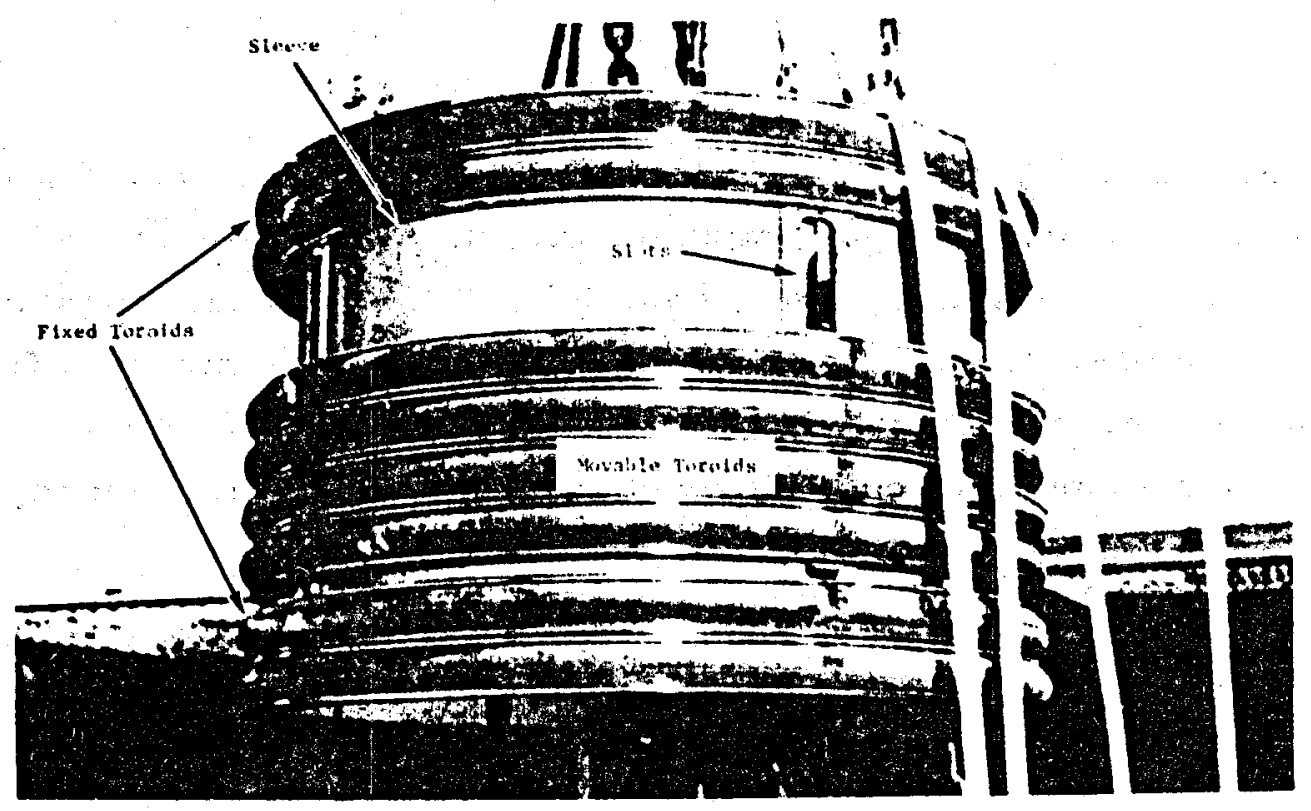

o) EXPERIMENTAL MODEL

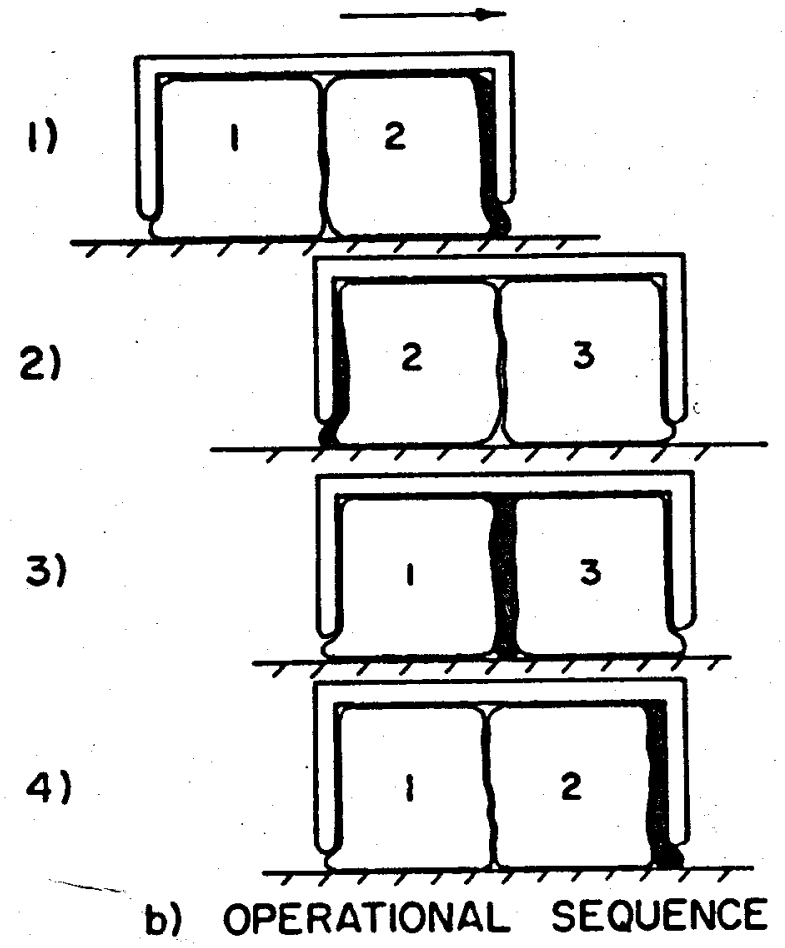

(After Williams \& Gaberson, 1973)

Figure 28 
Long Beach, California. The driling contractor was Titan Contractors Corp. of Sacramento, California. Details of this operation are given in Reference 12. Drilling was conducted from a slanted rig using a Dyna-Drill downhole motor. Bit force was generated at the rig and transmitted down the drill pipe. Directional control was achieved by use of a bent housing and a deflection pad. 


\section{Cluster Drilling}

The concept of drilling a group or "cluster" of wells from the bottom of a borehole to increase the productivity of the well is beginning to find application in several industries. Figure 29 shows a geothermal well at Raft River, Idaho, where two cluster wells were drilled from the initial well. The productivity of this well was increased three to four fold by the additional wells. The results of this test indicates that this technique may be critical for converting low productivity geothermal wells into commercial producers.

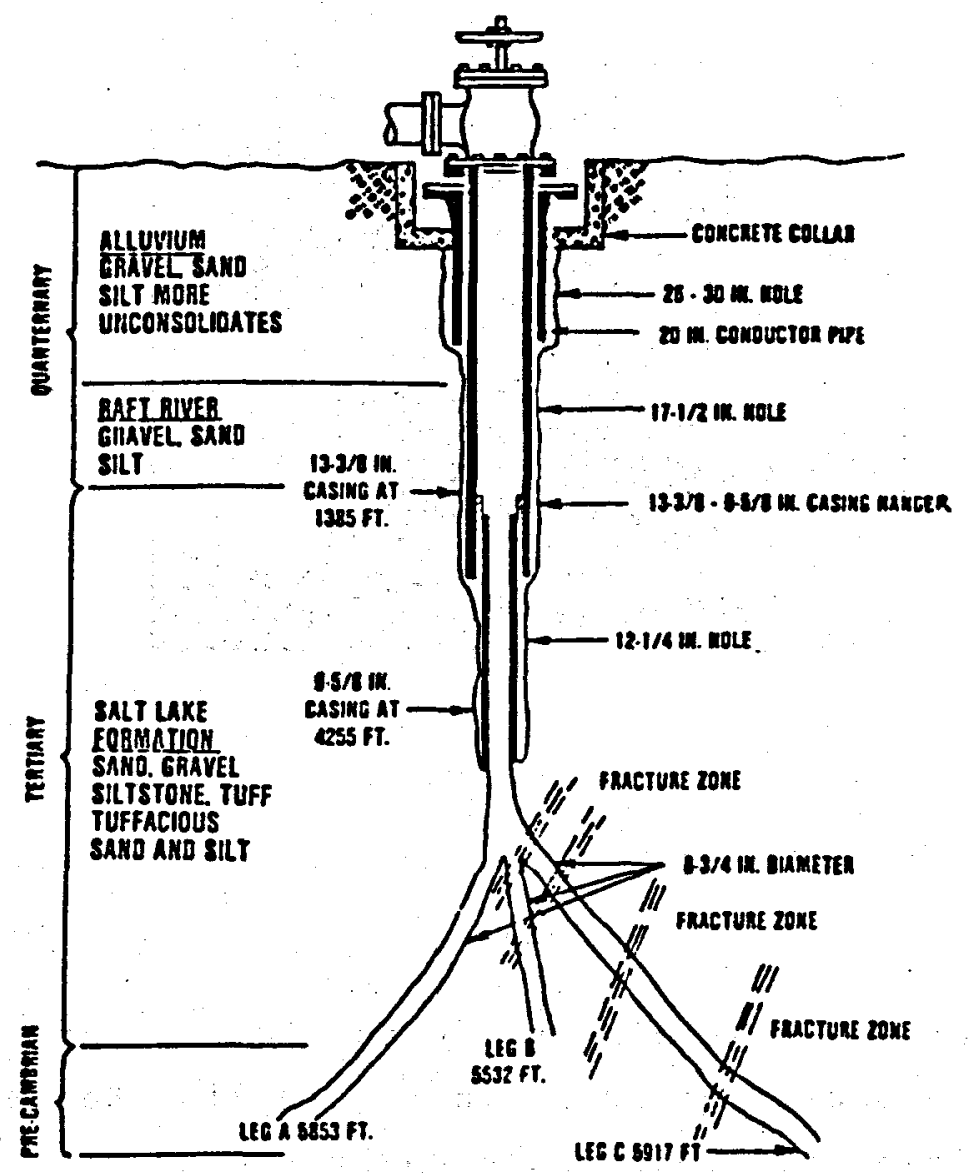

Figure 29 
Cluster drilling has been used in the Soviet Union to increase the productivity of oil and gas wells (Figure 30 ). This technique will probably find application in the United States for drilling producing tight oil and gas formations having low permeabilities.

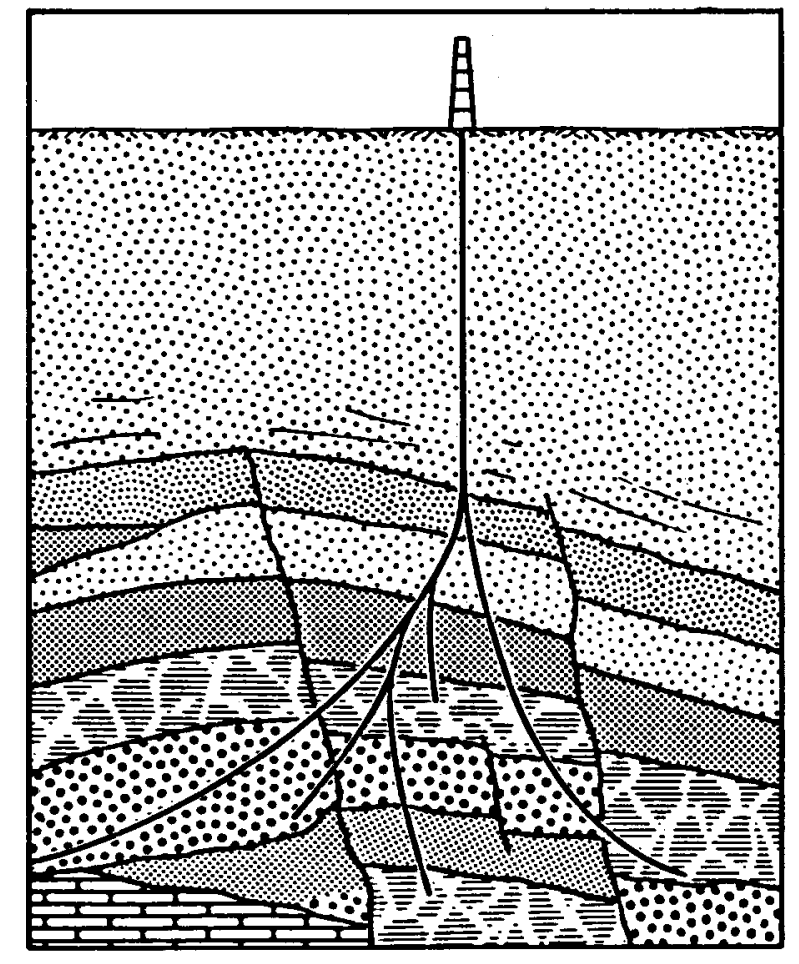

Figure 30

Cluster drilling is also being considered for in situ leaching of ore bodies as shown in Figure 31 . Kennecott and other large mining companies have major RED efforts on this type of in situ leaching process. 


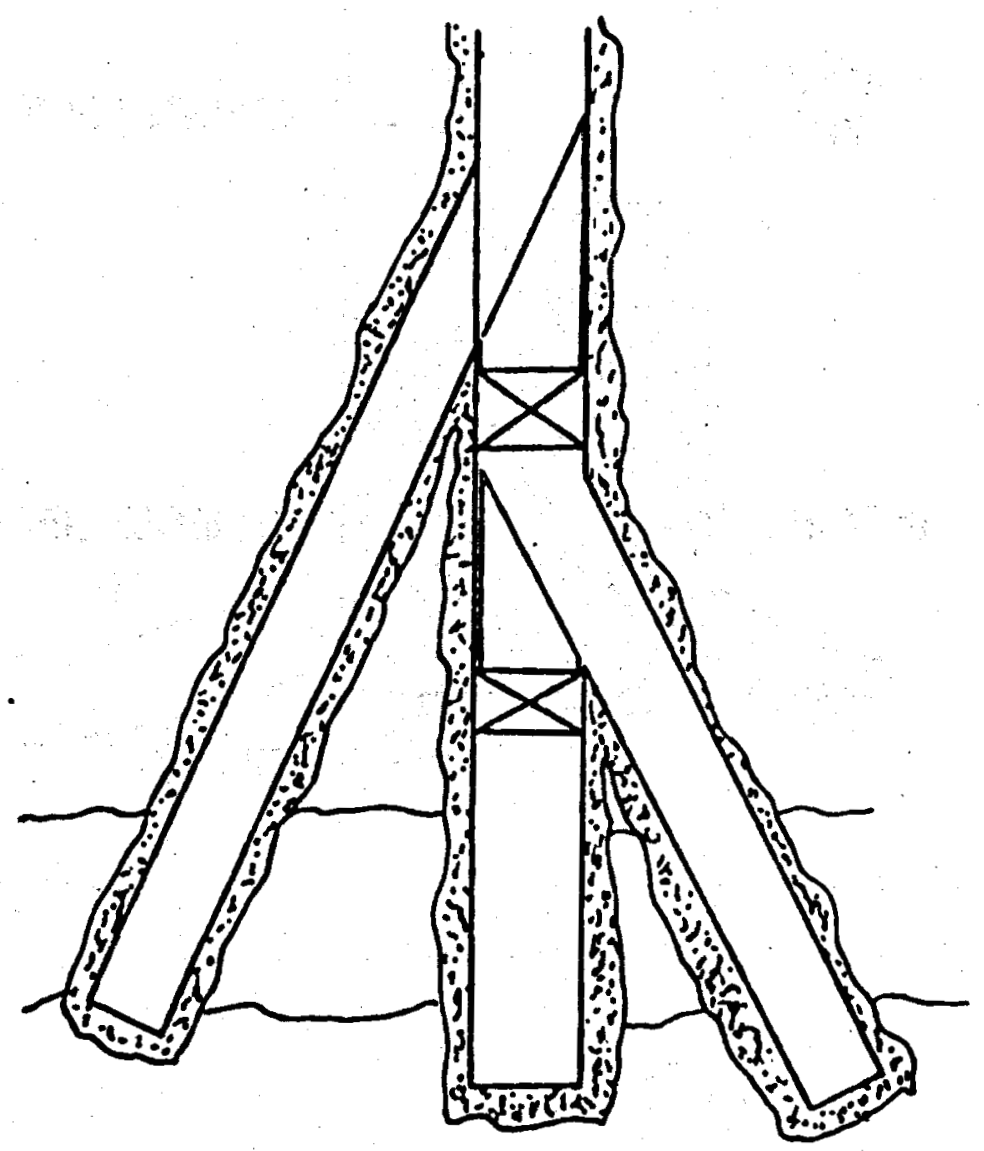

Figure 31

These and other applications will require widespread use of cluster drilling in the next few years. Additional hardware development is needed to reduce the time and cost of drilling cluster holes. Figure 32 shows an indexing mandrell that could significantly reduce the time and cost of driling cluster holes. The mandrell would remain stationary while a cluster hole is being drilled. Following completion of the cluster hole, the motor and bit would be retracted into the primary hole, the mandrell indexed to allow accurate drilling of the next cluster hole, the motor lowered and drilling resumed. 


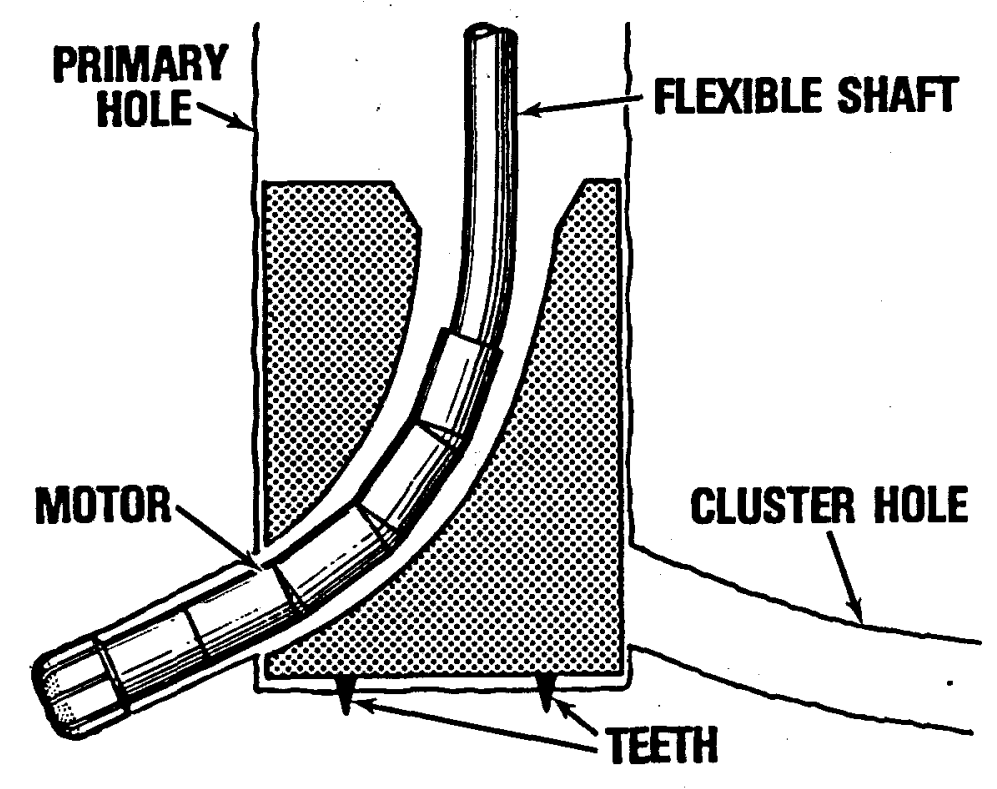

Figure 32

This concept will require several hardware developments including:

1. Indexing Mandrel

2. Short, Flexible Motors

3. Flexible Shaft

4. Improved Surveying Tools

Work should be initiated on these components because of the importance of cluster drilling for developing future mineral and energy resources in this country.

Patents relating to cluster drilling are identified in the Appendix. 
Underground Mining

At present, little directional drilling is done in the mining industry. Because of the critical energy problem and the increased worldwide shortage of many key minerals, it is likely that more sophisticated mining methods will be used in the future which will require the use of directional drilling techniques. Environmental problems will also require implementation of techniques which do less damage to the surface.

New mining techniques which may utilize directional drilling include:

1. In Situ Mineral Leaching

2. Borehole Mining Systems

3. Mining Steeply Sloping Seams

4. Mining Under Populated Areas

5. Undersea Mining

6. Drilling Safety Borehole Ahead of Miners

7. High Speed Tunneling and Mining Machines

Where possible, these systems will utilize advanced directional drilling systems developed by the petroleum and geothermal industries. Additional equipment will have to be developed specifically for mining applications because of problems unique to the mining industry (e.g., small diameter holes, magnetic orebodies, etc.).

Our patent search uncovered several concepts for applying force to the cutting surfaces of underground mining tools. The patent $(3,642,326)$ by steufmehl is similar in concept to the Kreepie-krawler and vermiculating thruster. 


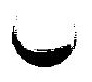

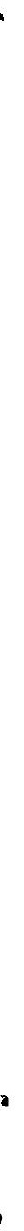

, 


\section{CONCLUSIONS}

Our survey uncovered several different concepts for generating force or thrust at drill bits. Some are fully developed and operational. Most are not. A basic requirement of a drill bit thruster is that it be rugged, mechanically uncomplicated, and simple to operate. While most of the patented concepts work in theory, they do not satisfy this basic requirement.

Thruster hardware that has worked successfully and accepted by the petroleum and mining industries are:

1. Drill Collars

2. Percussion or Impact Tools

3. Hydraulic Drill Pipe Pushers

4. Stabilizers

5. Bent Subs and Housings

6. Whipstocks

These are conventional tools used on a regular basis by driling contractors.

Nonconventional bit thrusters can be listed under the following categories:

1. Hydraulic Bit Thrusters (Axial and Transverse)

2. Heavy Metal Thrusters

3. Bodine Sonic Thrusters

4. Vermiculating Thrusters

The slant hole drilling program conducted by the $U$. S . Bureau of Mines at Waynesburg, Pennsylvania, showed that high 
curvature wellbores can be accurately drilled using bent housings with drill bit thrust generated at the rig by hydraulically pushing the drill pipe. Also, horizontal drilling at the face of coal beds is now being accomplished on a routine basis with bit force generated by hydraulic drill pipe pushers.

\section{Conventional directional drilling thrusters are not} completely satisfactory because drilling is stopped often for surveys and downhole hardware changes. Present directional drilling is therefore time consuming, costly, and there is need for improvements in both monitoring and directional control.

The ideal directional drilling system should allow continuous monitoring and directional control while drilling. Hydraulic bit thrusters are proven operational tools based on twenty years of development and testing. They are a viable candidate for future automatic directional drilling systems. Suitable downhole information gathering systems are now needed to tell the driller or his program what course of action to take next (i.e., what direction change is needed). Feedback loops can make this corrective action automatic. 


\section{RECOMMENDED FUTURE WORK}

Downhole thrusters will be only one part of the advanced directional drilling systems used in the future (Figure 33 ). The thrusters will have to be designed to be compatible with the other major downhole system components:

1. High Speed Bit

2. Motor

3. Steering Sub

4. Retracter

5. Survey Package

6. Sensors

7. Processing and Control

8. Receiver/Transmitter

9. Reelable Pipe

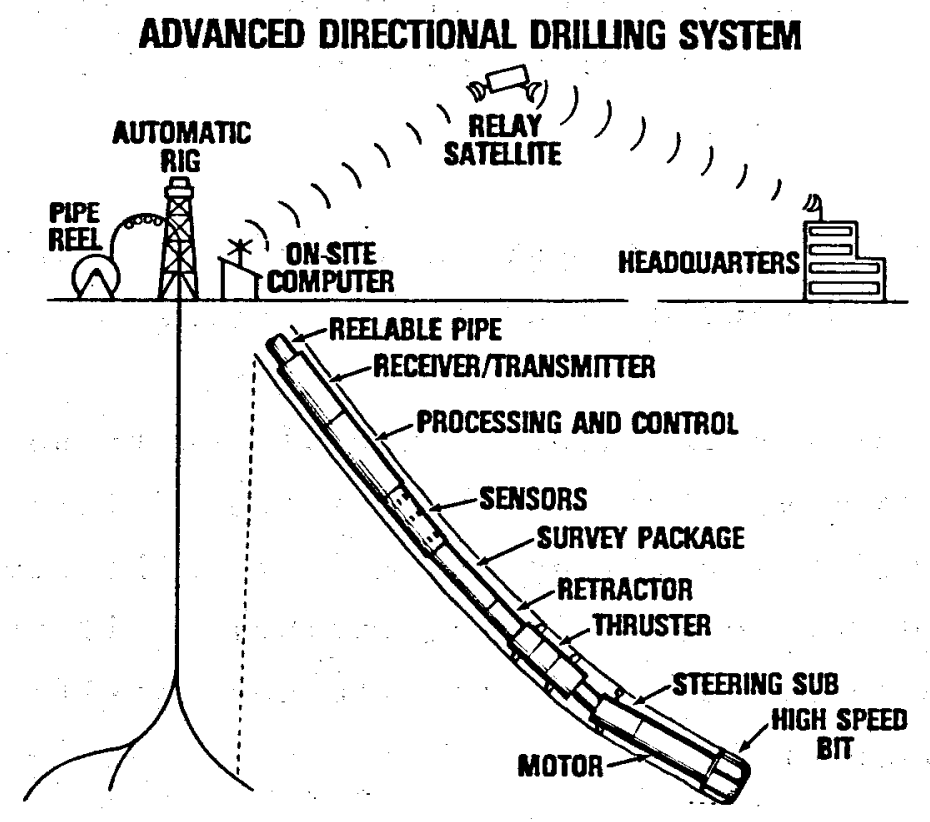

Figure 33 
Future work on drilling thrusters will have to be coupled with futuristic development of the above downhole components. The success of the system will depend on clever integration of these components into a viable economic and practical system.

Specific tasks required to develop a best thruster for each application of directional drilling are:

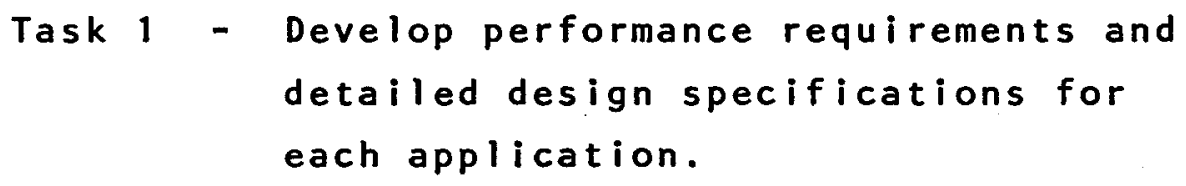

Task 2 - Develop preliminary thruster designs based on both conventional and nonconventional thruster concepts. Each design must integrate with other directional drilling equipment.

Task 3 - Evaluate each design from standpoint of cost, risk, performance, and schedule.

Task 4 - Recommend best thruster for future directional drilling systems.

The goal of the extended work would be to design preferred thruster alternatives that can be integrated into futuristic downhole directional drilling assemblies. The study would cover all areas of directional drilling including oil and gas, geothermal, mineral leaching, in situ coal gasification, and methane drainage drilling. 


\section{REFERENCES}

1. McDonald, W. J., Rehm, W. A., and Maurer, W. C.: "Improved Directional Drilling Will Expand Use," Oil \& Gas Journal, February 26, 1979.

2. Kellner, J. M. and Roberts, A. P.: 'Hydraulic Wall-Anchored Drill Collar Promises Lower Drilling Costs," 0il \& Gas Journal, Vol. 58, No. 40, October 3, 1960.

3. Bradley, W. B., Murphy, C. E., McLamone, R. T., and Dickson, L. L.: "Advantages of Heavy Medal Collars in Directional Drilling and Deviation Control," Journal of Petroleum Technology, May, 1976.

4. Lubinski, Arthur: "A Study of the Buckling of Rotary Drilling Strings," Drilling and Production Practice, API, New York, Pp. 178-214, 1950.

5. Rehm, W. A.: "State-of-the-Art Study - Directional Drilling," Maurer Engineering Inc. Report No. TR77-18, for Sandia Laboratories, July, 1977.

6. Garrett, W. R. and Rollins, H. M.: 'New Deviation Control Looks Good in Field Tests," World Oil, October, 1964.

7. Rollins, H. M.: "Deviation Control Using Fluid-Operated Bit-Guiding Tools," presented at the Spring Meeting of the Rocky Mountain District; API Division of Production, April 1966.

8. Cervik, J., Fields, H. H., and Aul, G. N.: "Rotary Drilling Holes in Coalbeds for Degasification," U. S. Bureau of Mines, RI 8097, 1975.

9. Thakur, P. C. and Poundstone, W. N.: "Horizontal Drilling Technology for Advance Degasification," Preprint No. 79-113, presented at the 1979 AIME Annual Meeting in New Orleans, February 18-22, 1979.

10. Diamond, W. P. and Oyler, D. C.: "Directional Drilling for Coalbed Degasification in Advance of Mining," presented at the Methane Recovery from Coalbeds Symposium, April 18-20, 1979.

11. Ciavatta, Armand, Black, S., Collier, S. E., Edwards, J. T., Pauley, Wm. R., Parekh, P. K., Treible, E. S., Jr., Vocaturo, J. M., : "System Requirements and Ánalys is of an Experimental Guided Tunneler," EPRI 7836 and ERDA E(49-18)-2127 Report, August 1975.

12. Dowding, C. H.: "Feasibility of Horizontal Boring for Site Investigation in Sail," Federal Highway Administration Report No. FHWA-RD-76-1. 
$\omega$

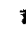

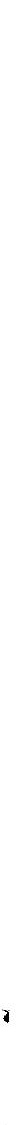


APPENDIX

DRILLING THRUSTER PATENTS

Pages

$0 i 1$ and Gas Production . . . . . . . . . 75 to 104

Horizontal Drilling Into Coal Seams. . ... . 105 to 116

Shallow Horizontal Holes for Utility

Lines and Site Investigation . . . . . . . 117 to 126

Cluster Drilling . . . . . . . . . . . . 127 to 137

Underground Mining .. . . . . . . . . . . 138 to 152 


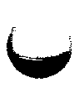

i

$+$

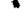



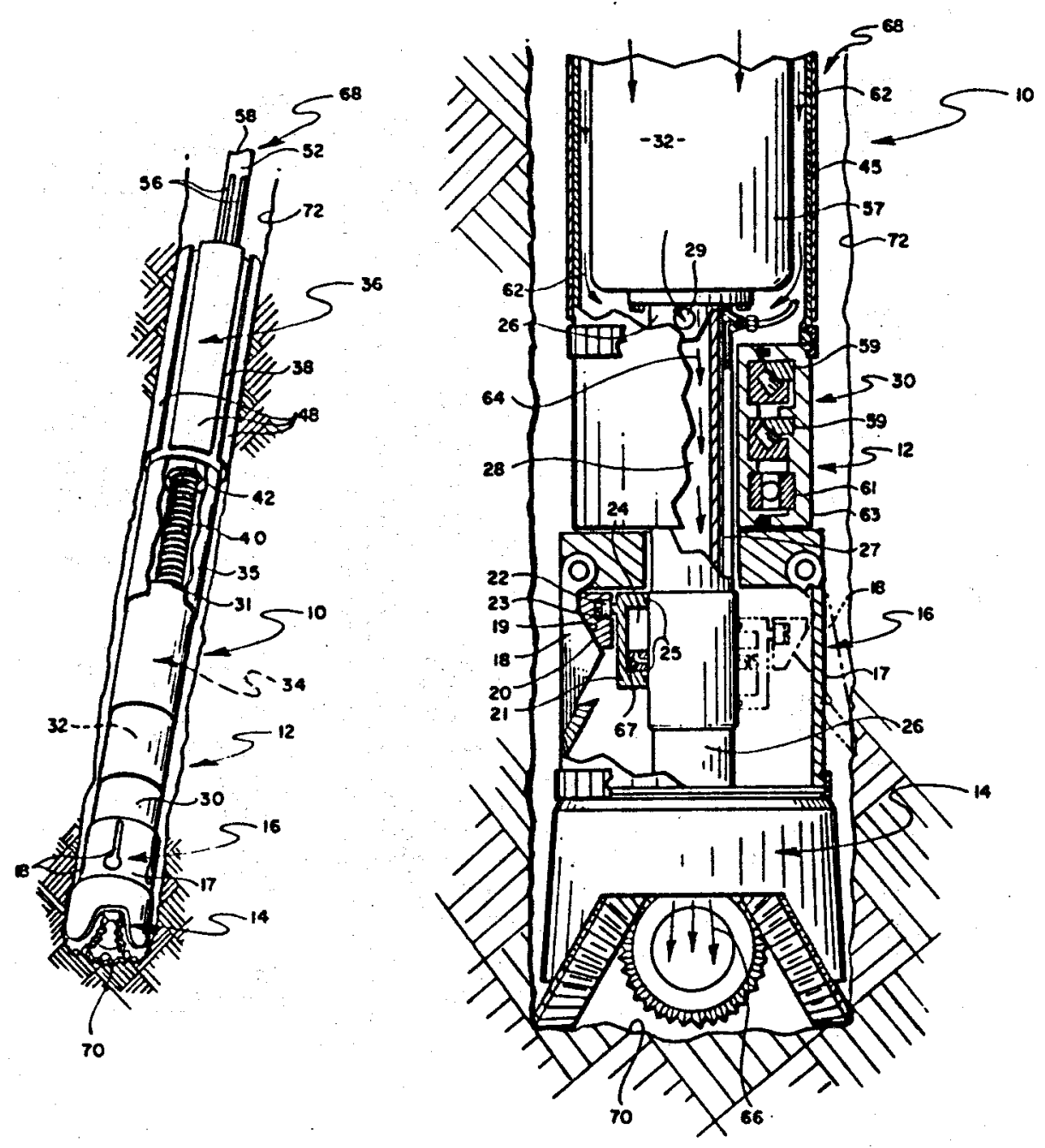

Patent No: $\quad 4,060,141$

Date: November 29, 1977

Inventor: Fritz C. Catterfeld

Assignee: Rockwell International Corporation

Title: Self-Propelled Deep Well Turbine Drill 

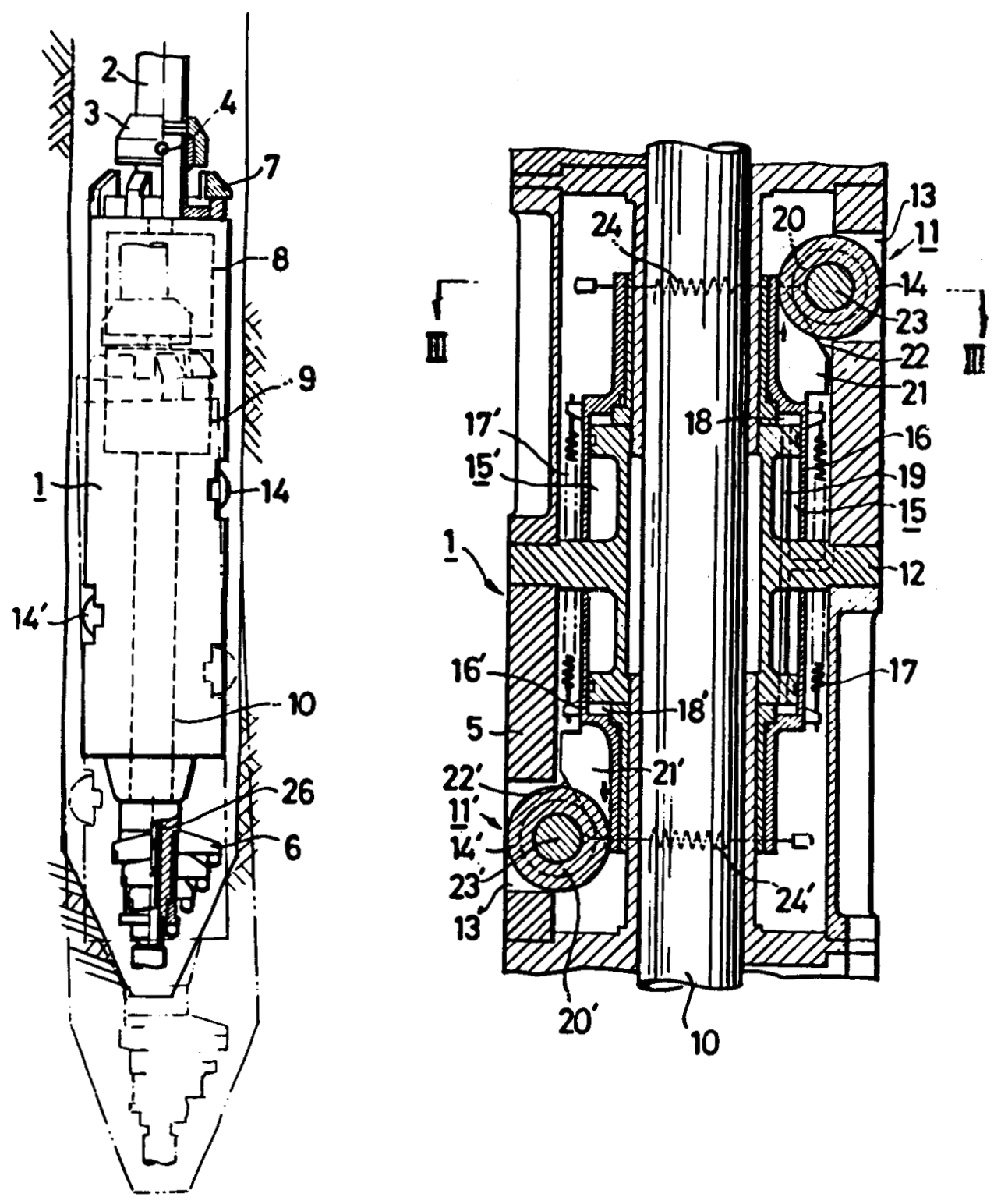

\footnotetext{
Patent No: $\quad 4,046,204$

Date: $\quad$ September 6, 1977

Inventor: Sabro Takaoka et al

Assignee: Agency of Industrial Science $\varepsilon$ Technology

Title: Controlled Directional Drilling Tool
} 


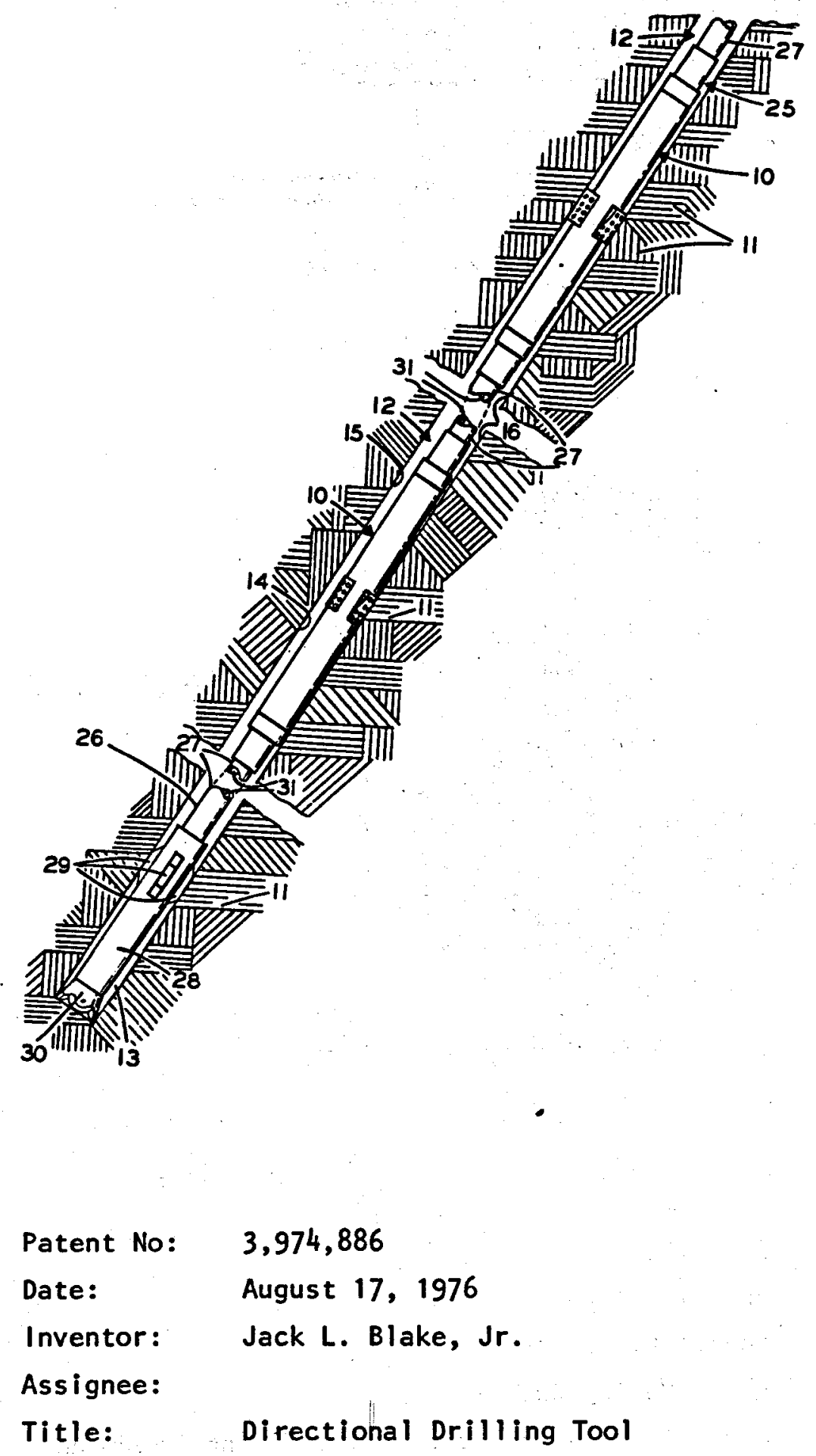




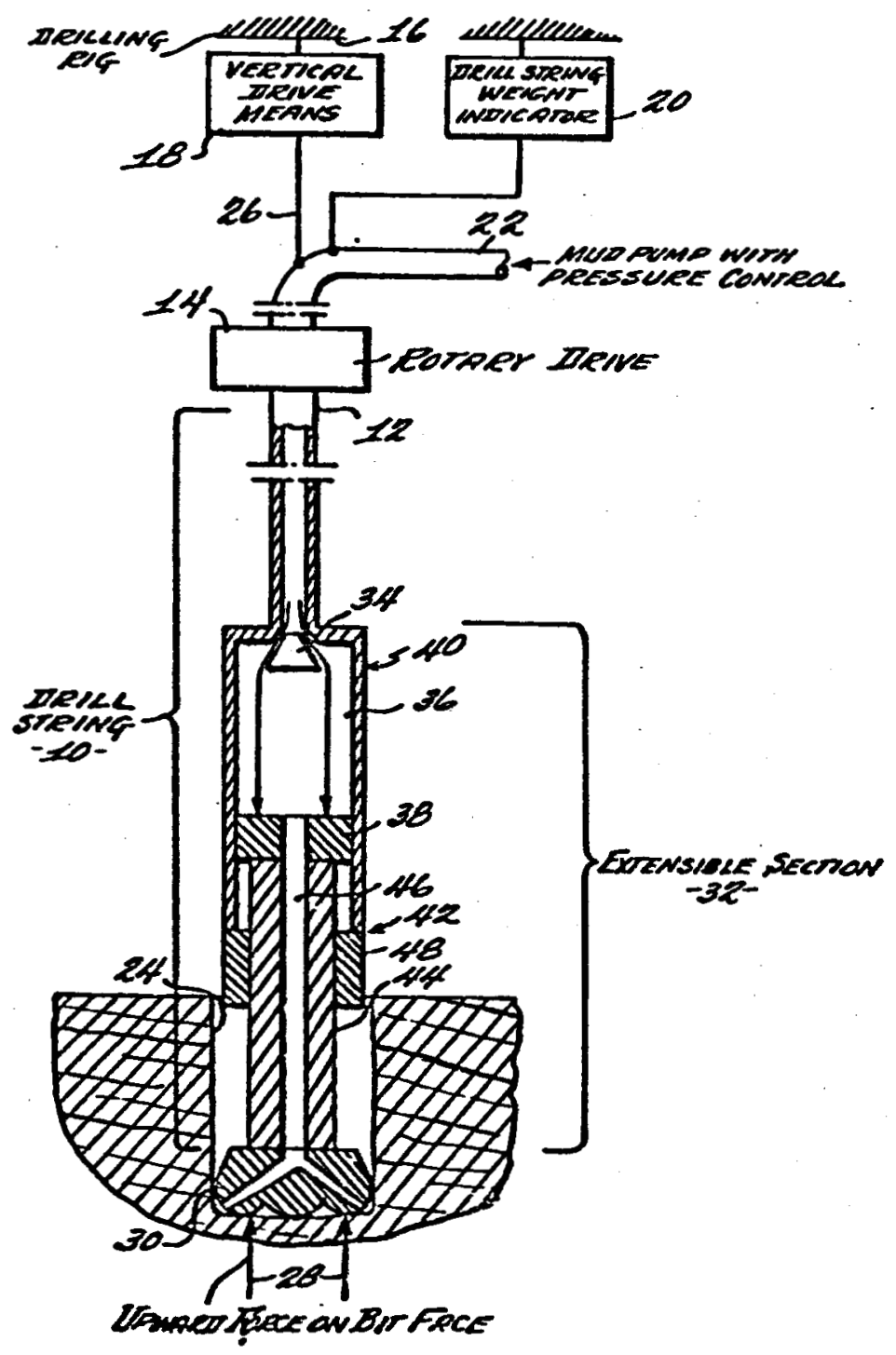

Patent No: $\quad 3,815,692$

Date: June 11, 1974

Inventor: Robert F. Varley

Assignee: R. F. Varley Co., Inc.

Title: Hydraulically Enhanced Well Drilling Technique 


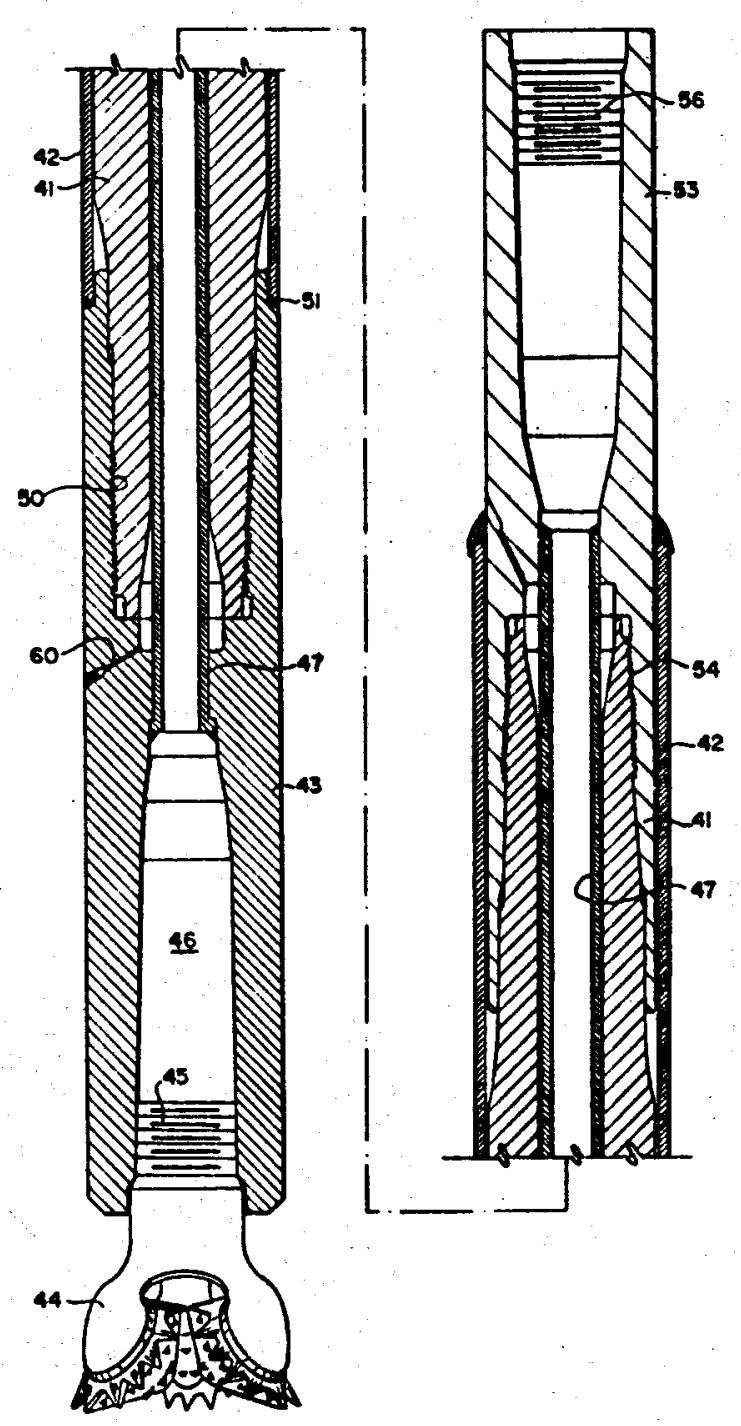

Patent No: $\quad 3,706,348$ (U.S.), 949,059 (Canadian)

Date:

December 19, 1972

Inventor: Carey E. Murphey, Jr.

Assignee: Shell oil Company

Title: Well Deviation Control System 


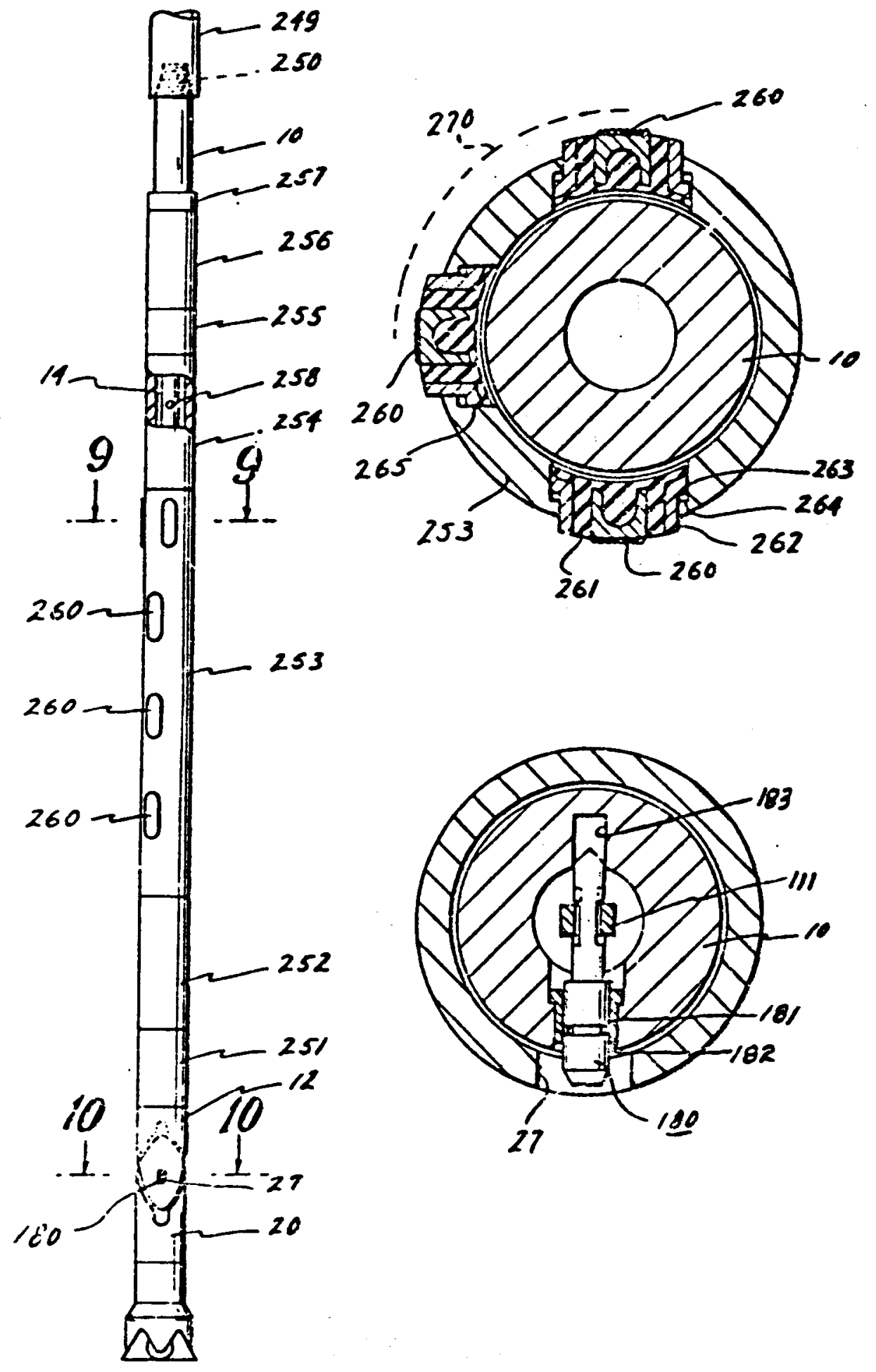

Patent No: $\quad 3,460,639$

Date: $\quad$ August 12, 1969

Inventor: W. R. Garrett

Assignee: Smith Industries International Inc.

Title: $\quad$ Latch for Drill Bit Control Apparatus 


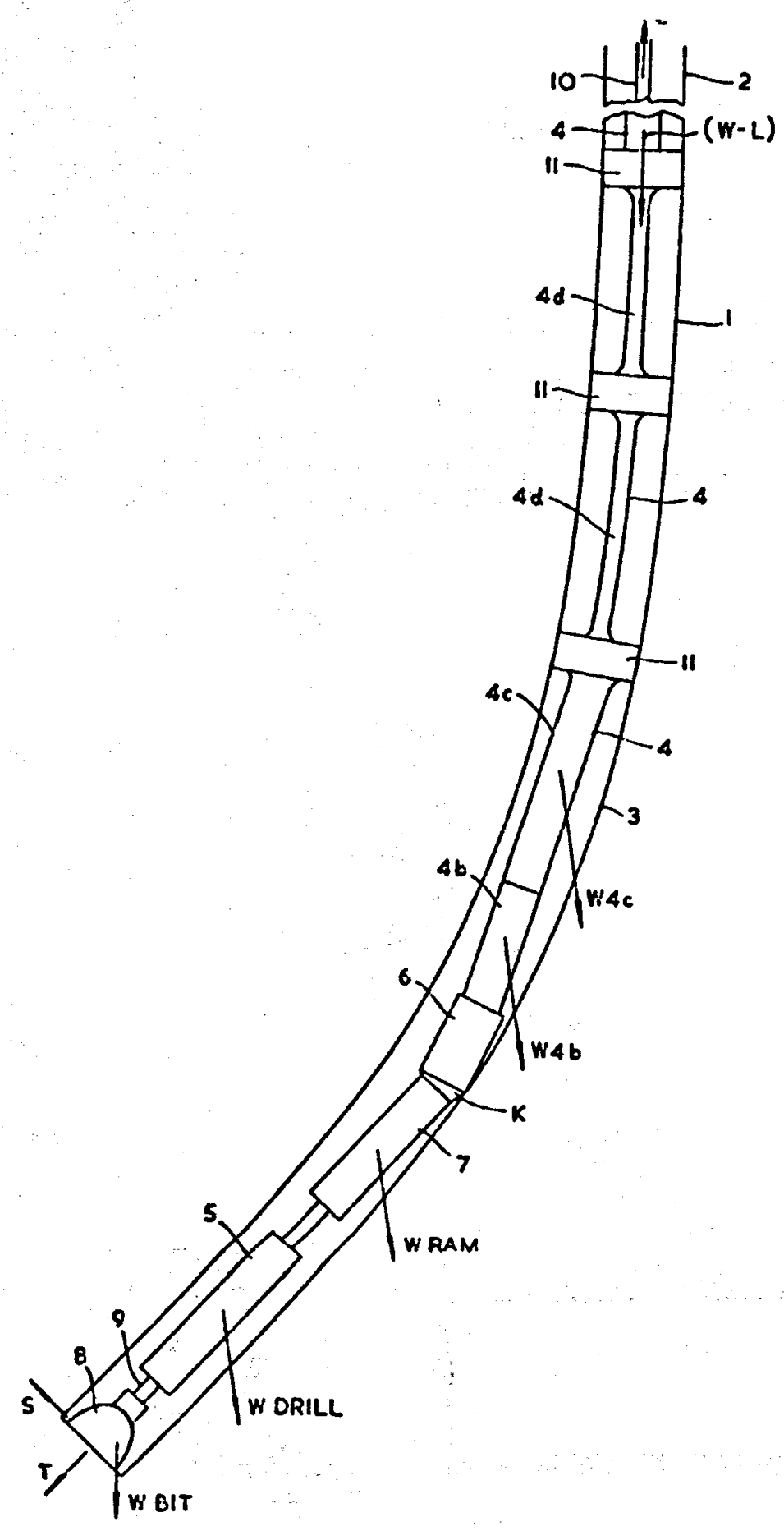

Patent No: 1212915 (British)

Date: January 17, 1969

Inventor: Howard Trethewein Edgecombe

Assignee:

Title:

Apparatus for Bore-Hole Drilling 


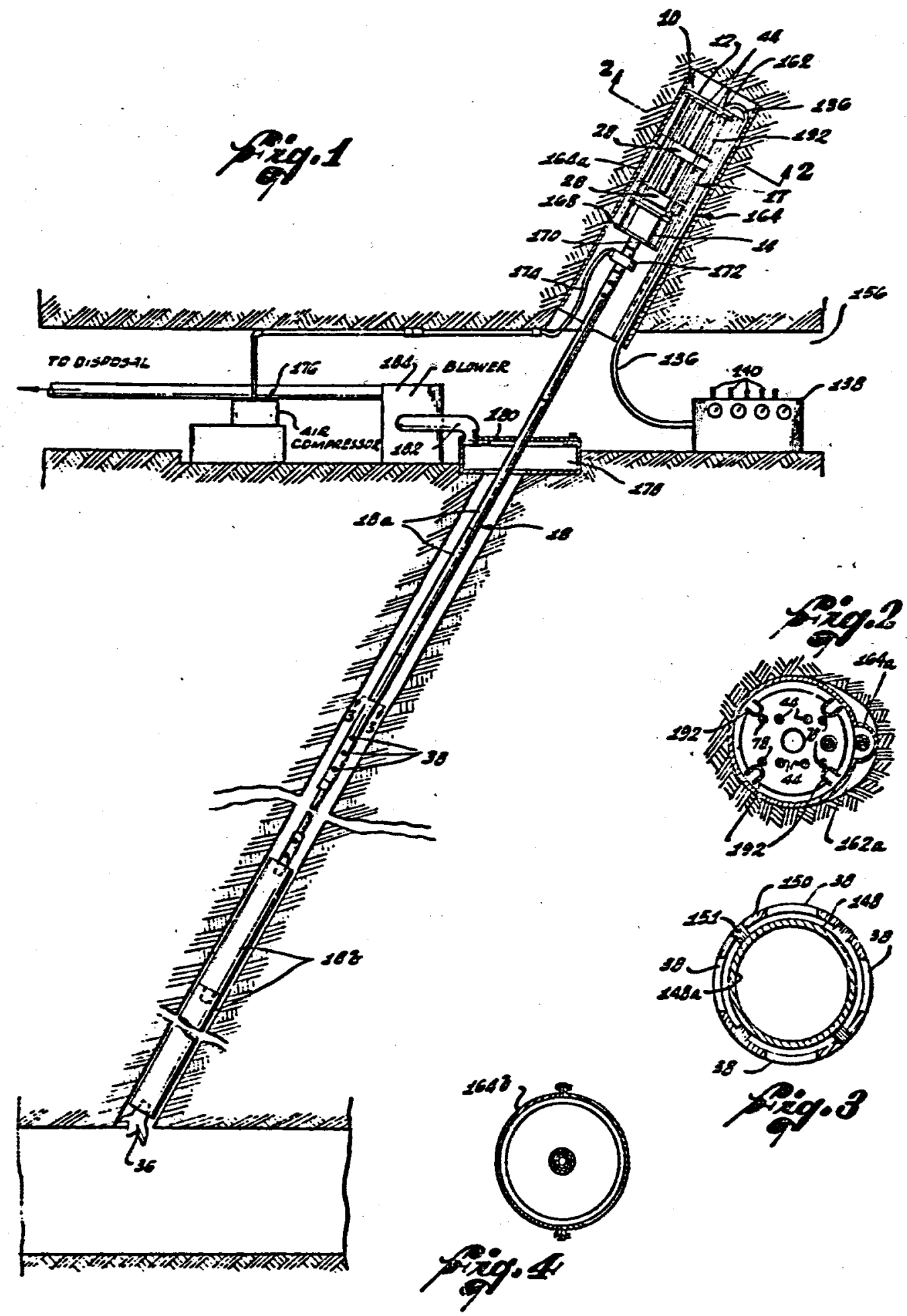

Patent No: $\quad 3,399,738$

Date: $\quad$ September 3, 1968

Inventor: J. C. Haspert

Assignee: Smith Industries International, Inc.

Title: $\quad$ Raise Driver 


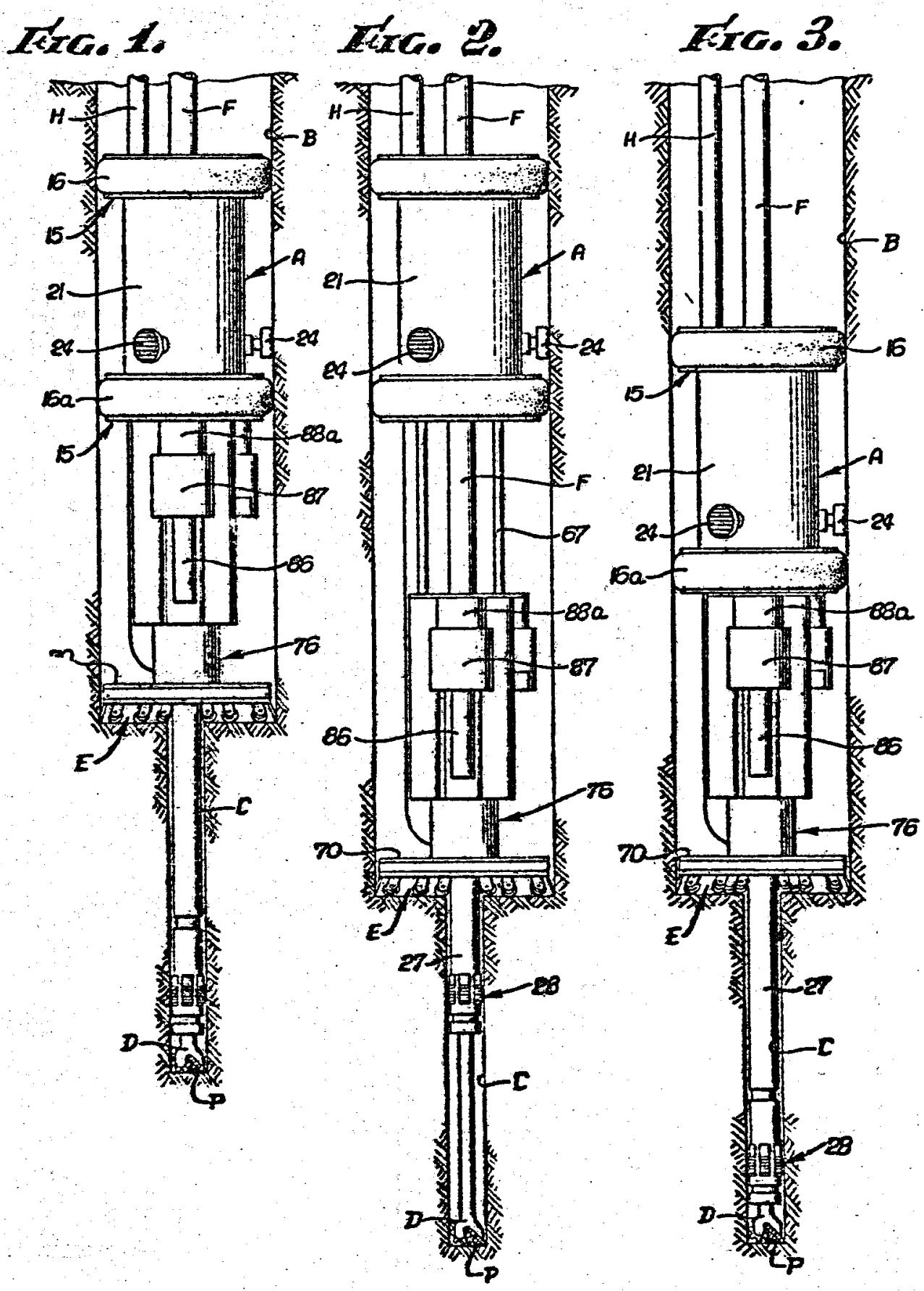

Patent No: $\quad 3,376,942$

Date: April 9, 1968

Inventor: D. W. Van Winkle

Assignee: Baker Oil Tools, Inc.

Title: $\quad$ Large Hole Vertical Drilling Apparatus 


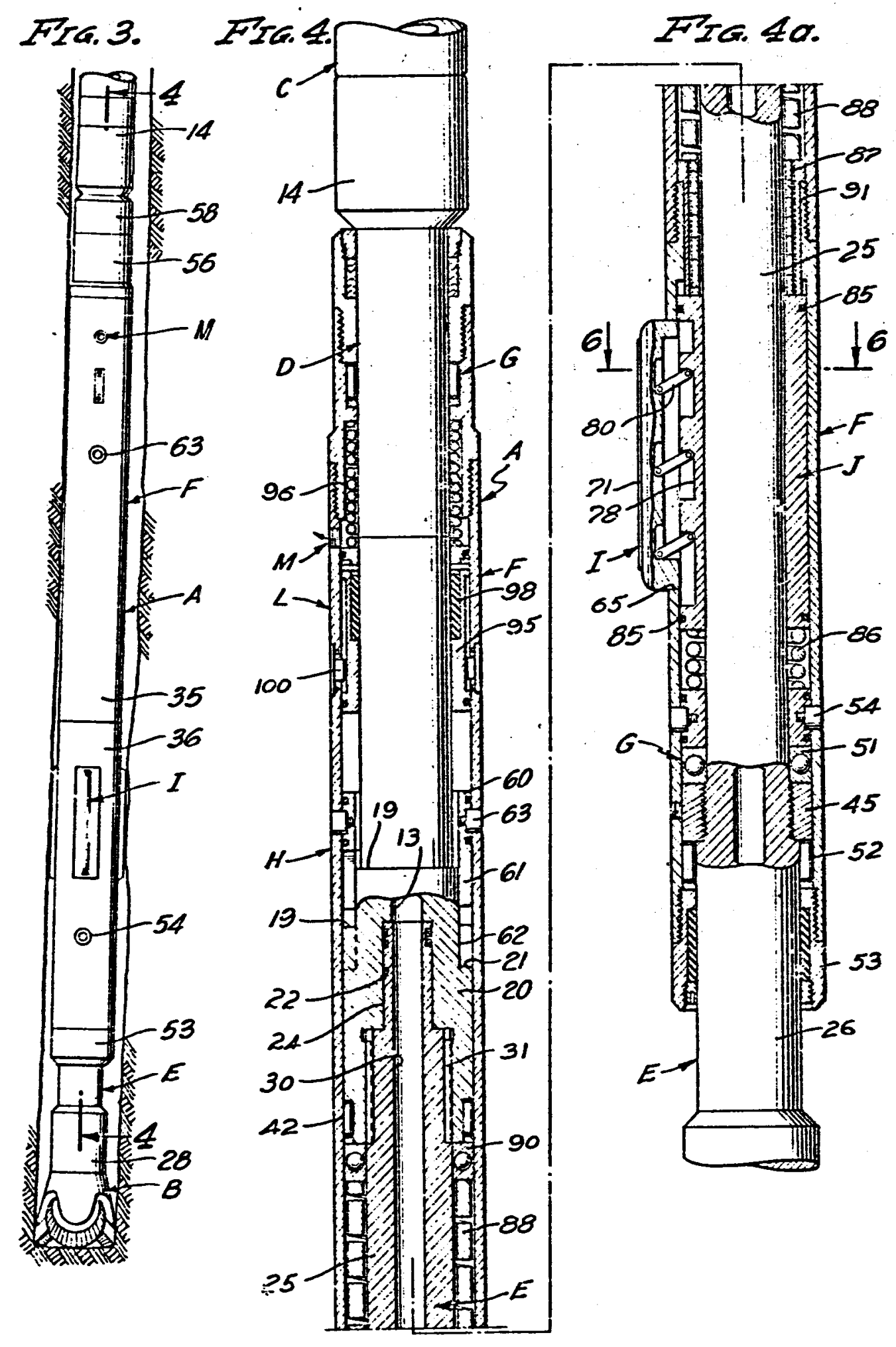

Patent No: $\quad 3,370,657$

Date:

February 27, 1968

Inventor: W. H. Antle

Assignee: Trudril, Inc.

Title:

Stabilizer and Deflecting Tool 


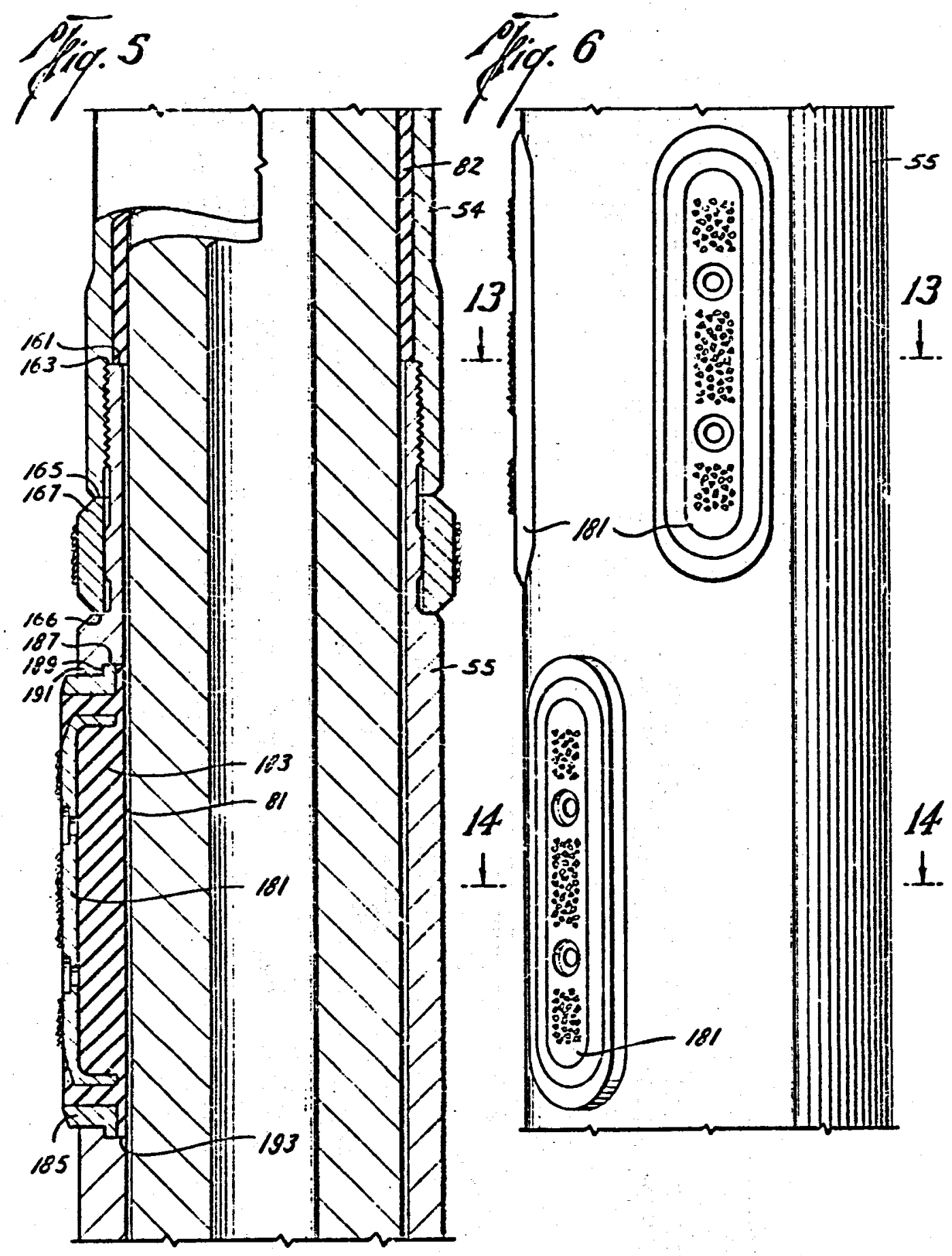

Patent No: $\quad 3,326,305$

Date: June 20, 1967

Inventor: W. R. Garrett et al

Assignee: Drilco Oil Tools, Inc.

Title: Drill Bit Control Apparatus 


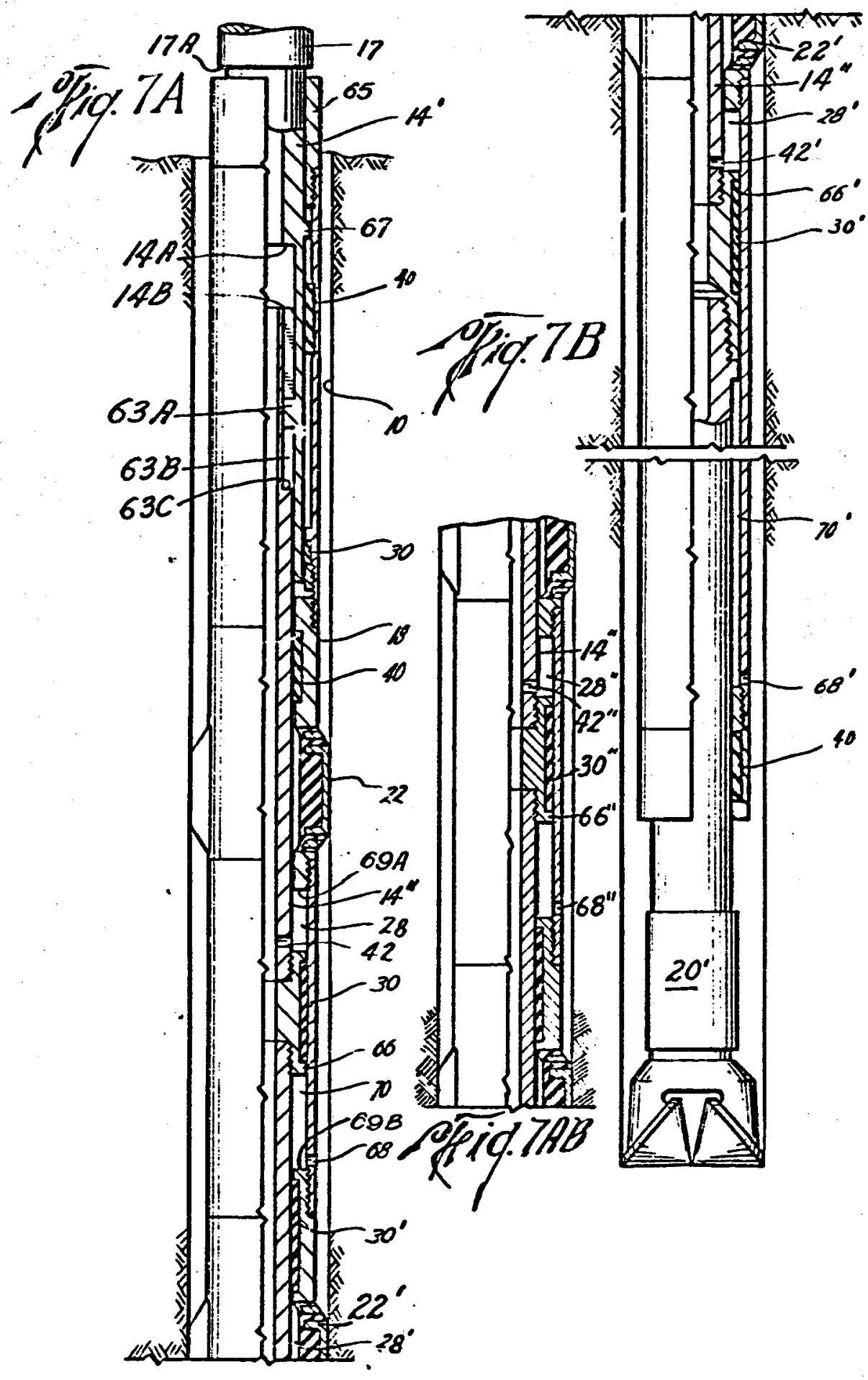
Patent No: $\quad 3,298,449$
Date: January 17, 1967
Inventor: W. S. Bachman et al
Assignee: Drilco Oil Tools, Inc.
Title: Well Bore Apparatus 
Fig.8

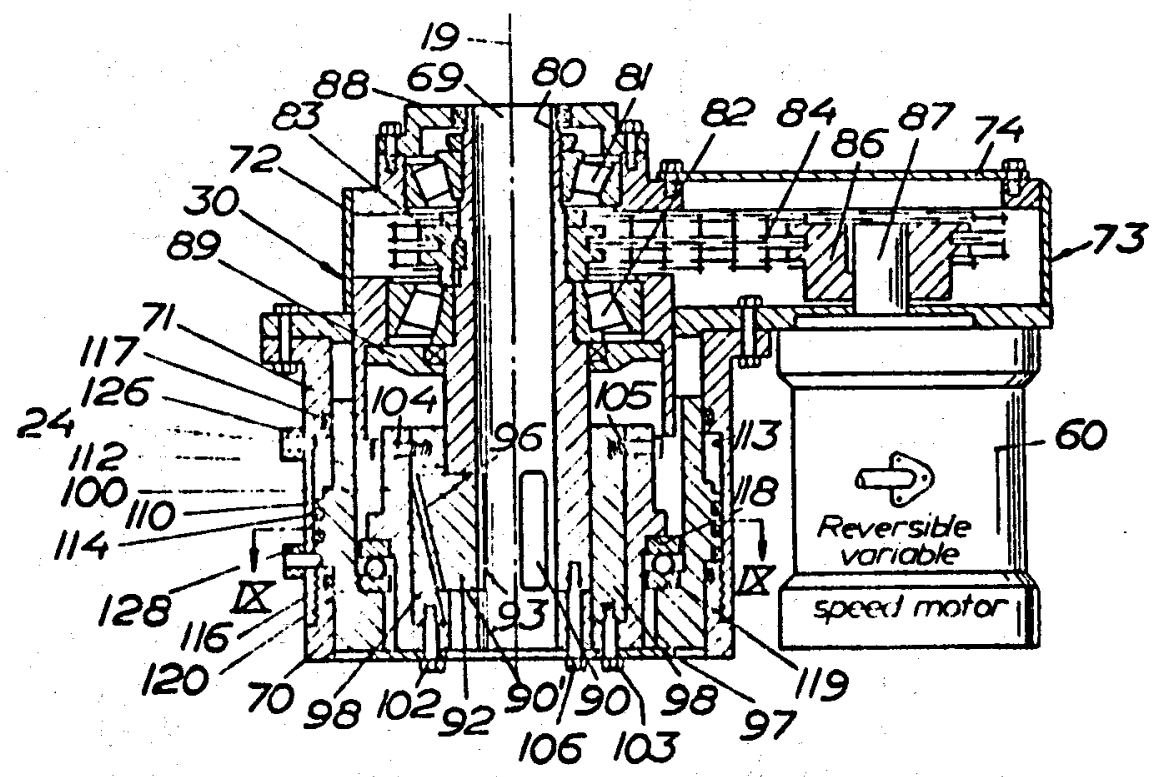

Fig.9

Fig.10

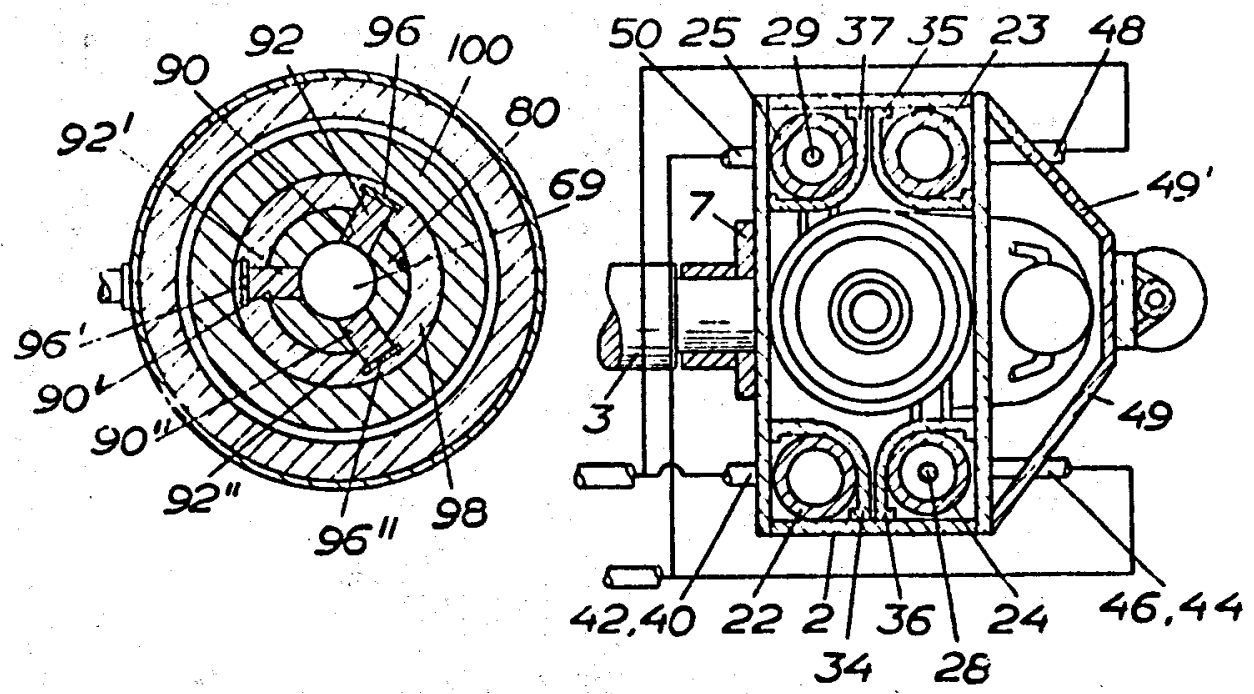

Patent No: 742,984 (Canadian)

Date: $\quad$ September 20, 1966

Inventor: Alf G. Kvello-Aune and Per F. Troften, Trondhein, Norway

Assignee: Atlas Copco Aktiebolag

Title:

Drive and Feed Device for a String of Rotary Drill String Elements 


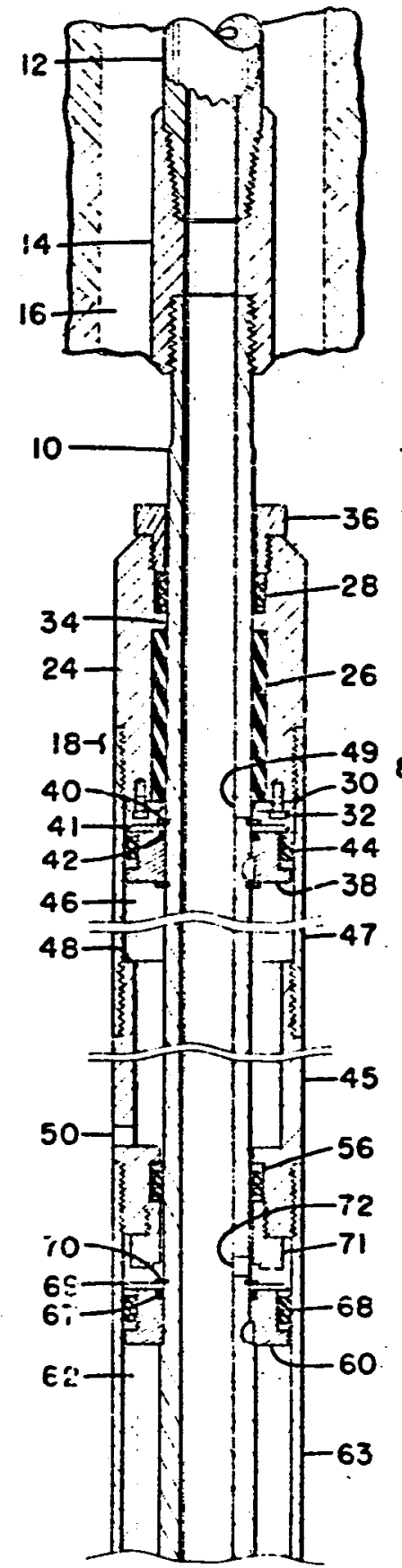

FIG. IA

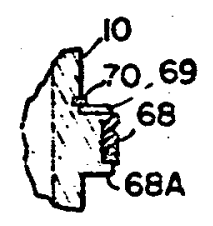

FIG. 3

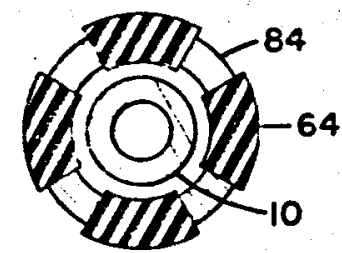

FIG. 2

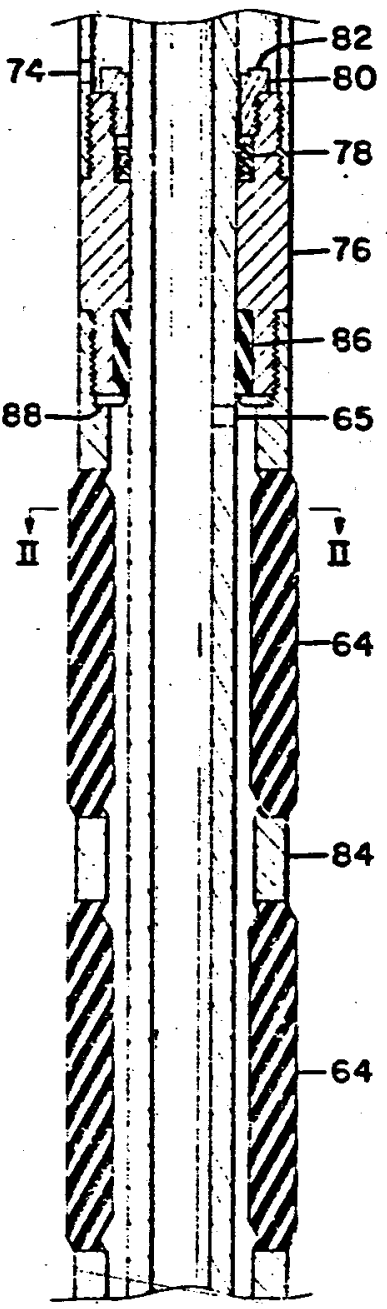

FIG: :

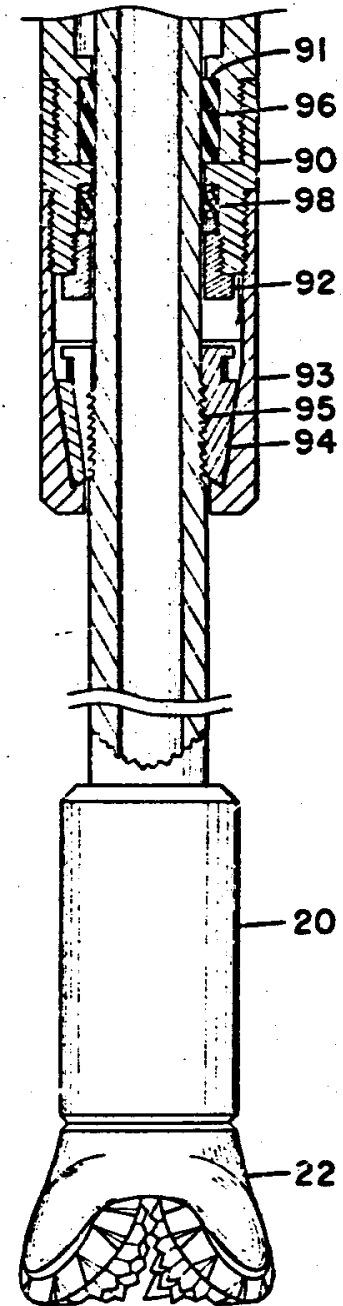

FIG. IC

Patent No: $\quad 3,225,844$

Date: December 28, 1965

Inventor: A. P. Roberts

Assignee: Exxon Production Research Company

Title: Bit Weight Applicator 


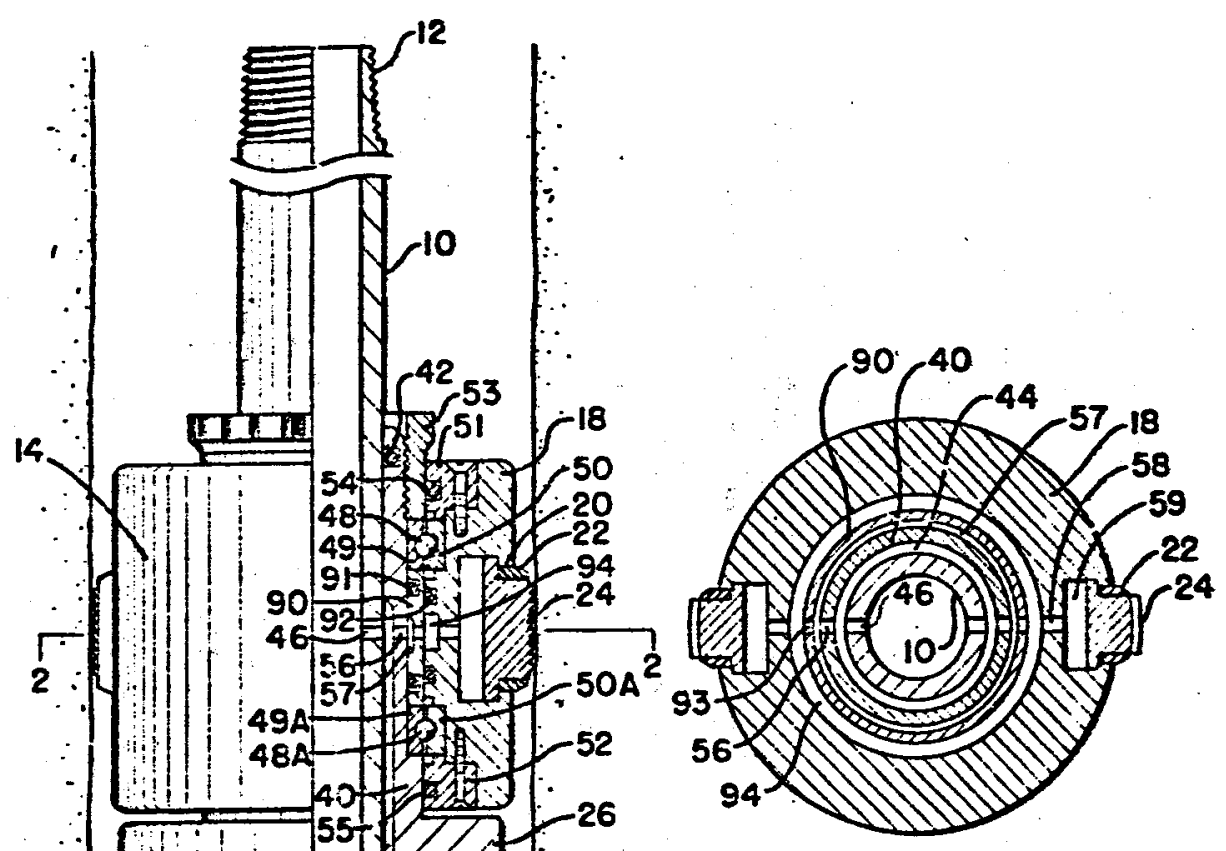

FIG. 2

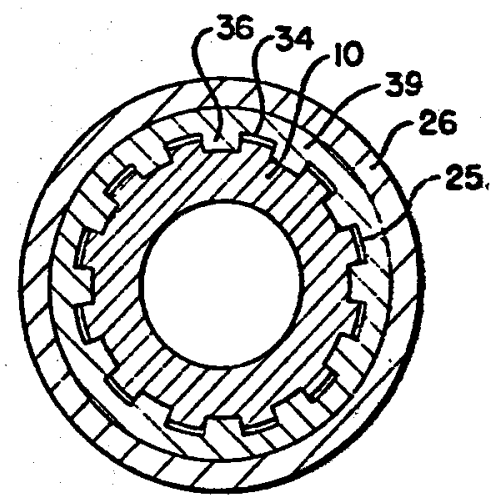

FIG. 3

FIG. I

Patent No: $\quad 3,225,843$

Date: December 28, 1965

Inventor: J. E. Ortloff et al

Assignee: Exxon Production Research Company

Title: $\quad$ Bit Loading Apparatus 


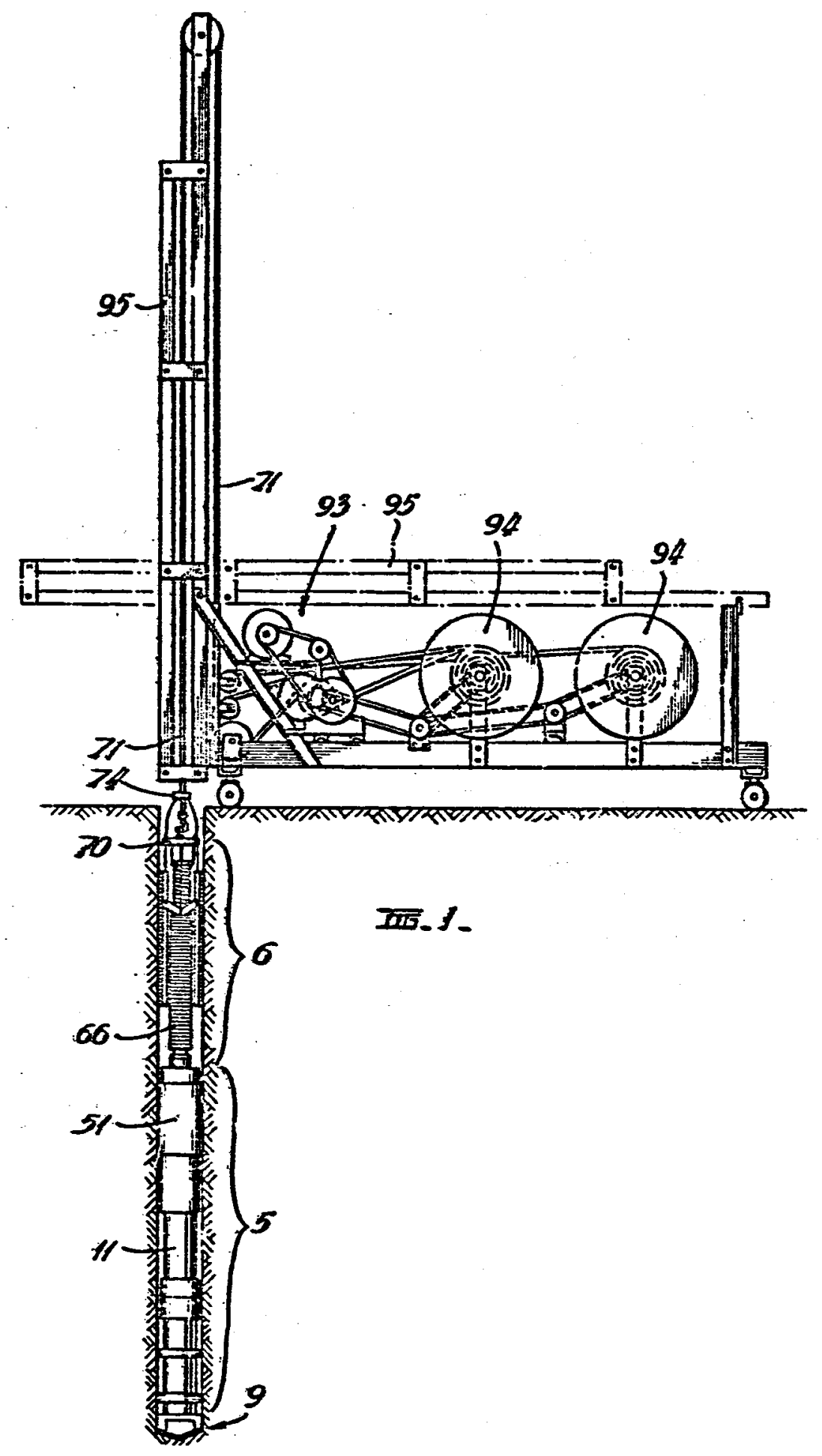

Patent No: $\quad 3,185,225$

Date: $\quad$ May 25, 1965

Inventor: W. C. Ginies

Assignee: Wolstan C. Ginies Enterprises Proprietary Limited, Eitham, Victoria, Australia

Title: $\quad$ Feeding Apparatus for Down Hole Drilling Device

90 


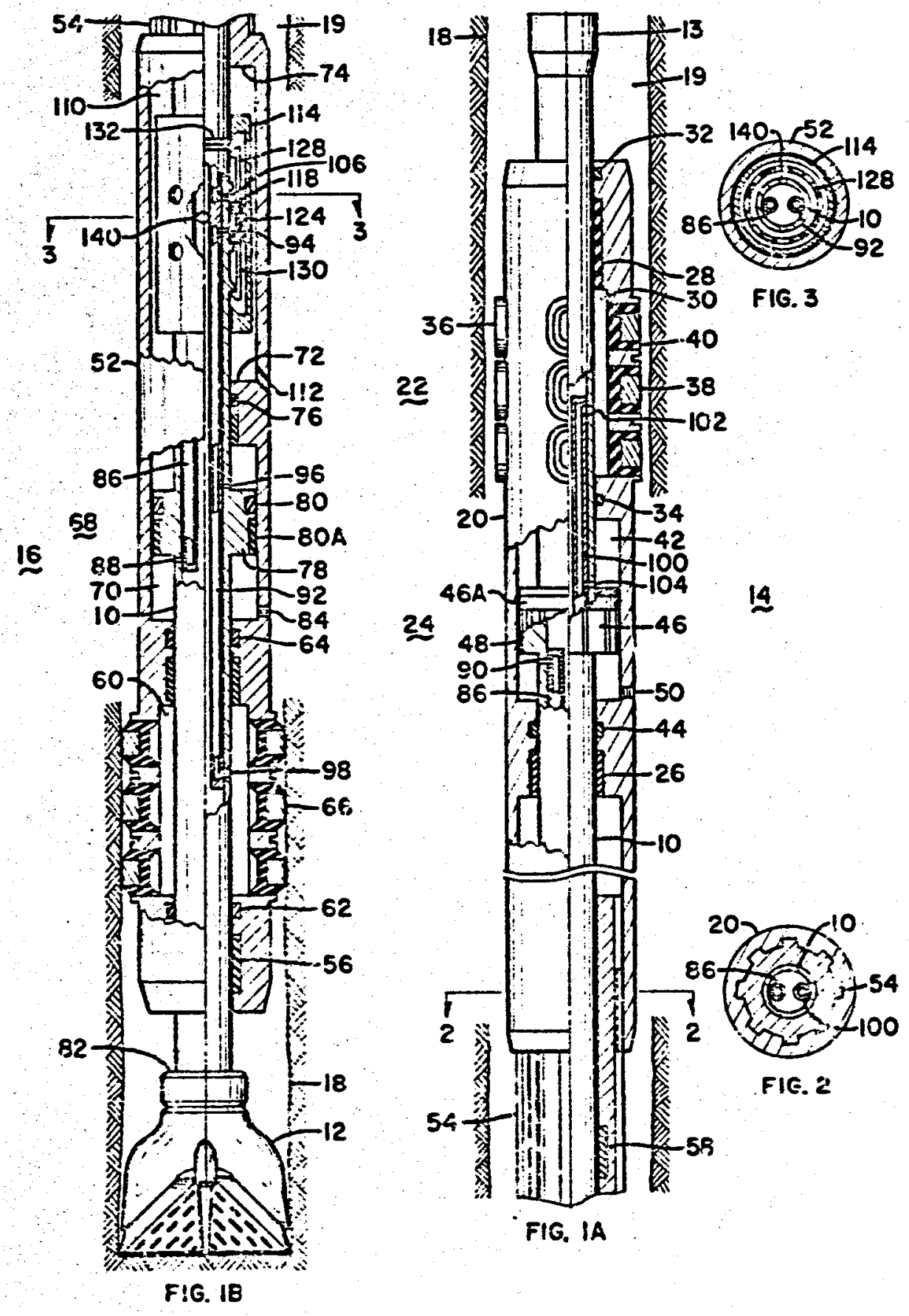

\footnotetext{
Patent No: $\quad 3,180,437$

Date: April 27, 1965

Inventor: J. M. Kellner, Allen, T. 0.

Assignee: Jersey Production Research Company

Title: $\quad$ Force Applicator for Drill Bit
} 

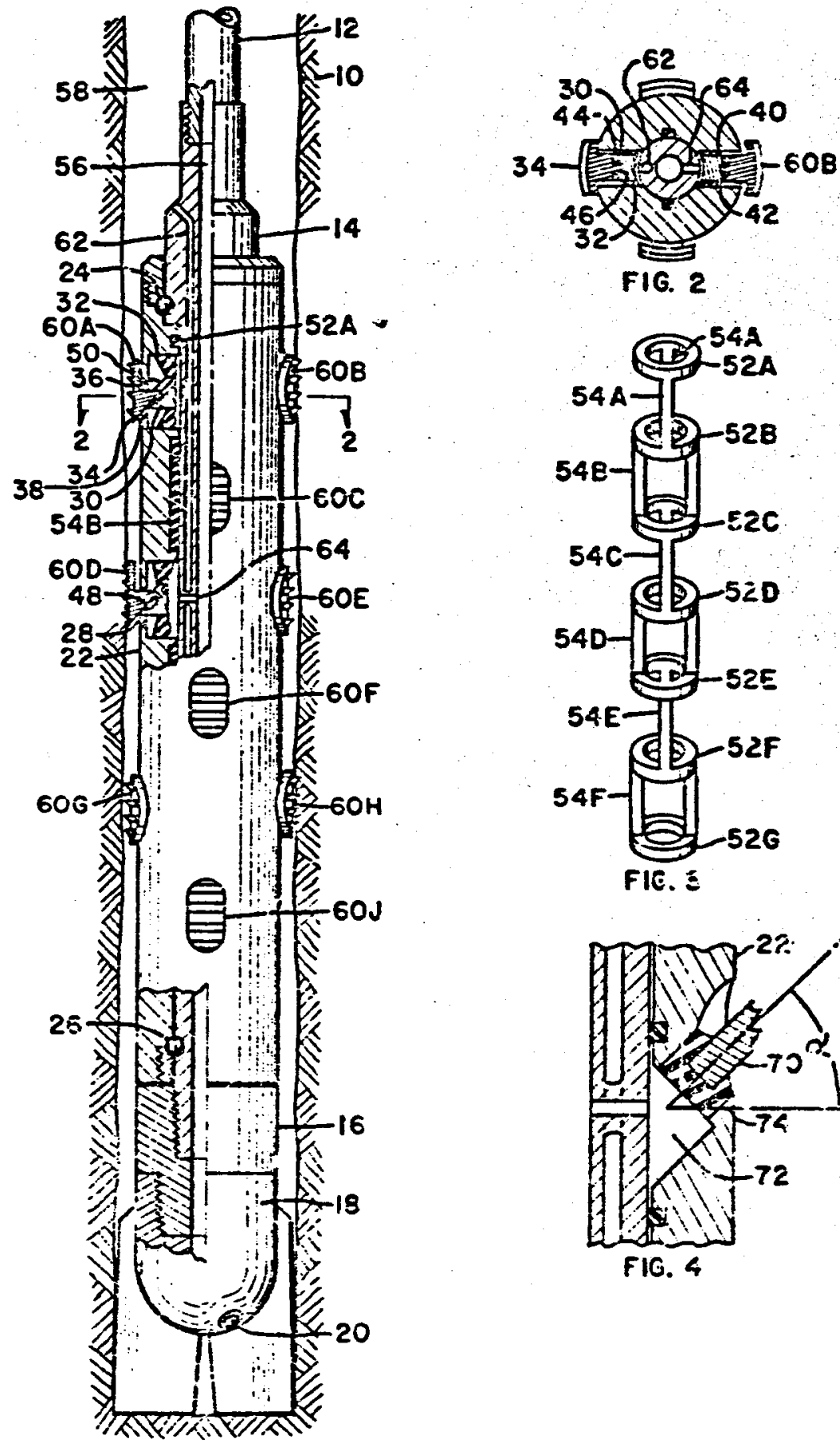

FIG. 2
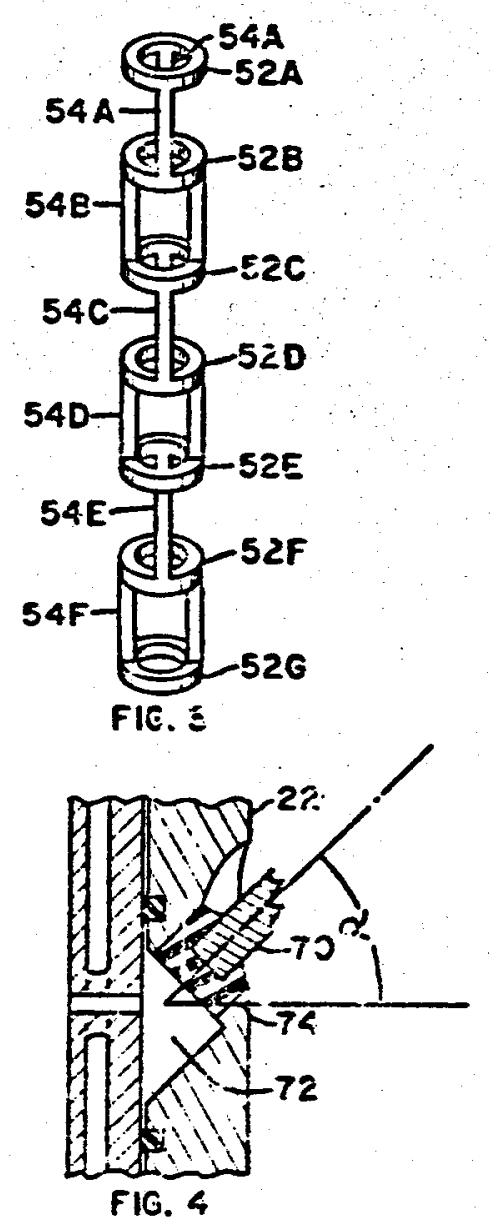

FIG. 1

Patent No: $\quad 3,180,436$

Date: $\quad$ April 27, 1965

Inventor: J. M. Kellner, Reed, J. E., and Hildebrandt, A. B.

Assignee: Jersey Production Research Company

Title: Borehole Drilling System 

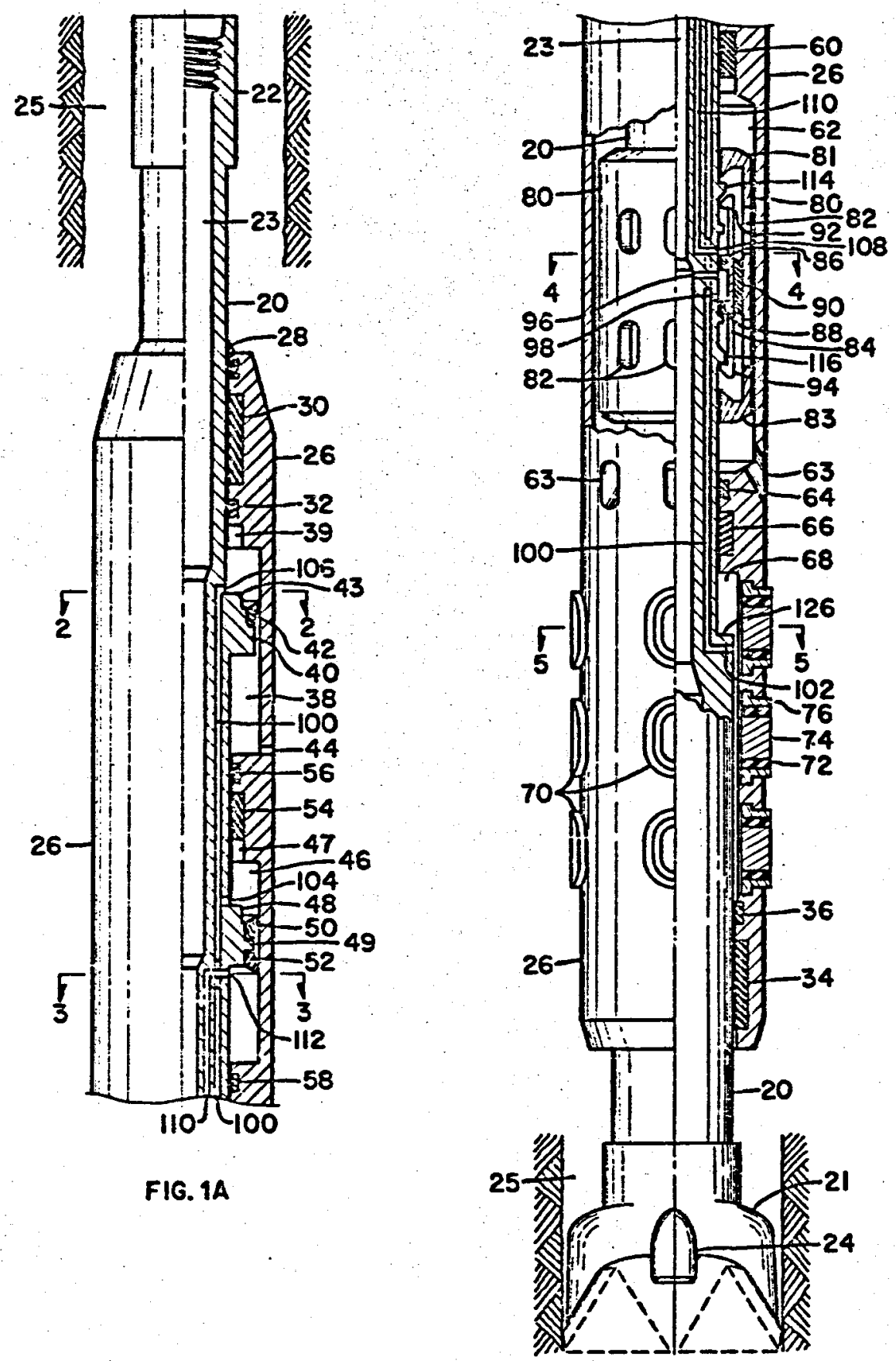

FIG. IB

Patent No: $\quad 3,105,561$

Date: October 1, 1963

Inventor: J. M. Kellner

Assignee: Jersey Production Research Company

Title: Hydraulic Actuated Drill Collar 


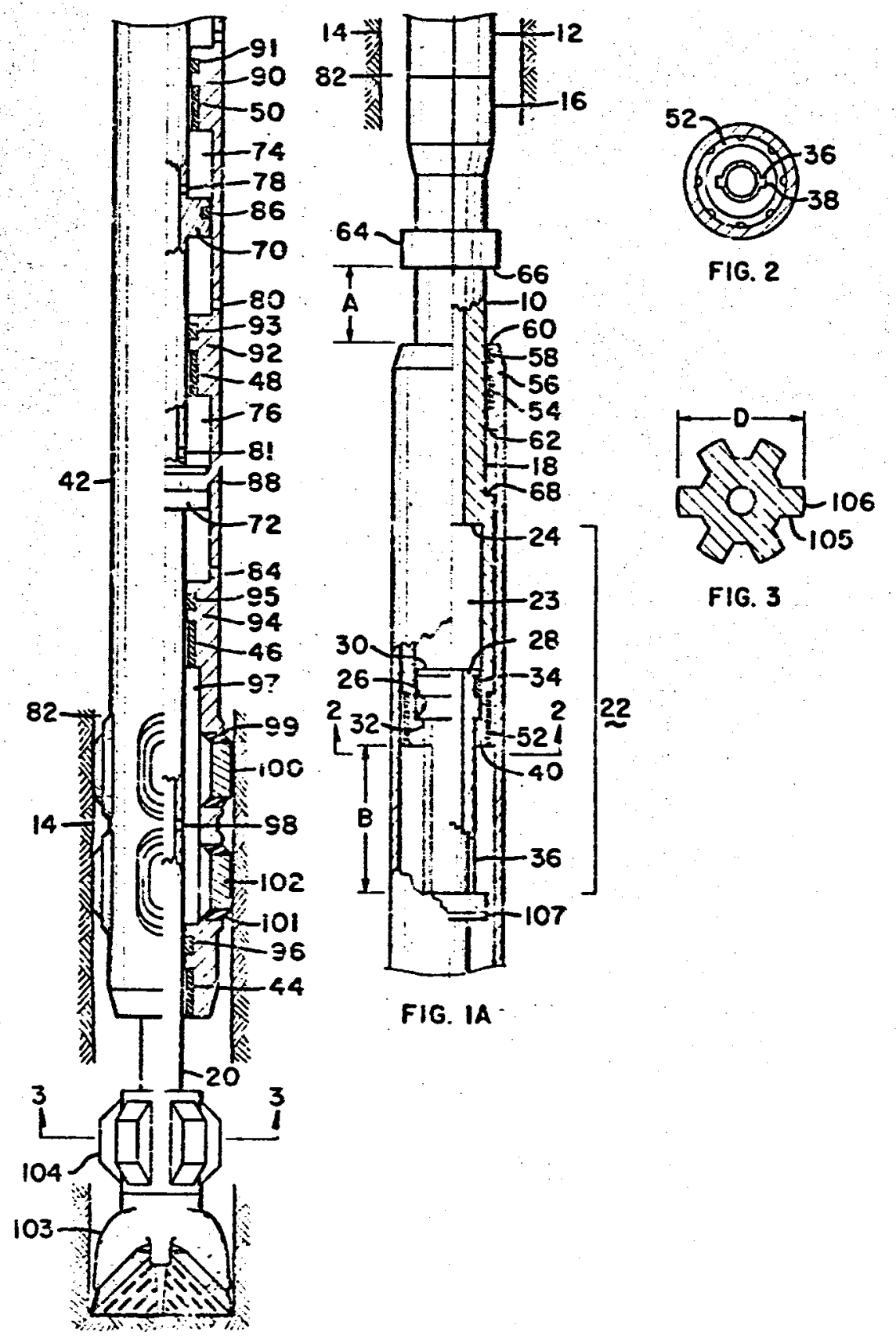

FIG. IB

Patent No: $\quad 3,088,532$

Date: $\quad$ May 7, 1963

Inventor: J. M. Kellner

Assignee: Jersey Production Research Company

Title: Bit Loading Device 


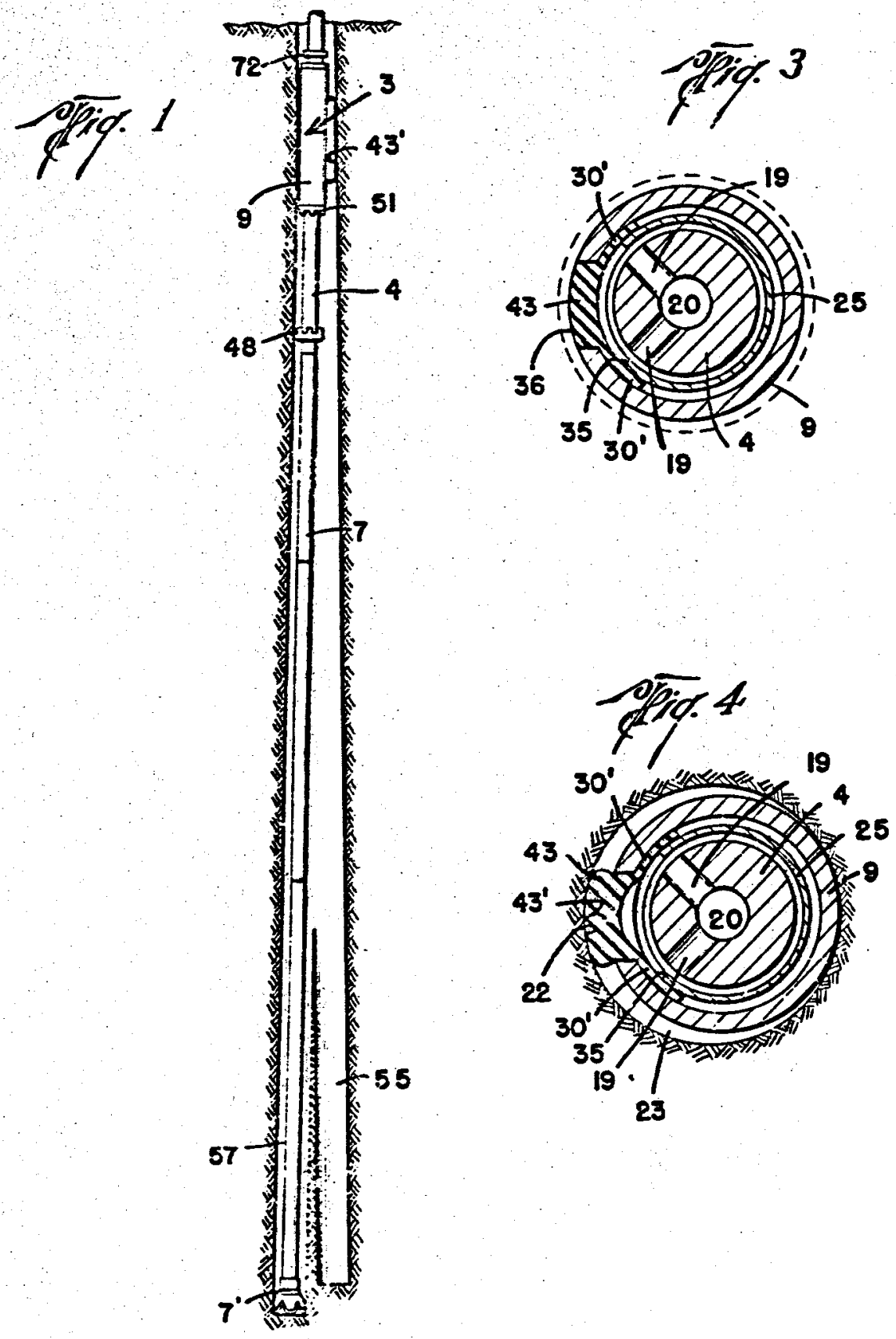

\footnotetext{
Patent No: $\quad 3,023,821$

Date: March 6, 1962

Inventor: W. H. Etherington

Assignee:-

Title: Well Tool
} 


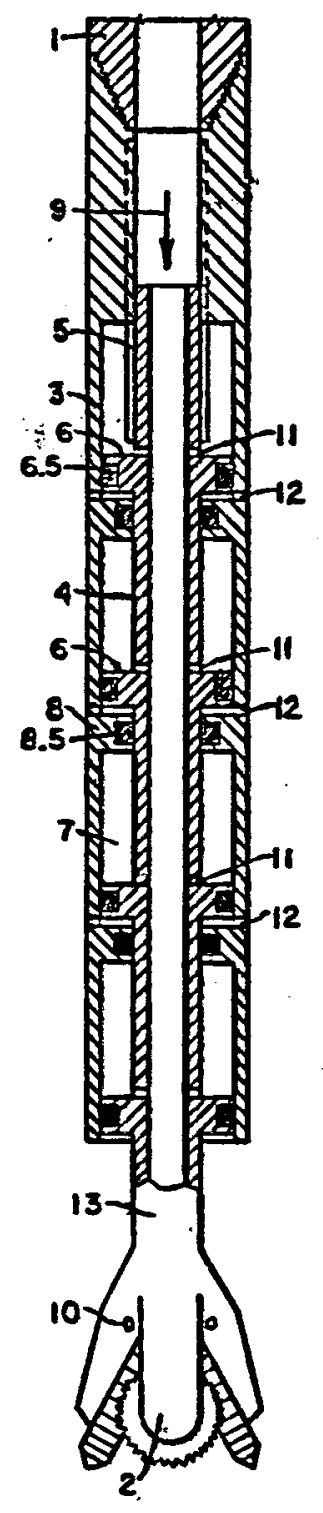

FIG.I

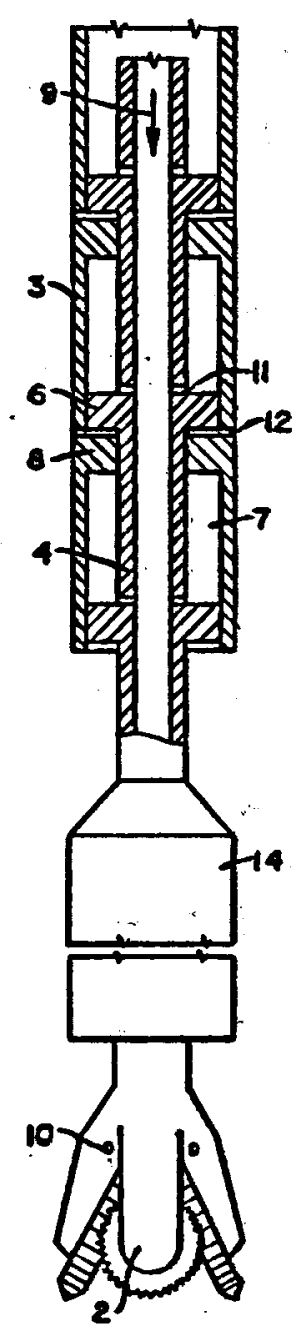

FIG. 2

\footnotetext{
Patent No: $\quad 2,937,007$

Date: May 17, 1960

Inventor: Frank Whittle

Ass ignee:

Title: Well Drilling System
} 


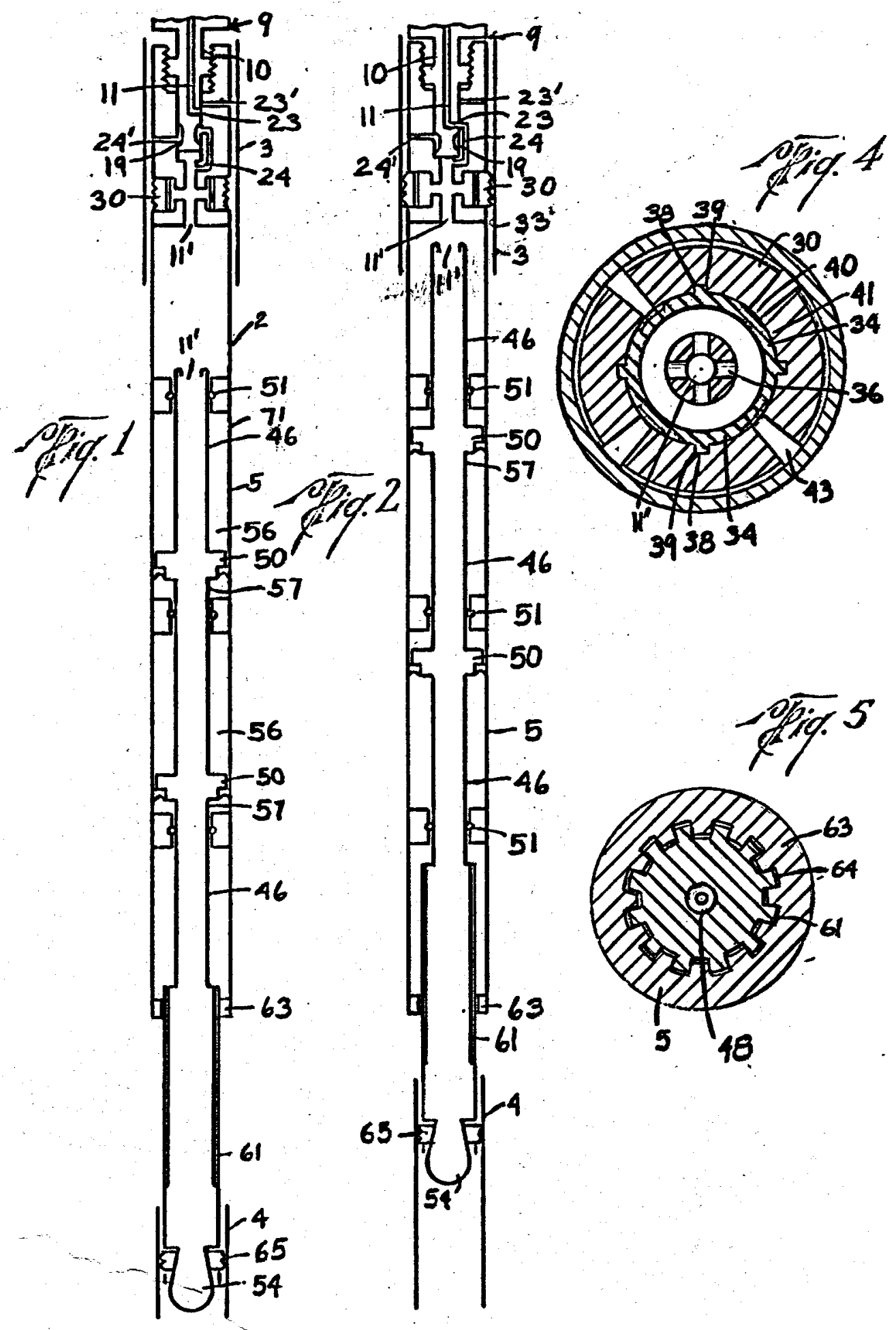

\footnotetext{
Patent No: $\quad 2,901,044$

Date: August 25, 1959

Inventor: E. W. Arnold

Assignee:

Title:

Pulling Tool
} 


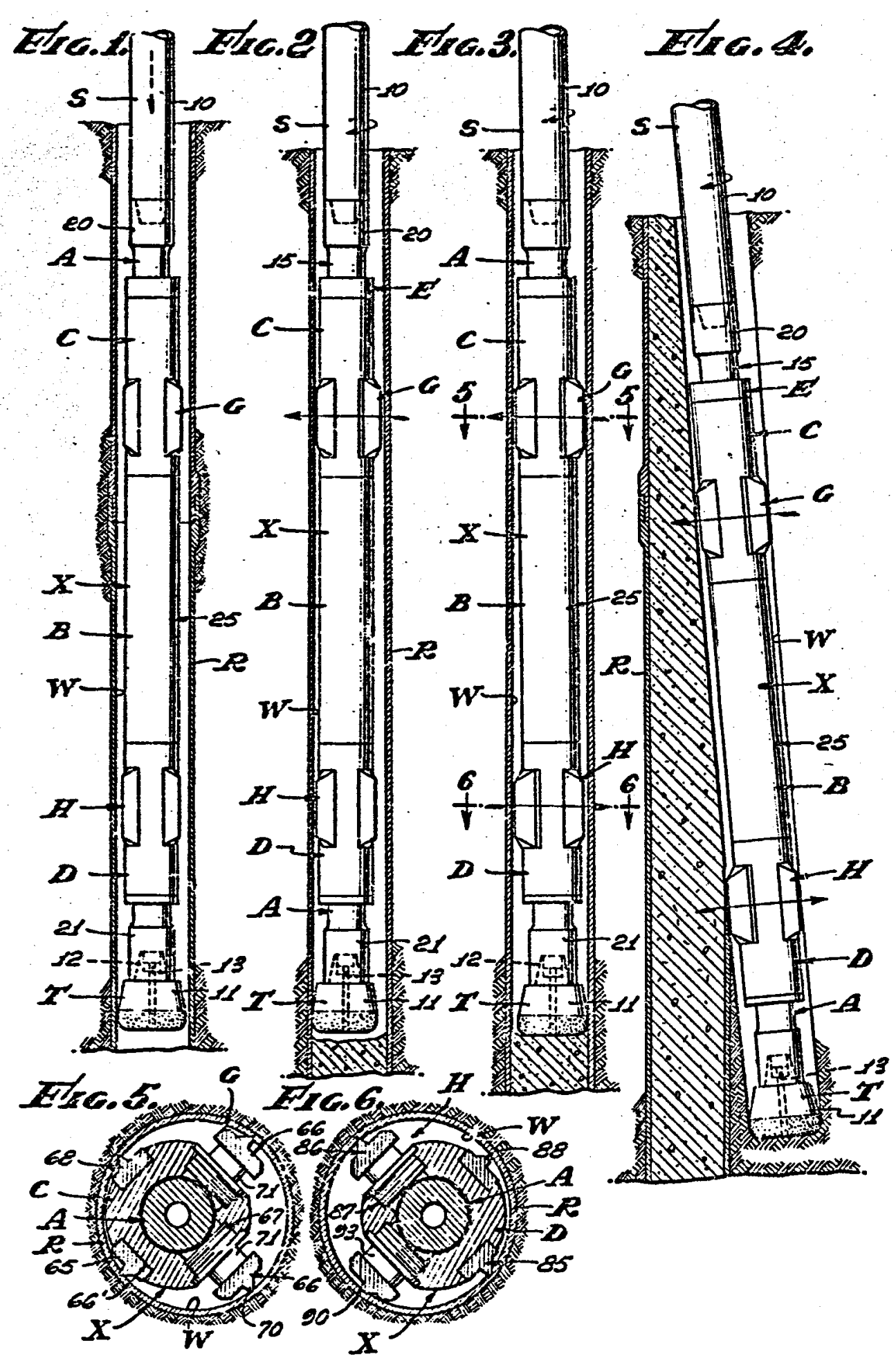

\footnotetext{
Patent No: $2,891,769$

Date: June 23, 1959

Inventor: J. S. Page, Sr. et al

Assignee: Directional Engineering Company

Title: Directional Drilling Tool
} 


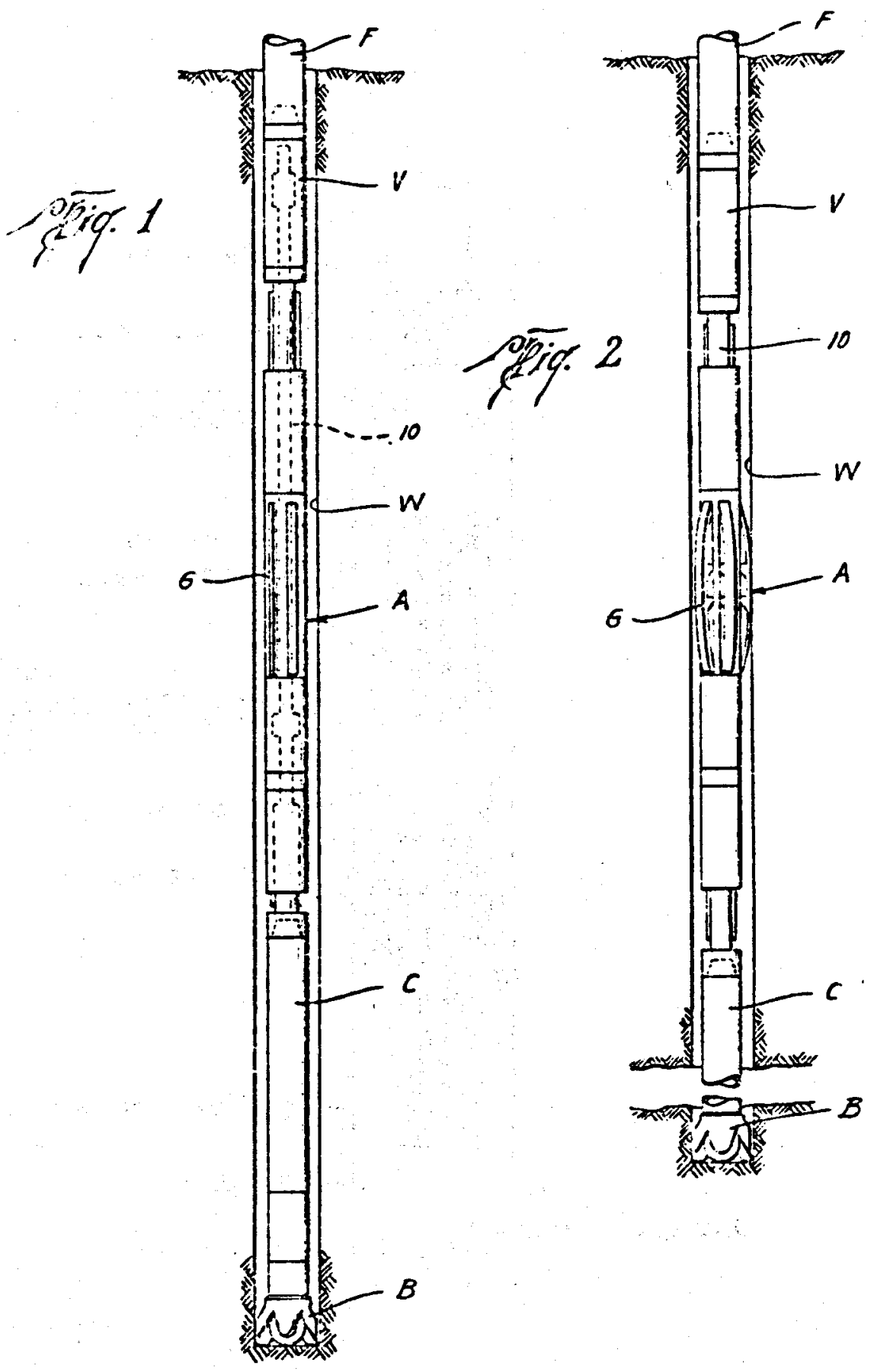

Patent No: $\quad 2,712,920$

Date:

July 12, 1955

Inventor: R. H. Cullen et al

Assignee: Cullen

Title: Torque Arrestors 


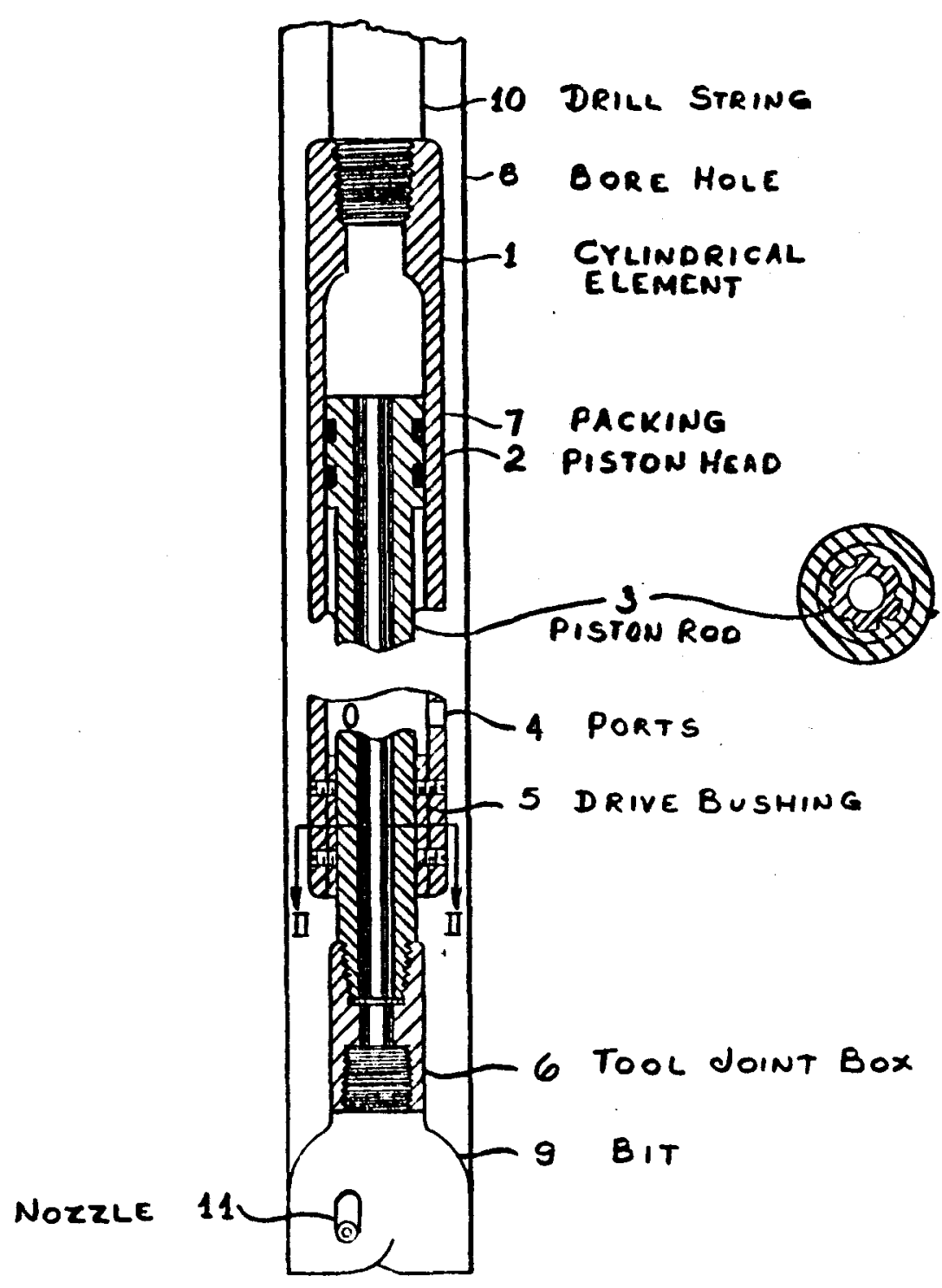

Patent No: $2,684,835$

Date: July 27, 1954

Inventor: $\quad T$. V. Moore

Assignee: Standard 0 il Development Company

Title: Apparatus for Drilling Well Boreholes 


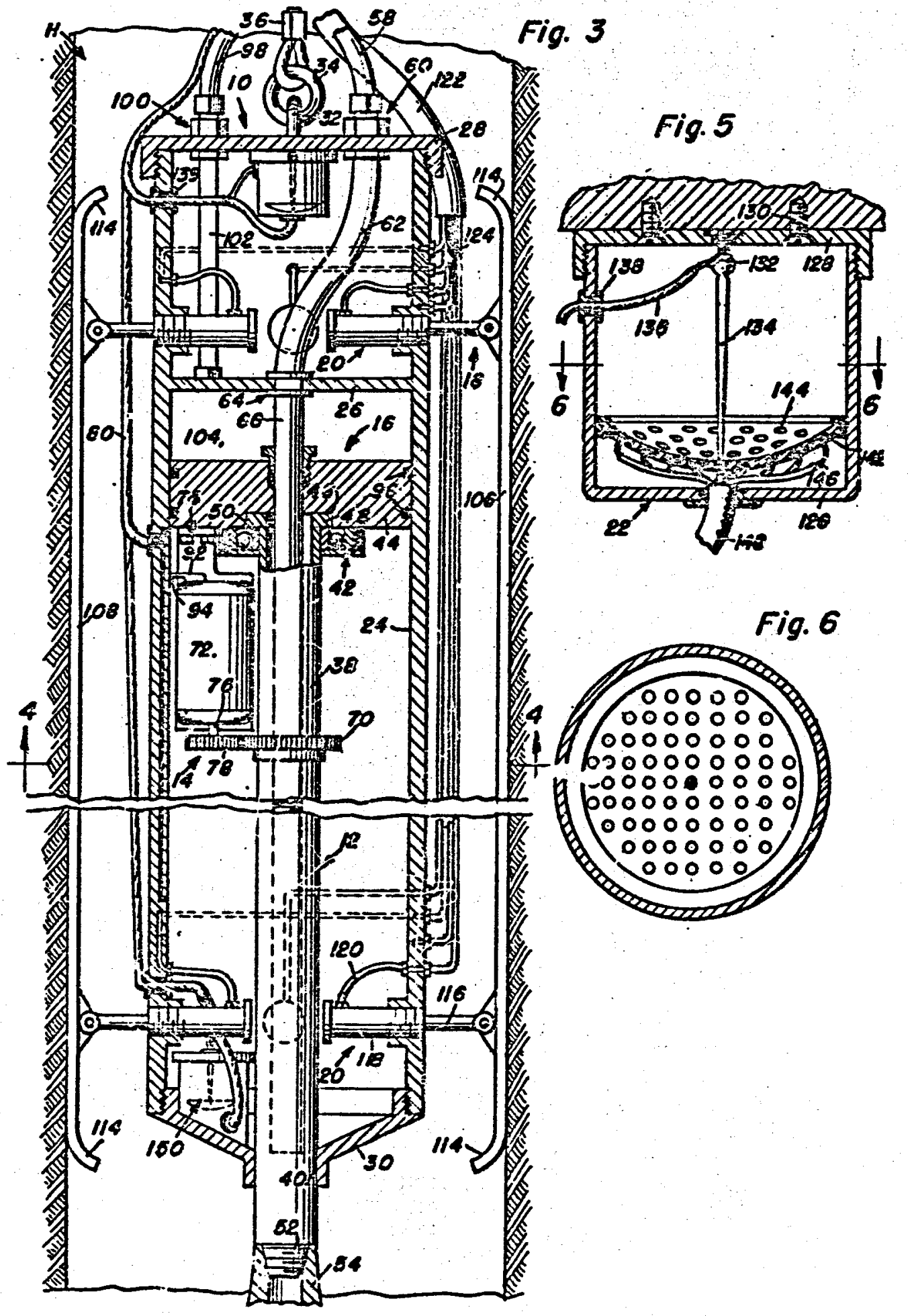

Patent No: $\quad 2,637,527$

Date: May 5, 1953

Inventor: J. B. Andrews, Jr.

Assignee:

Title: Well Drilling Device 


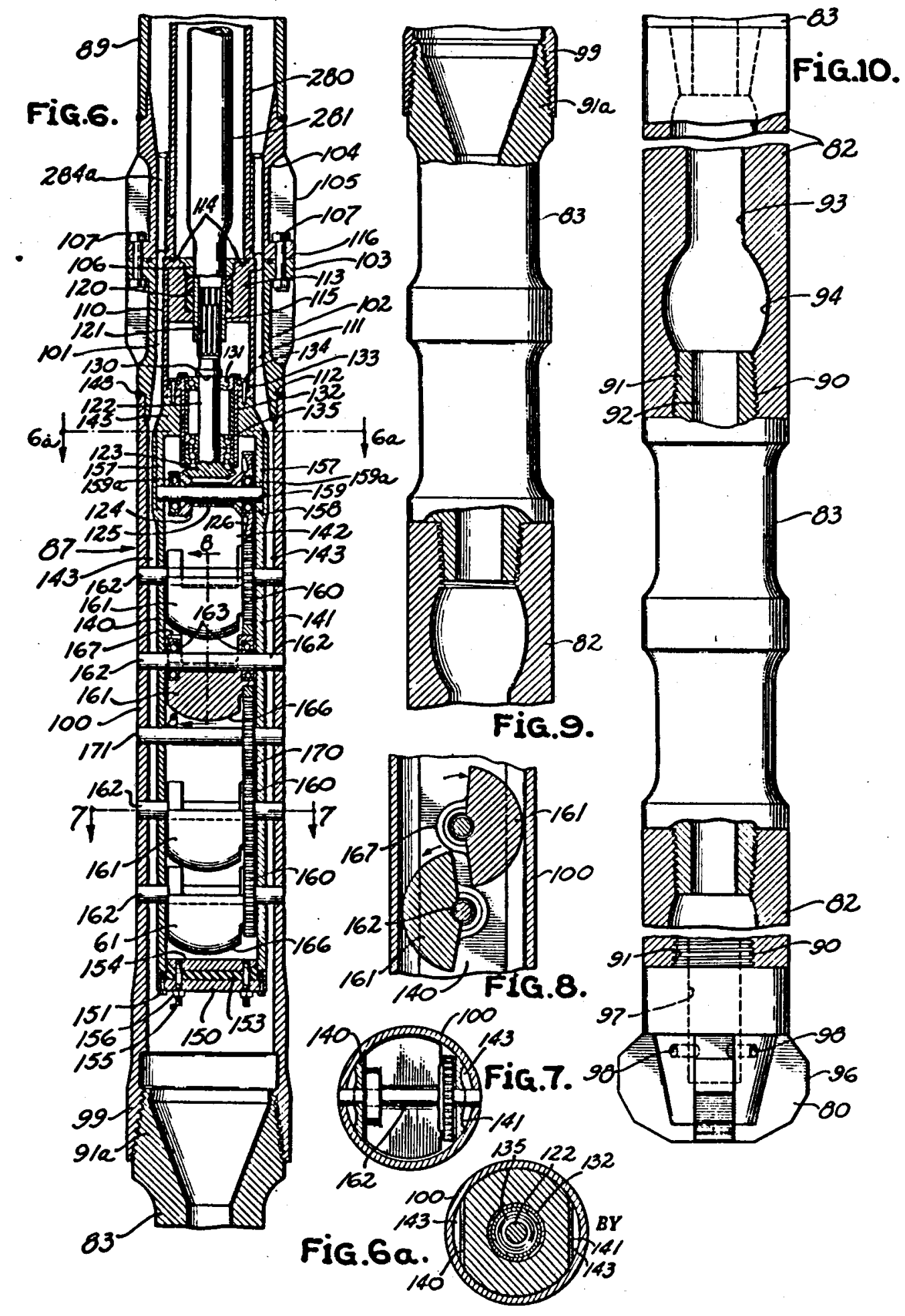

Patent No: $\quad 2,554,005$

Date: May 22, 1951

Inventor: Albert G. Bodine, Jr.

Assignee: Soundrill Corporation

Title: $\quad$ Earth Boring Apparatus 

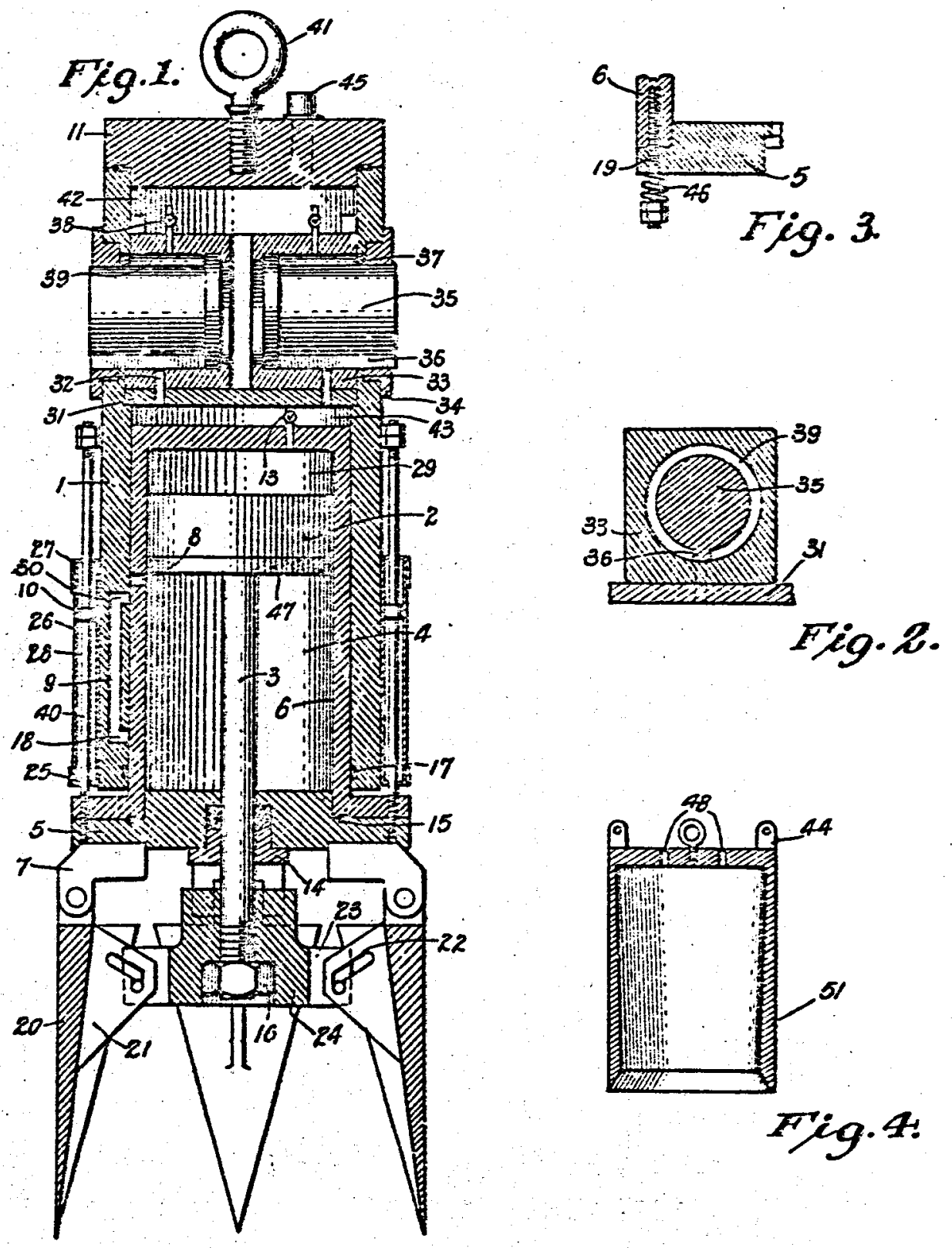

Patent No: , 2,223,645

Date: December 3, 1940

Inventor: G. J. Solomon

Assignee:

Title:

Well and the Like Sinking Apparatus 


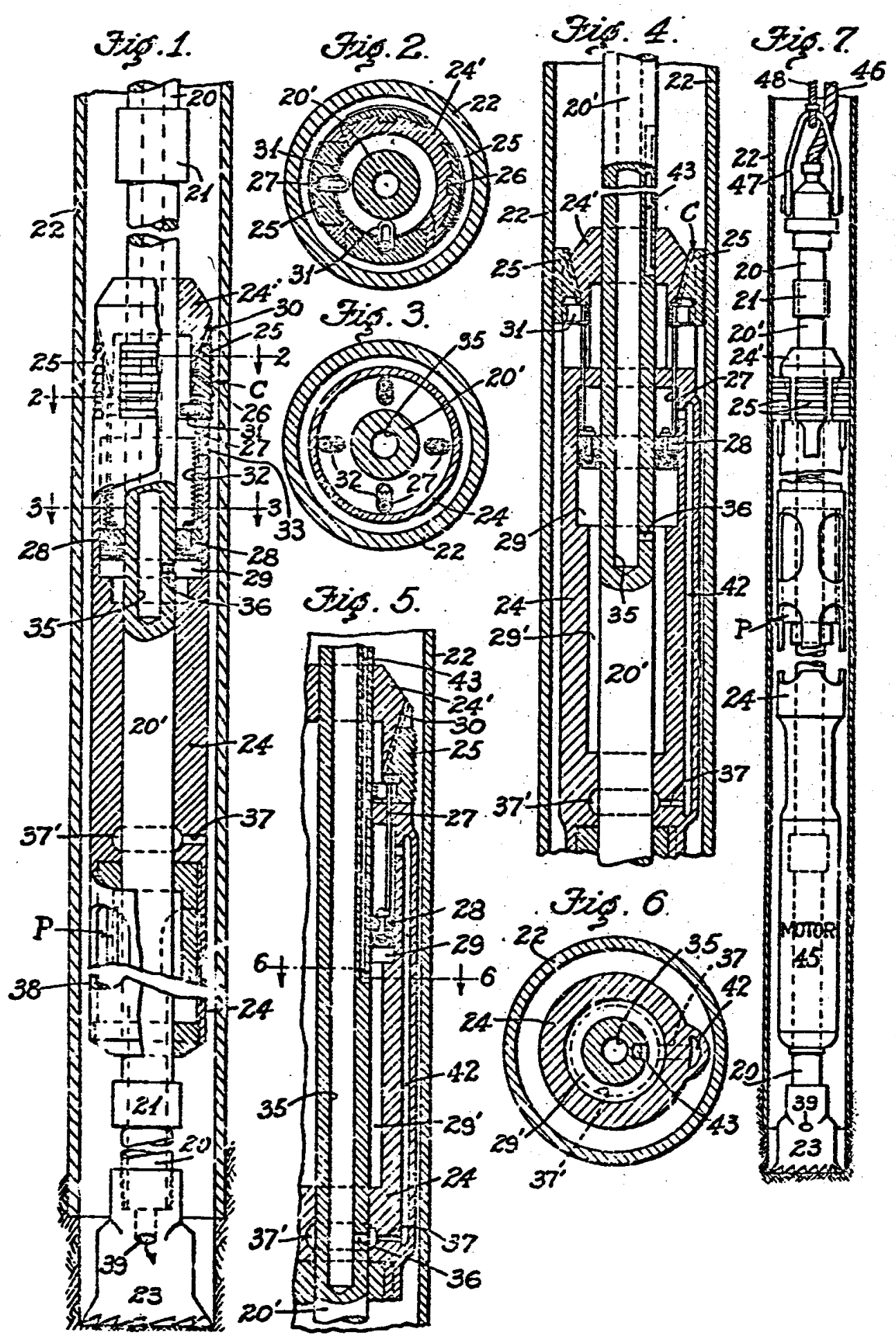

\footnotetext{
Patent No: $1,983,287$

Date: $\quad$ December 4, 1934

Inventor: S. H. Grinnell et al

Assignee: Union $0 i l$ of California

Title: $\quad$ Drilling Structure and Circulating Pump
} 


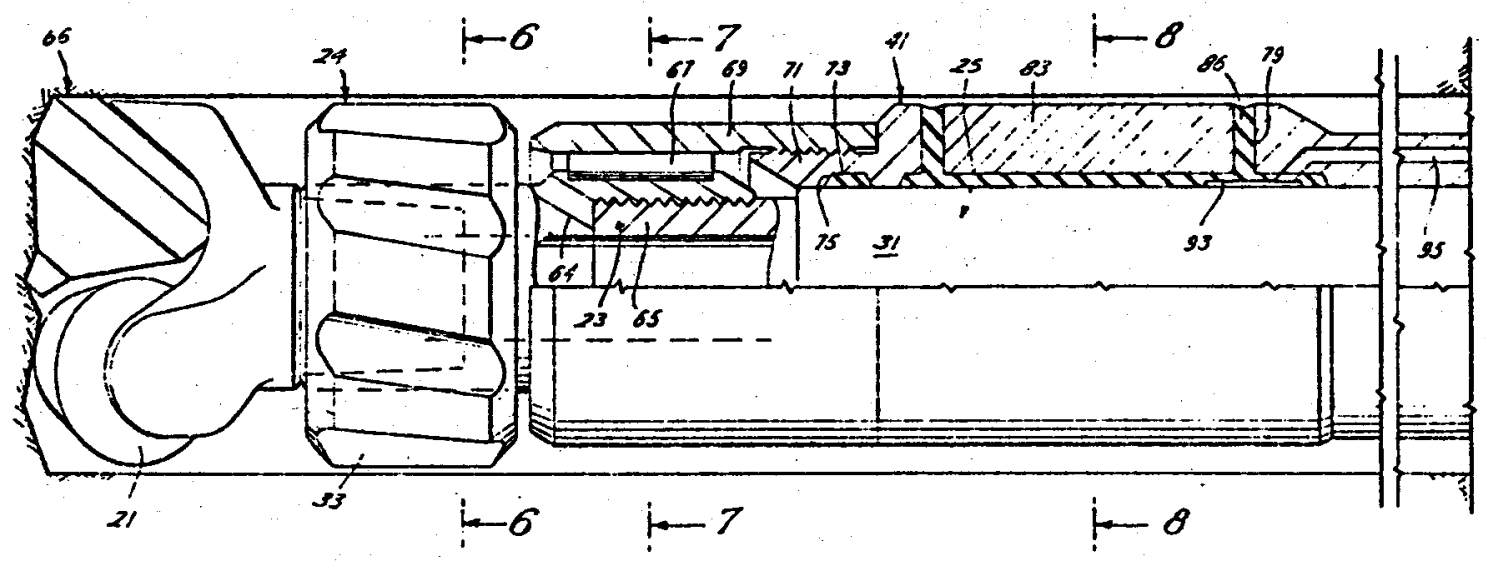

Patent No: $\quad 4,040,495$

Date: $\quad$ August 9, 1977

Inventor: Jackson M. Kellner et al

Assignee: Smith International, Inc.

Title: Drilling Apparatus 

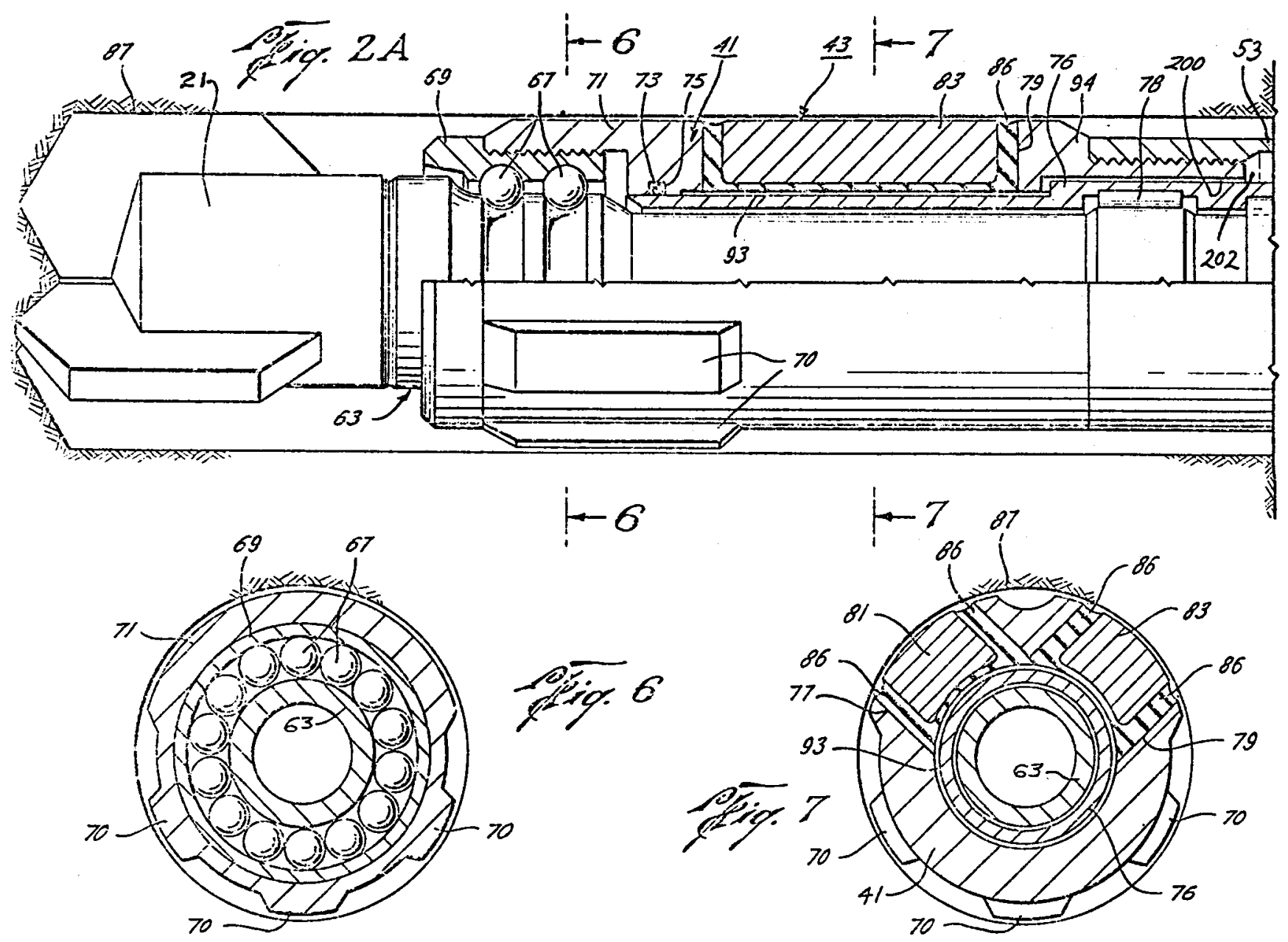


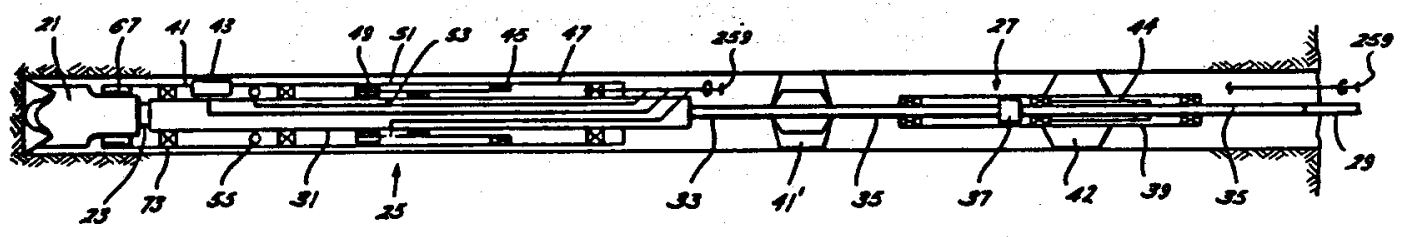

Patent No: $\quad 3,997,008$

Date: December 14, 1976

Inventor: Jackson M. Kellner

Assignee: Smith International, Inc.

Title: Drill Director 


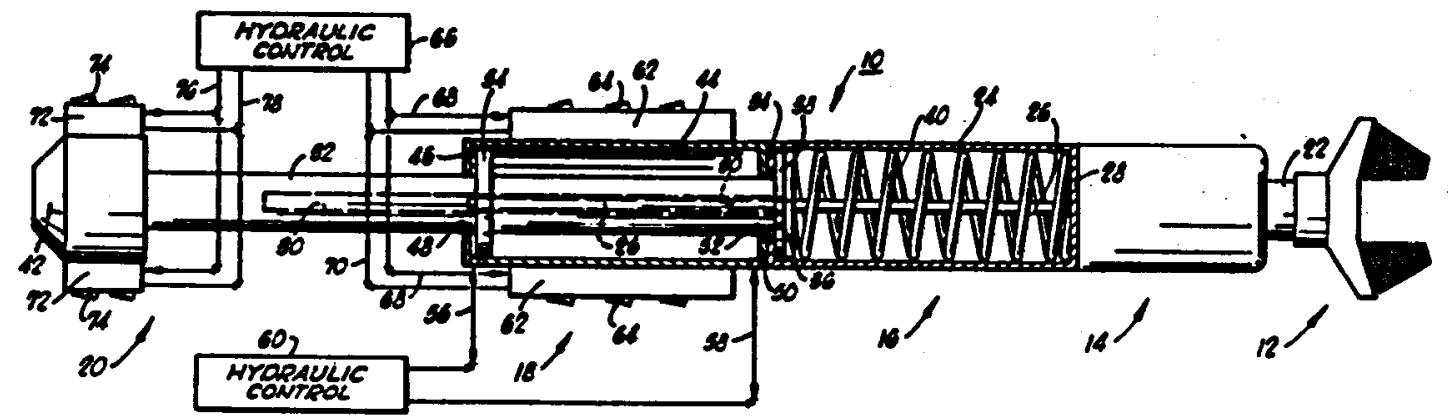

Patent No: $\quad 3,978,930$

Date: $\quad$ September 7, 1976

Inventor: Rondon L. Schroeder

Assignee: Continental 0il Company

Title: $\quad$ Earth Drilling Mechanisms 


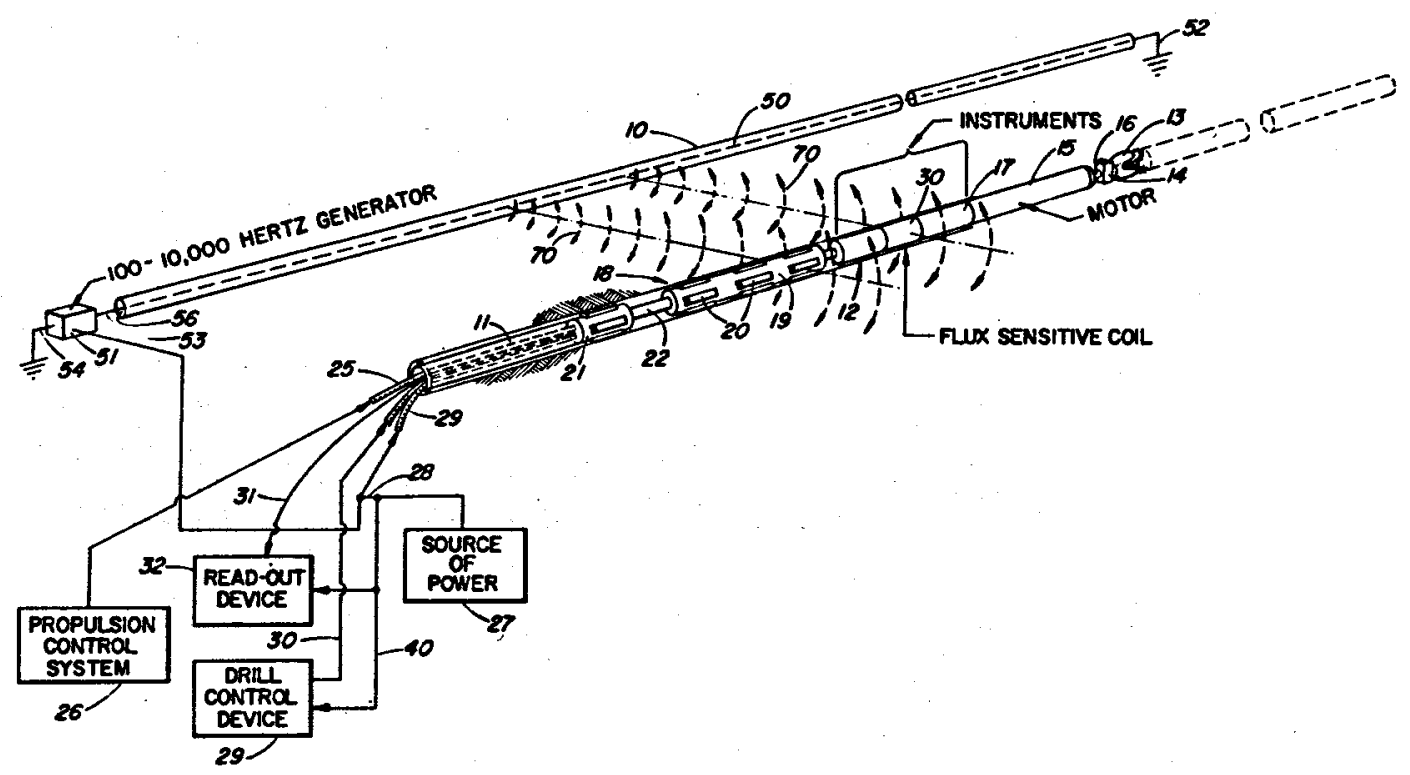

Patent No: $\quad 3,907,045$

Date: $\quad$ September 23, 1975

Inventor: Herbert D. Dahl

Assignee: Continental 0 il Company

Title: Guidance System for a Horizontal Drilling Apparatus 


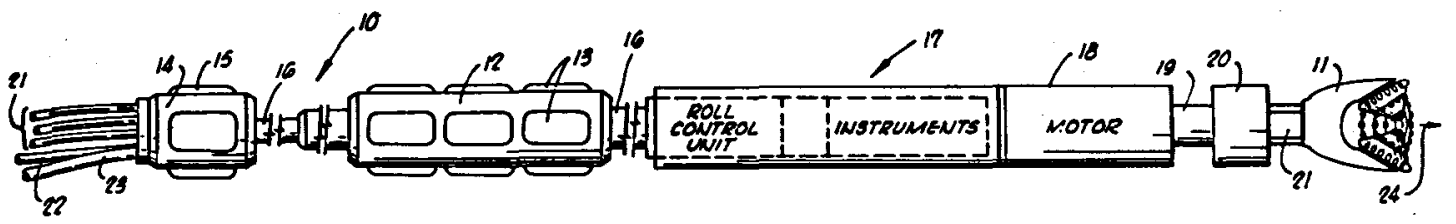

Patent No: $\quad 3,888,319$

Date: June 10, 1975

Inventor: Henry A. Bourne, Jr.

Assignee: Continental Oil Company

Title: Control System for a Drilling Apparatus 


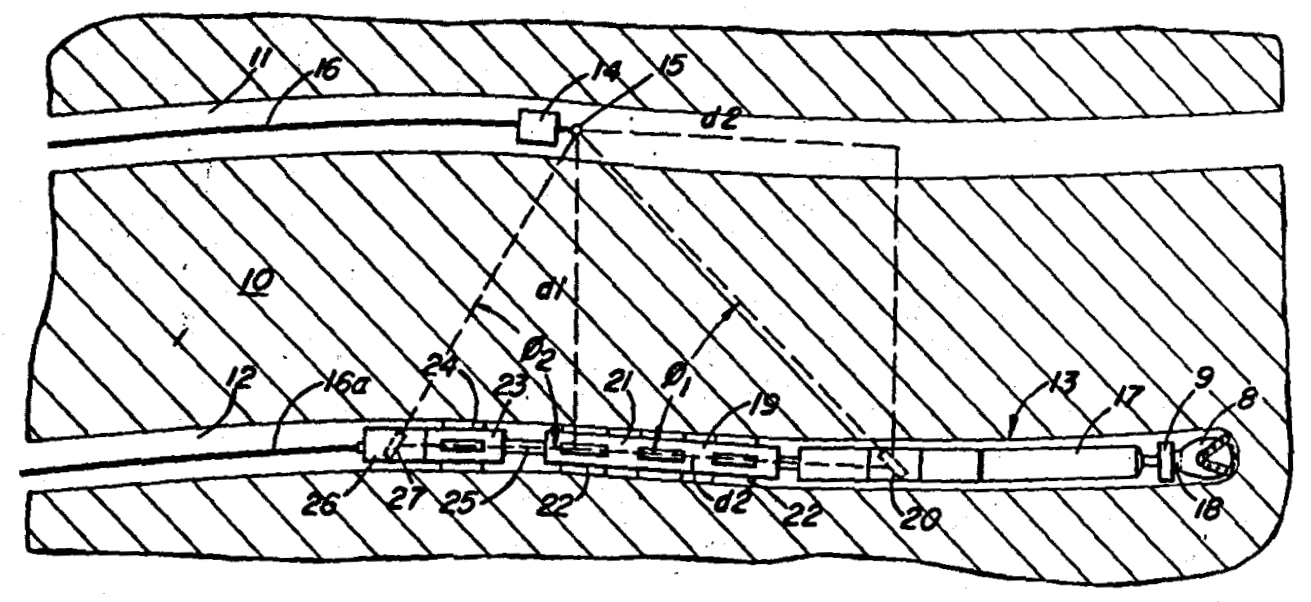

Patent No: $\quad 3,853,185$

Date: December 10, 1974

Inventor: - Herbert Douglas Dahl et al

Assignee: Continental oil Company

Title: Guidance System for a Horizontal Drilling Apparatus 


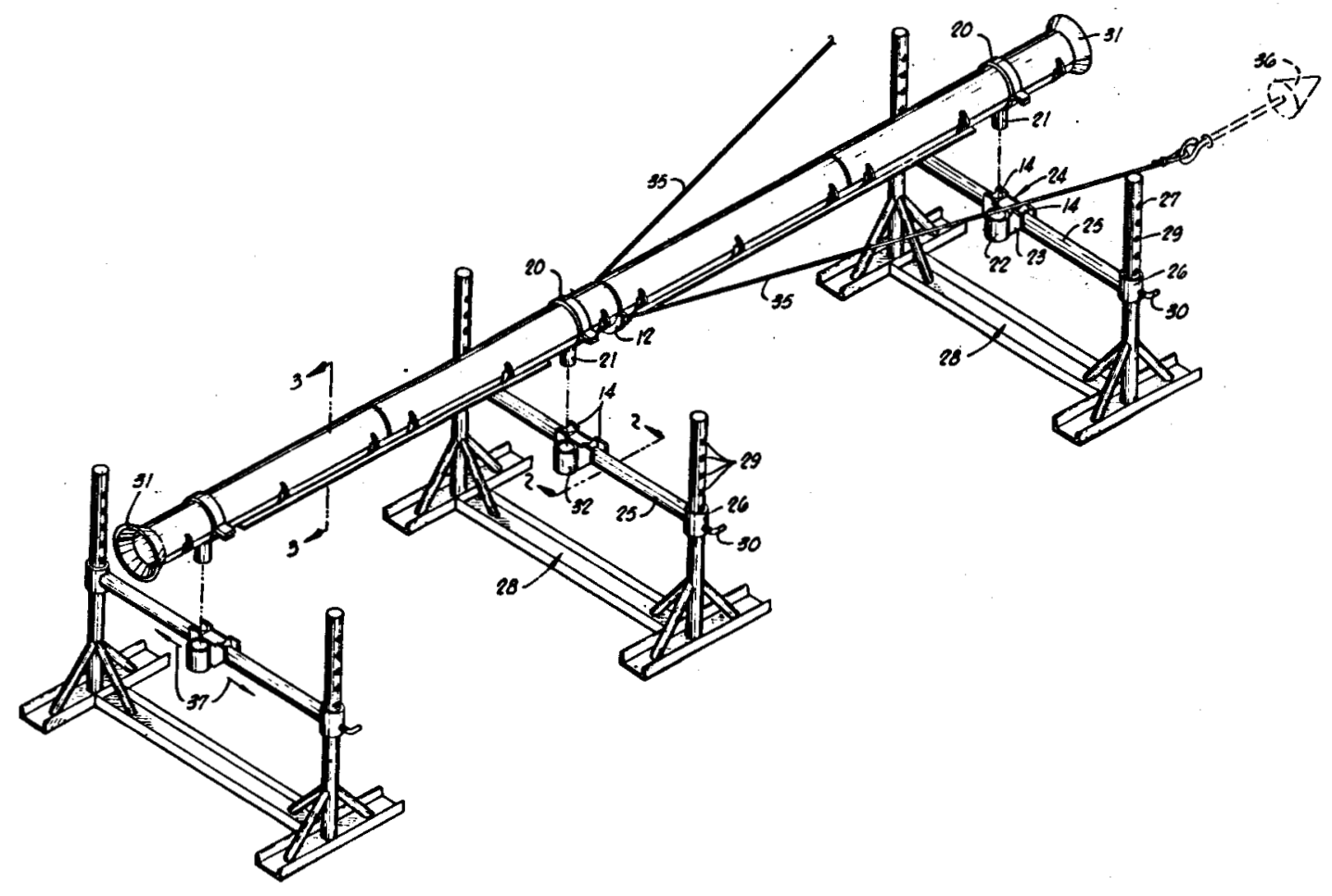

\footnotetext{
Patent No: $\quad 3,853,182$

Date: December 10, 1974

Inventor: Henry A. Bourne, Jr.

Assignee: Continental oil Company

Title: Launch Tube for a Long Hole Drilling Apparatus
} 


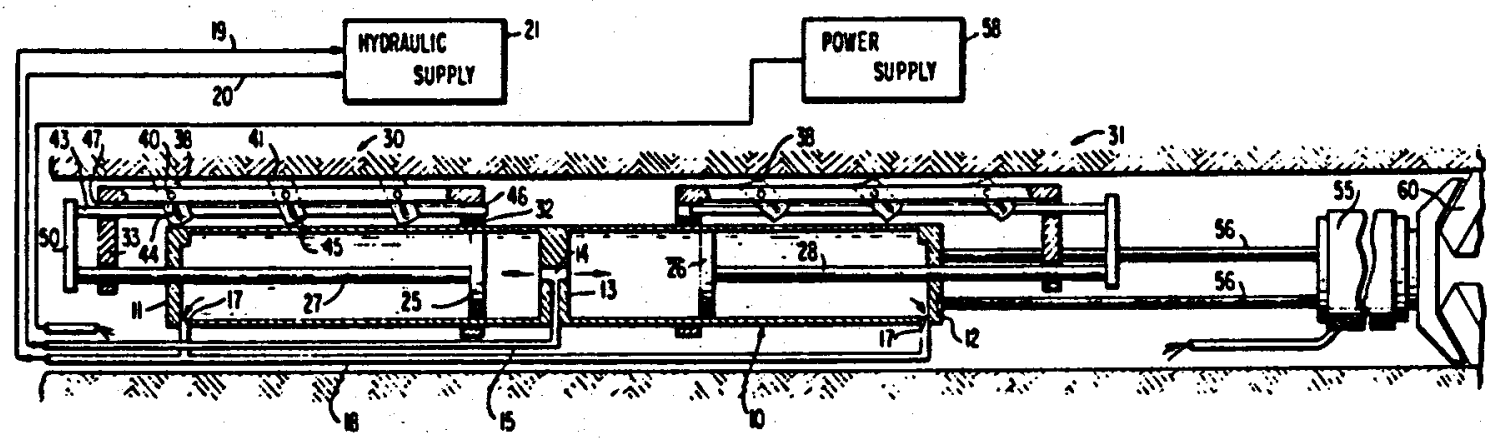

\footnotetext{
Patent No: $\quad 3,827 ; 512$

Date: $\quad$ August 6, 1974

Inventor: Tibor 0. Edmond

Assignee: Continental Oil Company

Title: Anchoring and Pressuring Apparatus for a Drill
} 


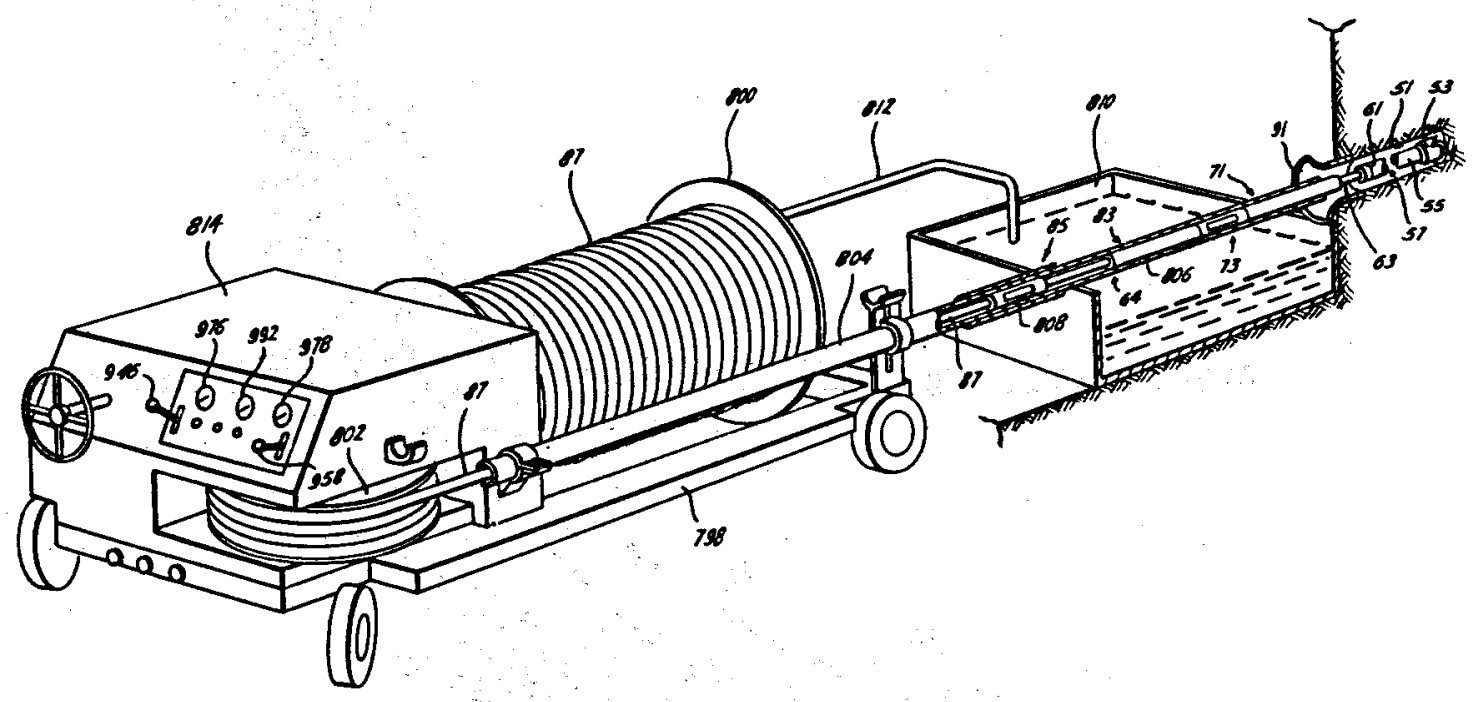

Patent No: $\quad 3,797,589$

Date: March 19, 1974

Inventor: Jackson M. Kellner

Assignee: Smith International, Inc.

Title: $\quad$ Self Guiding Force Applicator 


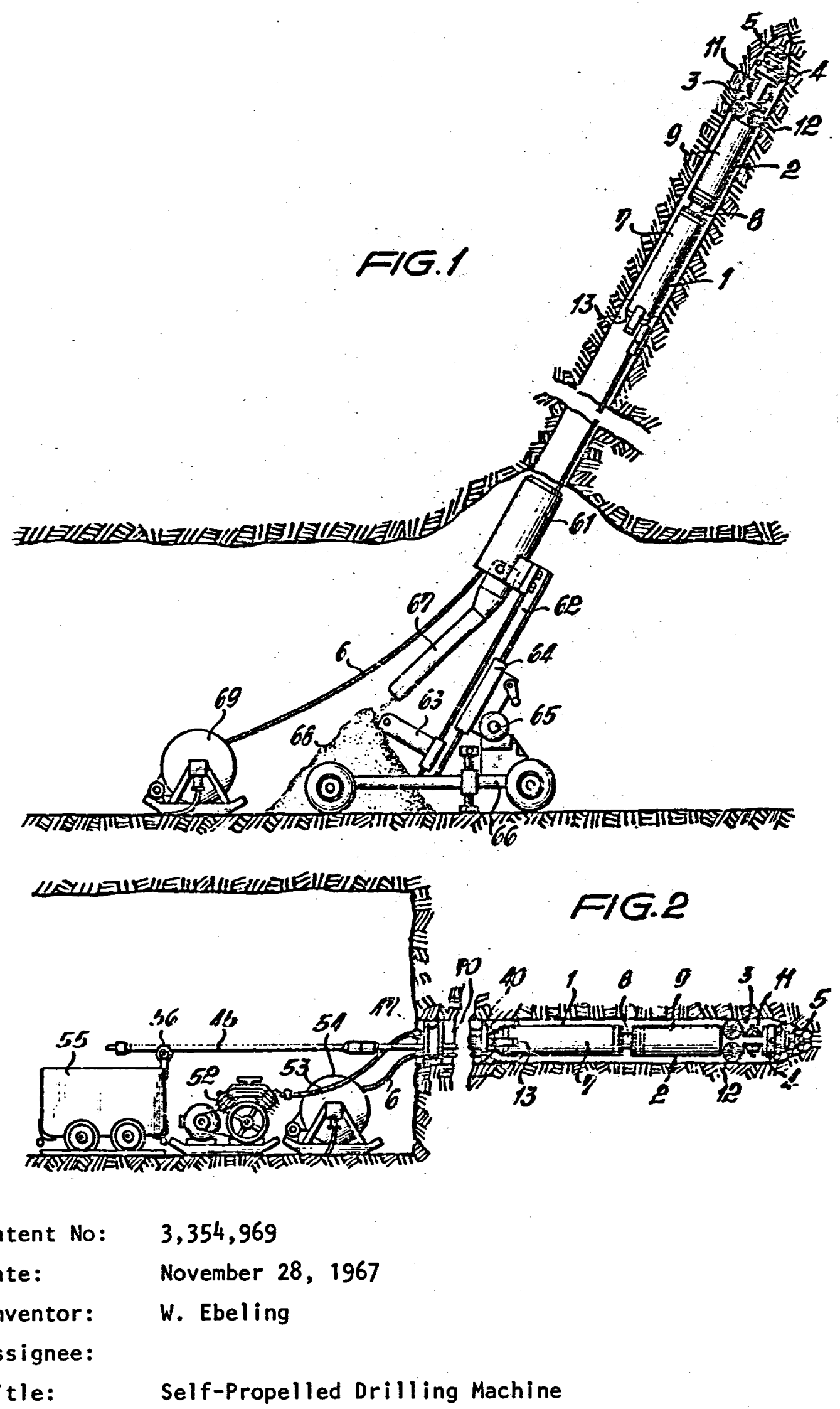




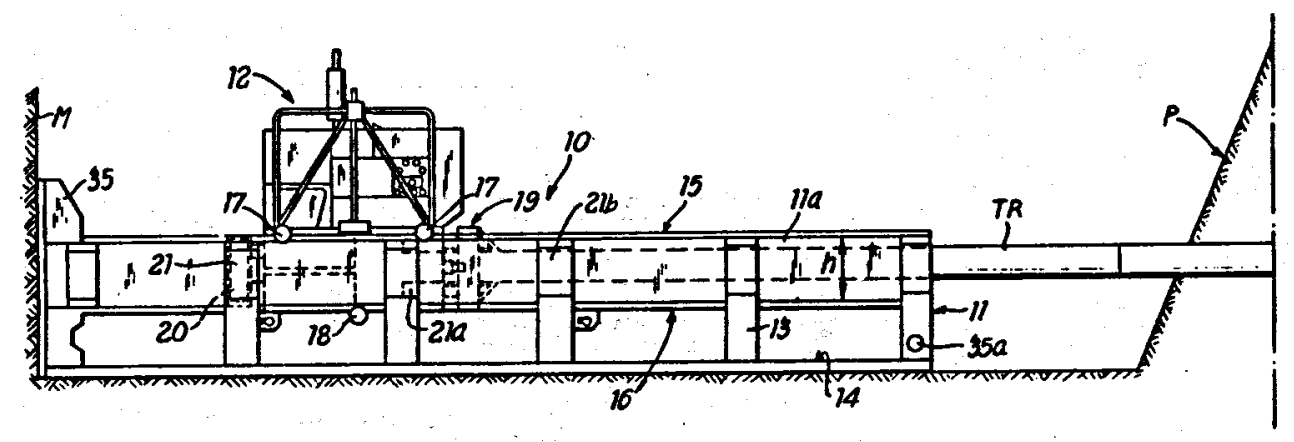

Patent No: $\quad 3,881,558$

Date: - May 6, 1975

Inventor: Claudio Dolza

Assignee:

Title: $\quad$ Pipe Thrust Machine for Horizontal Drilling 


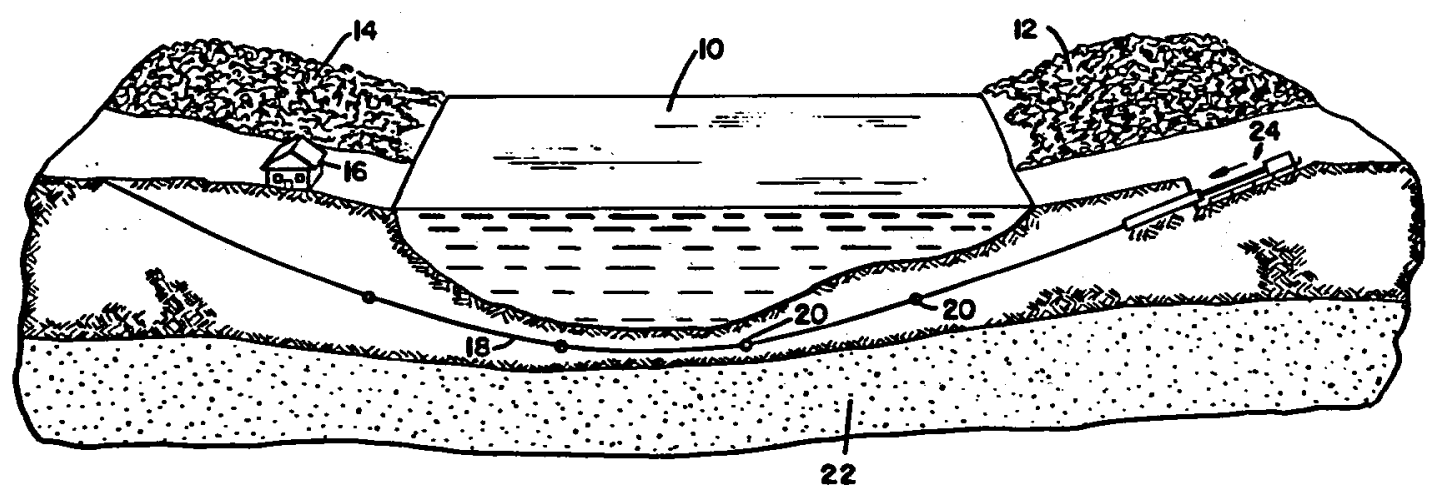

Patent No: $\quad 3,878,903$

Date: $\quad$ April 22, 1975

Inventor: Martin Dee Cherrington

Assignee:

Title: $\quad$ Apparatus and Process for Drilling Underground Arcuate Paths 


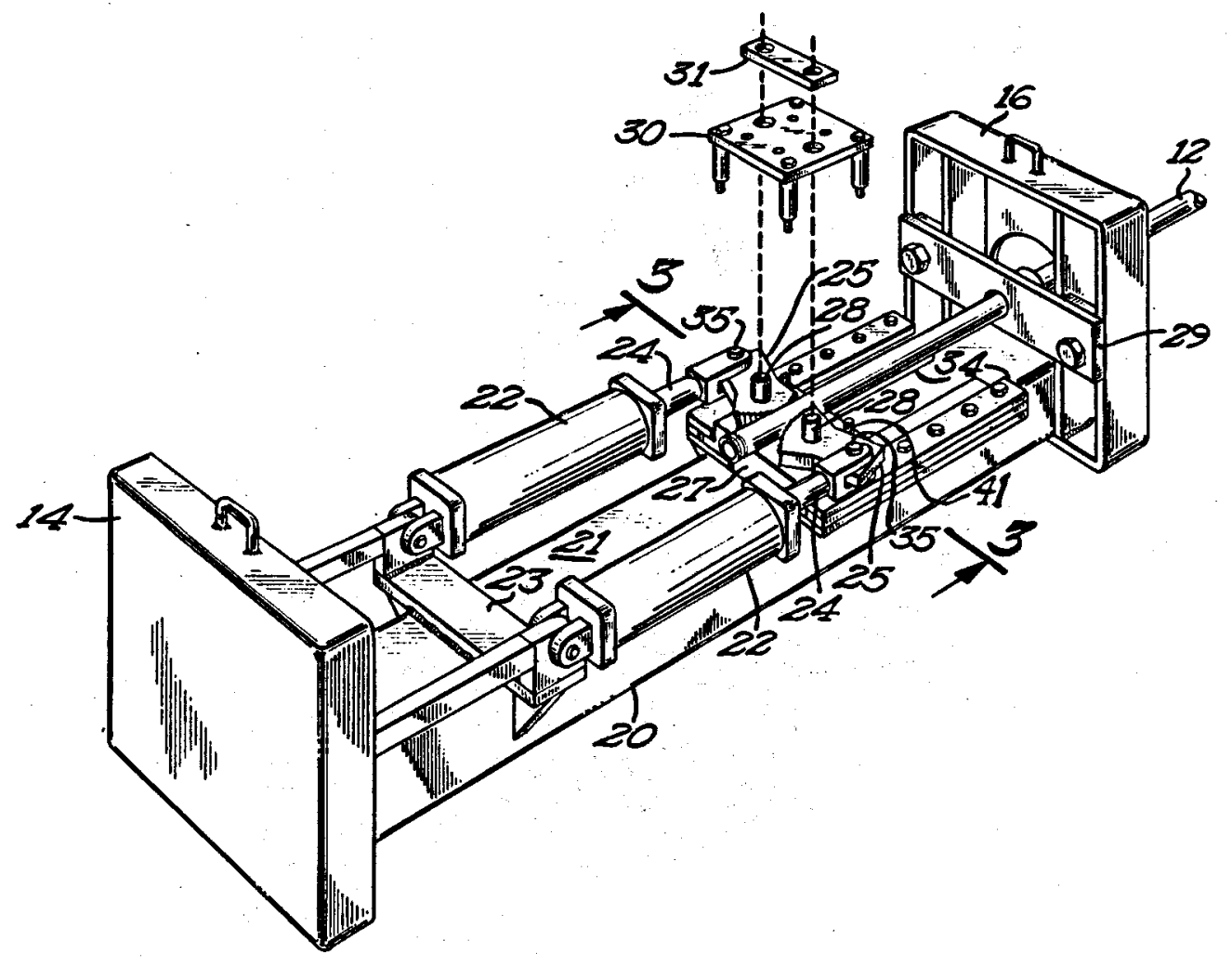

Patent No: $\quad 3,834,668$

Date: $\quad$ September 10, 1974

Inventor: John William Casey

Assignee:

Title: Pipe Pushing Apparatus 


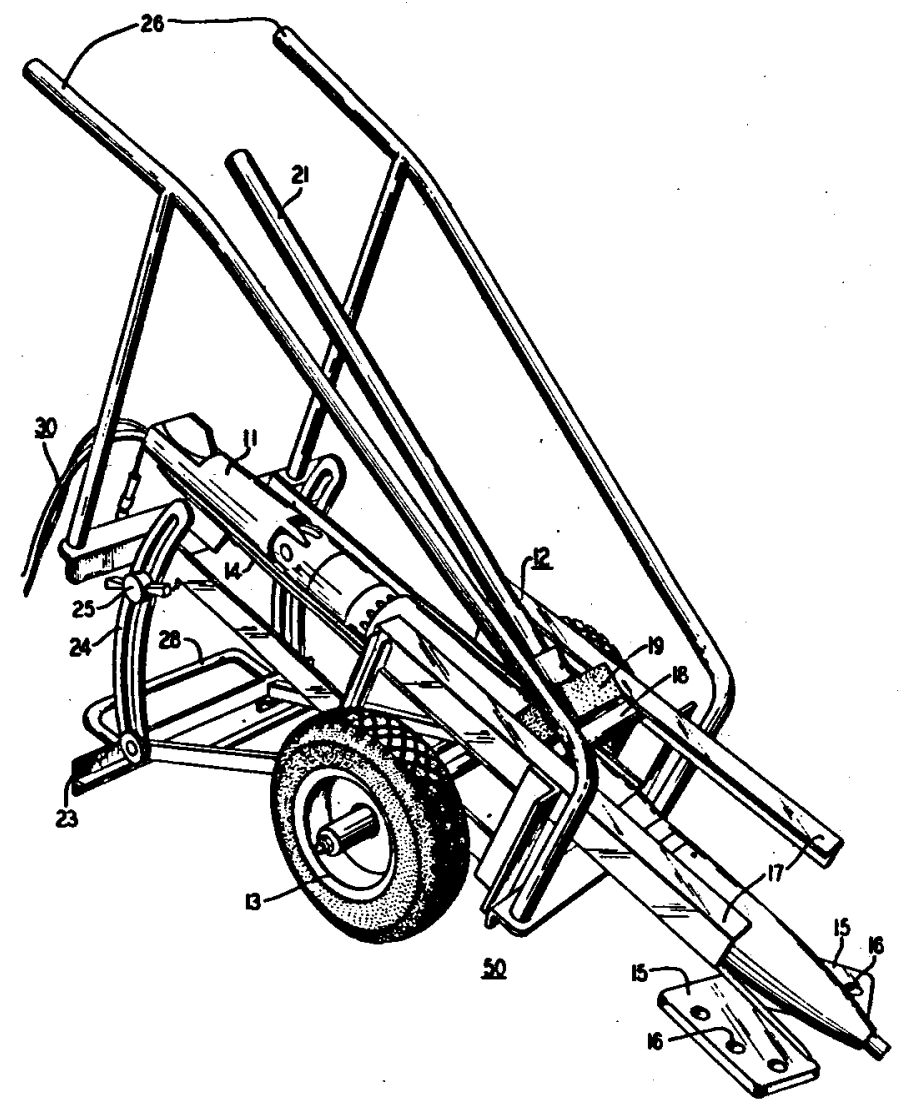

Patent No: $\quad 3,814,192$

Date: June 4, 1974

Inventor: Douglas Rodney Steen

Assignee: Bell Telephone Laboratories Inc.

Title: Apparatus for Launching a Soil Burrowing Mole 


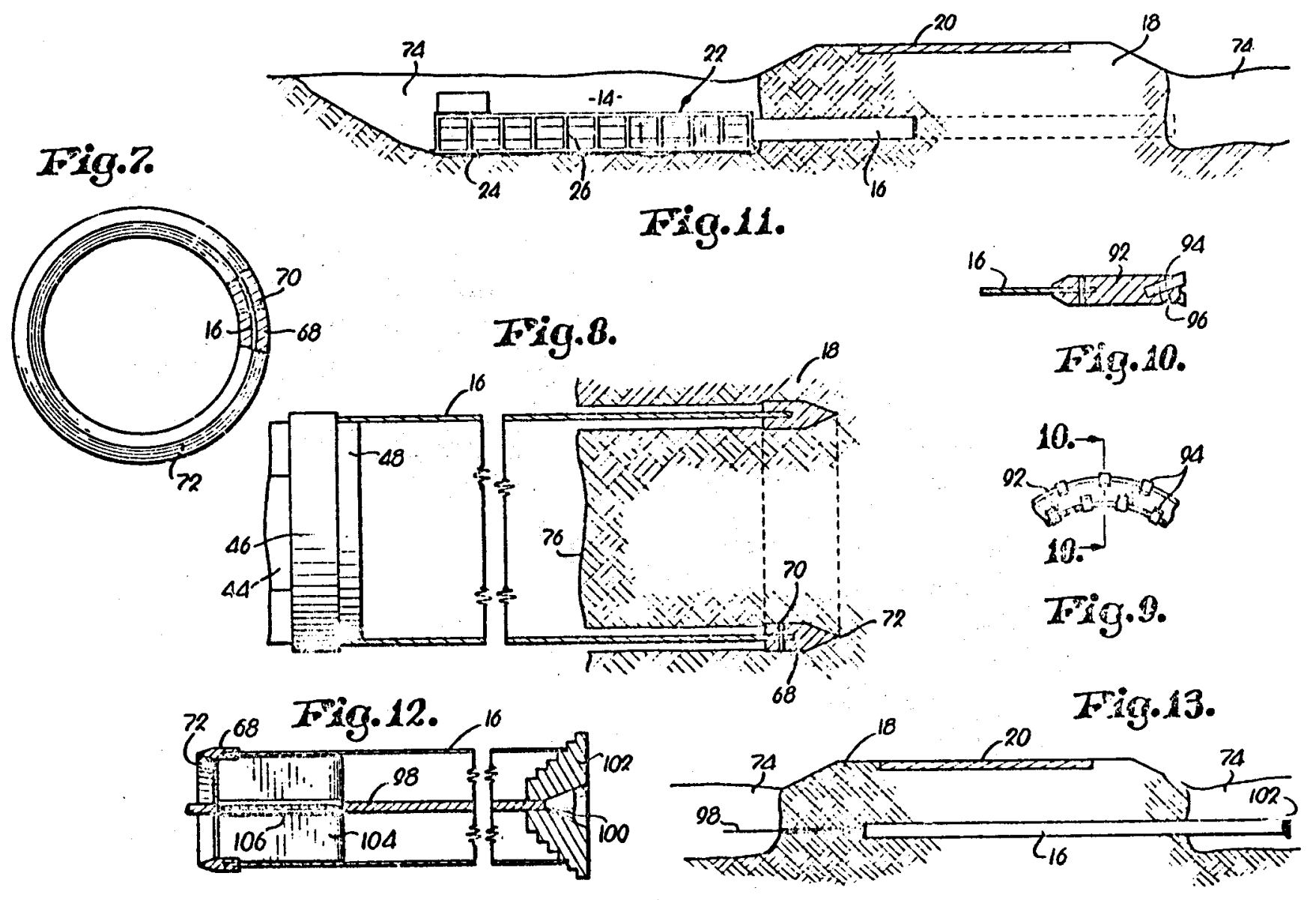

Patent No: $\quad 3,656,563$

Date: April 18, 1972

Inventor: Charles F. Blinne .

Assignee:

Title: Apparatus and Method for Inserting Casing Beneath Roadbeds 


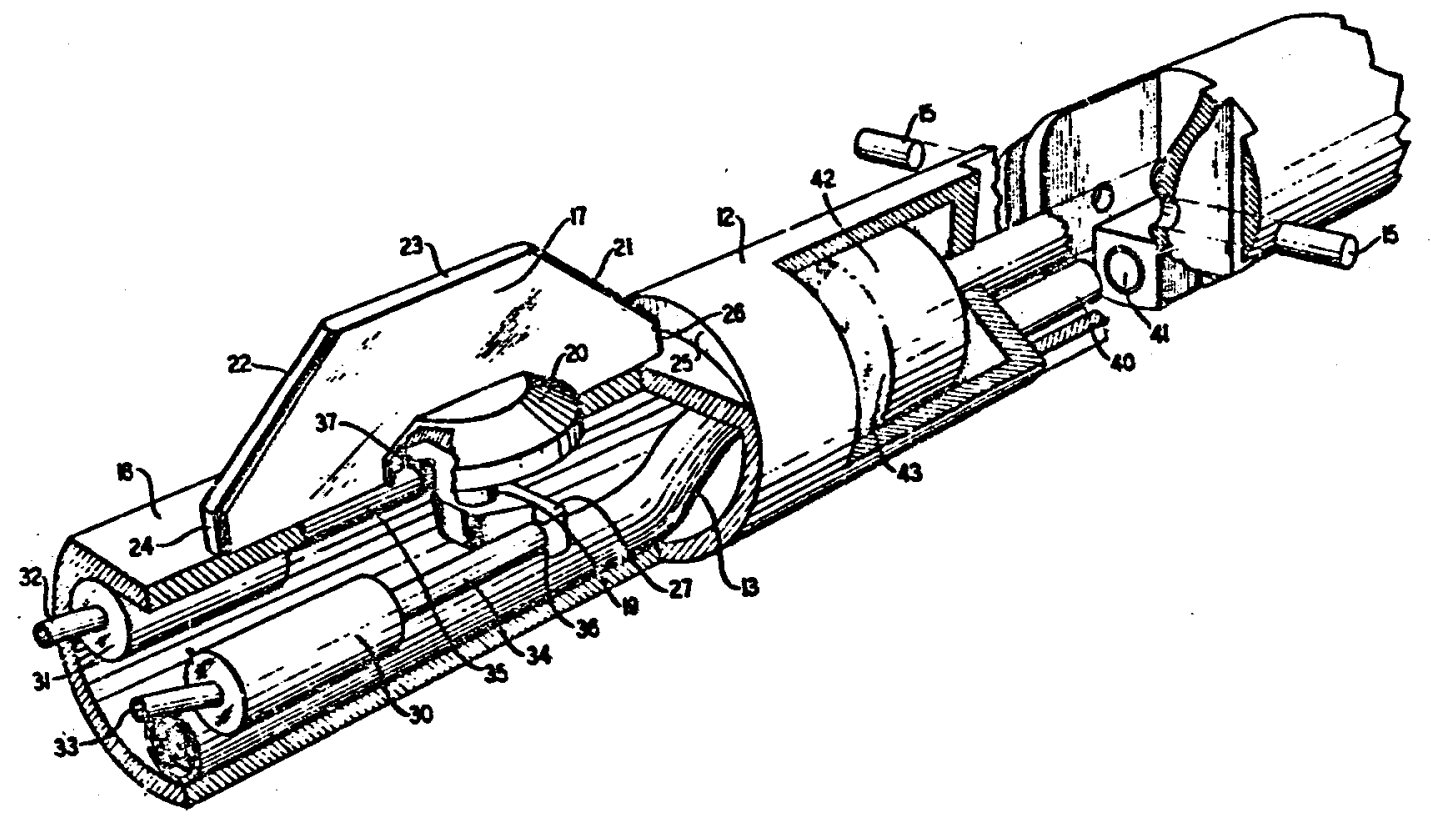

Patent No: $\quad 3,630,295$

Date: $\quad$ December 28, 1971

Inventor: James C. Coyne

Assignee: Bell Telephone Laboratories Inc.

Title: Steering Apparatus for Soil-Burrowing Mole 


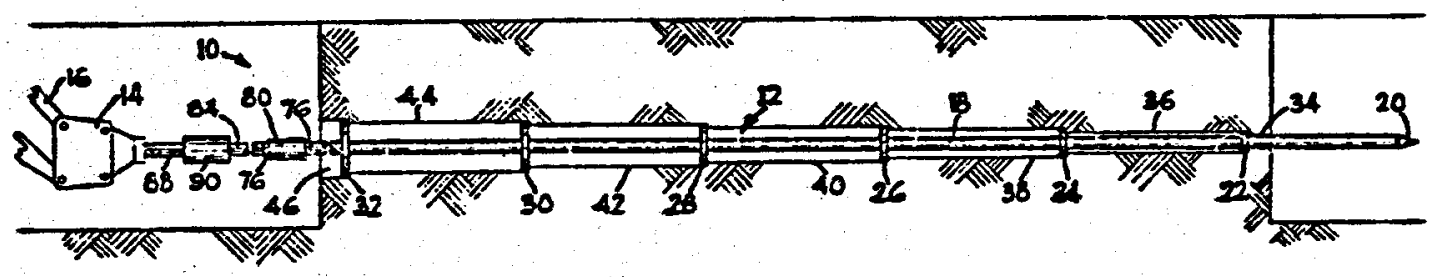

Patent No: 3,554,303

Date: January 12, 1971

Inventor: William Zajkowski

Assignee:

Title: $\quad$ Earth Piercing Apparatus and Method 

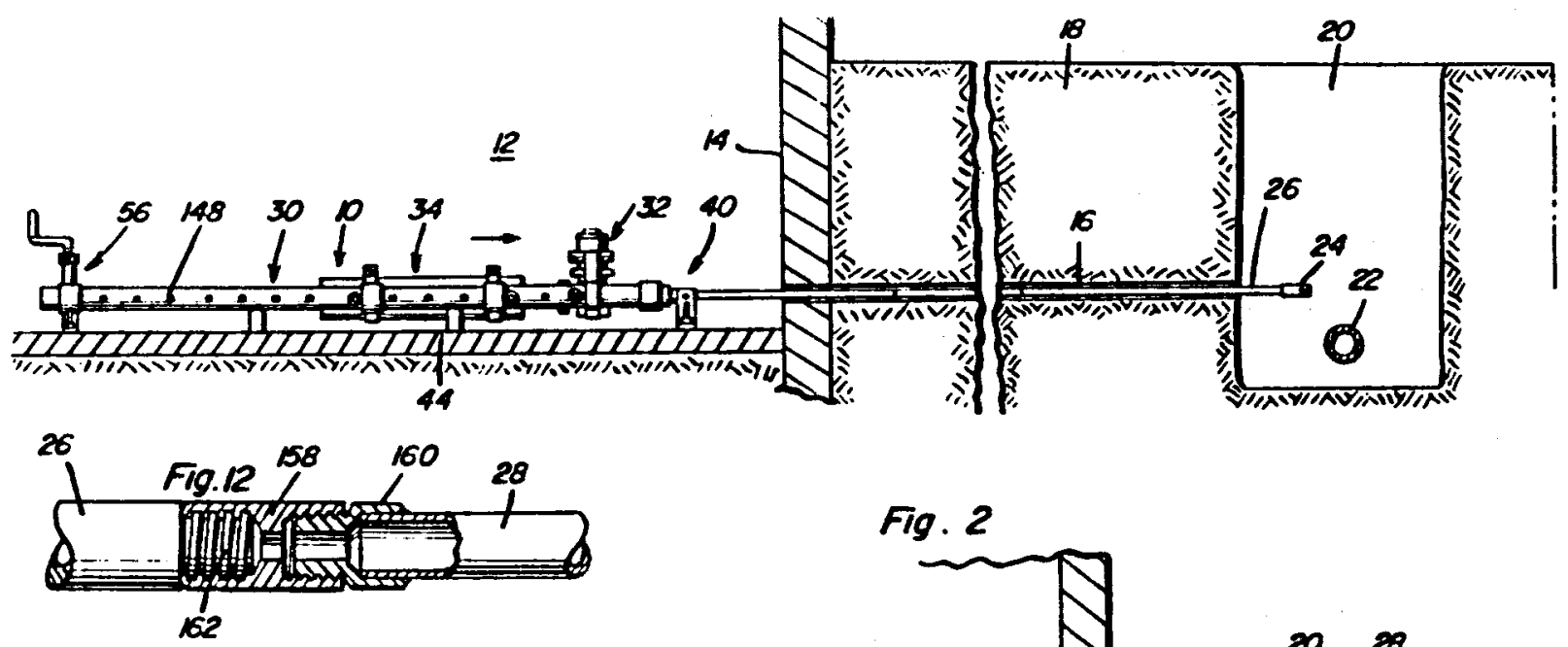

Fig. 2

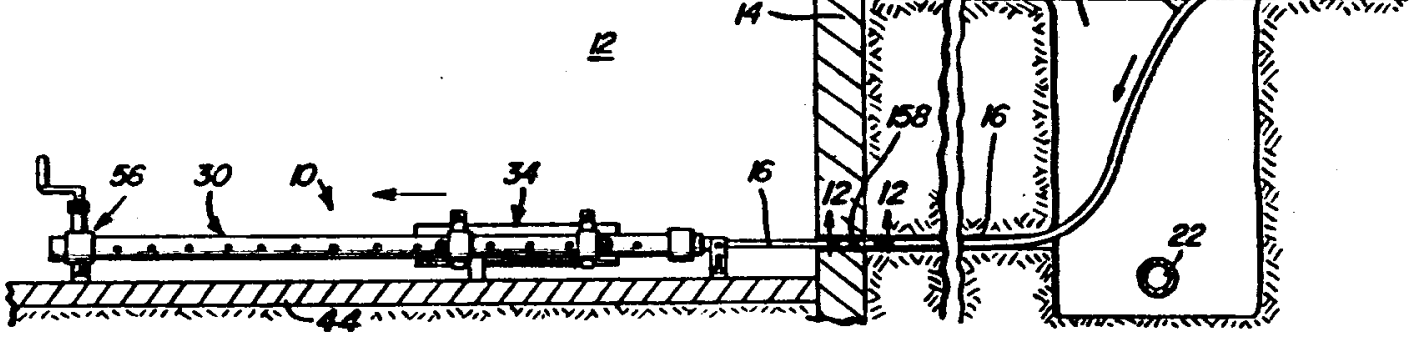

Patent No: 853926 (Canadian)

Date: $\quad$ October 20, 1970

Inventor: Patrick J. Clelland

Assignee:

Title:

Horizontal Drill Slide and Recoveyor for Installing Underground Lines 


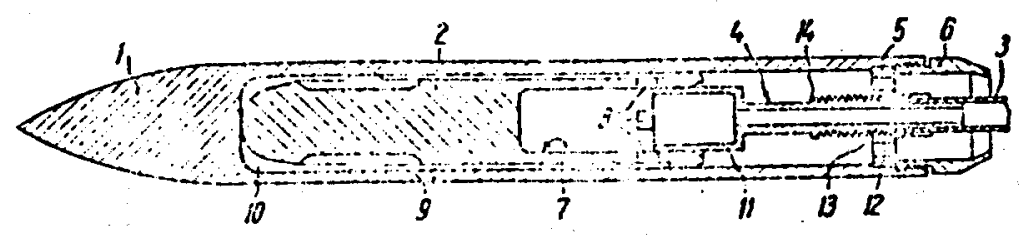

FIG.I
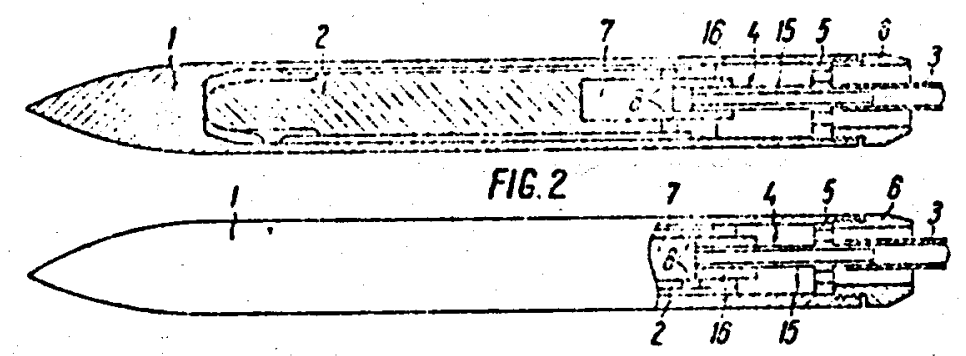

Fi6.3

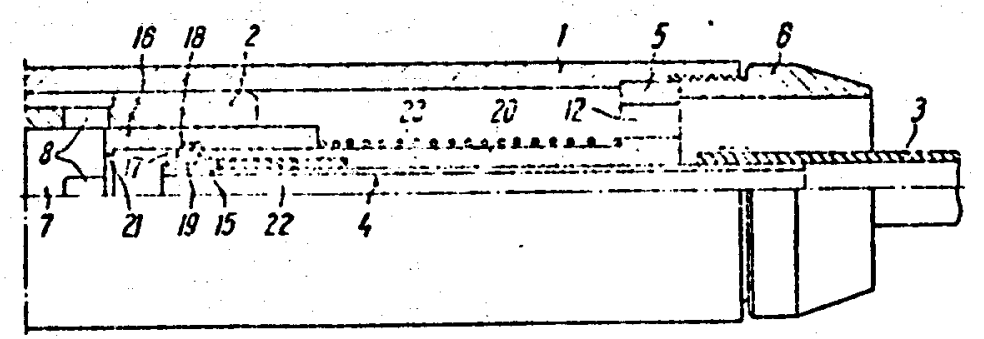

FI6. 4

Patent No: $\quad 1,170,167$ (British)

Date: March 14, 1967

Inventor: Kostantin K. Tupitsyn, Valdimir V. Kl imashko, Vladimir D. Plavskikh, Lazar M. Lipovetsky, Boris S. Danilevich, Leonid G. Aldonov, Viktor B. Khan, Bor is V. Sudnishnikov, Alexandr D. Kostylev, and Konstantin S. Gurkov

Assignee:

Title:

Percussion Ground-Burrowing Device 

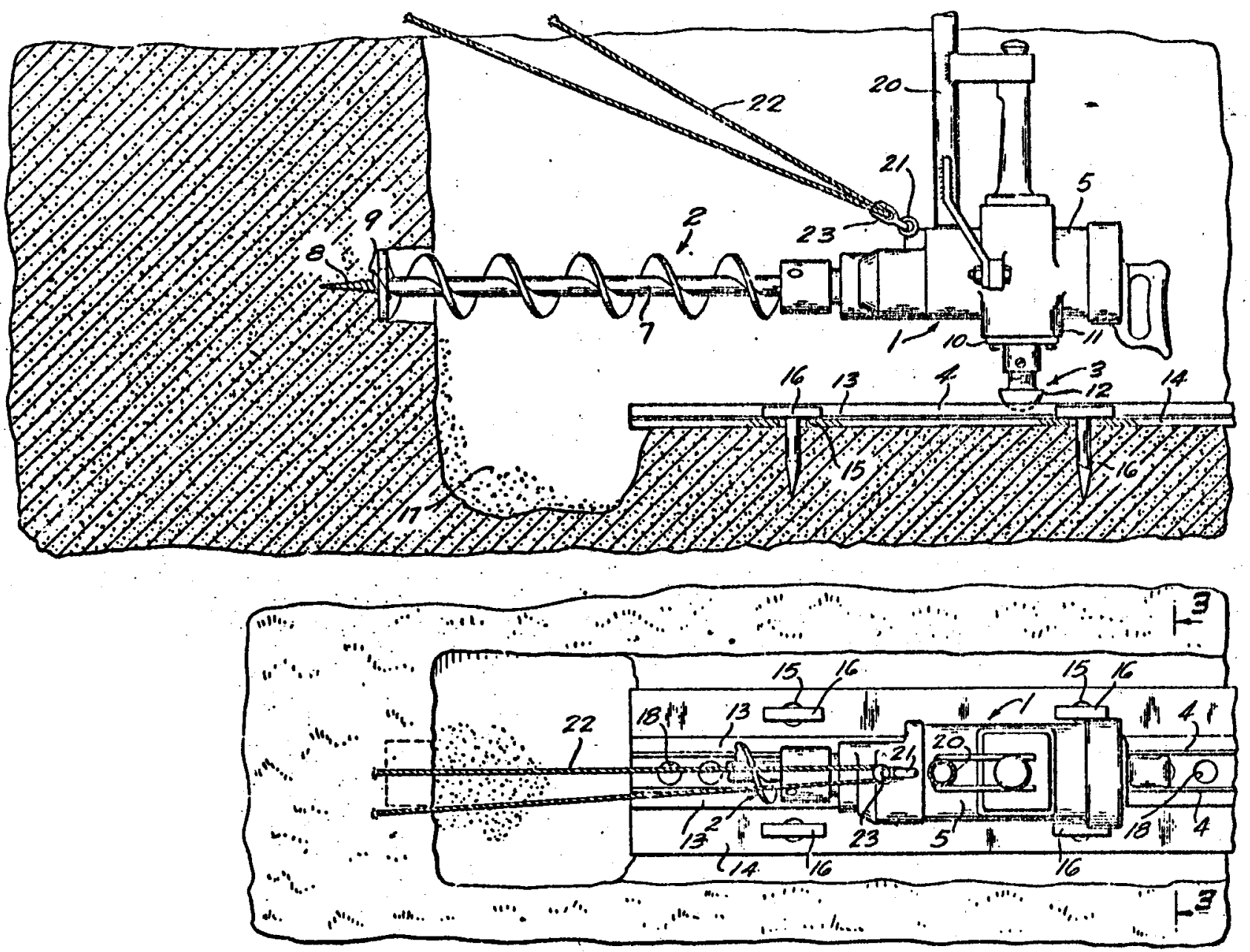

Patent No: $\quad 2,524,262$

Date: $\quad$ October 3, 1950

Inventor: C. W. Kandle

Assignee:

Title: Drill Guide 


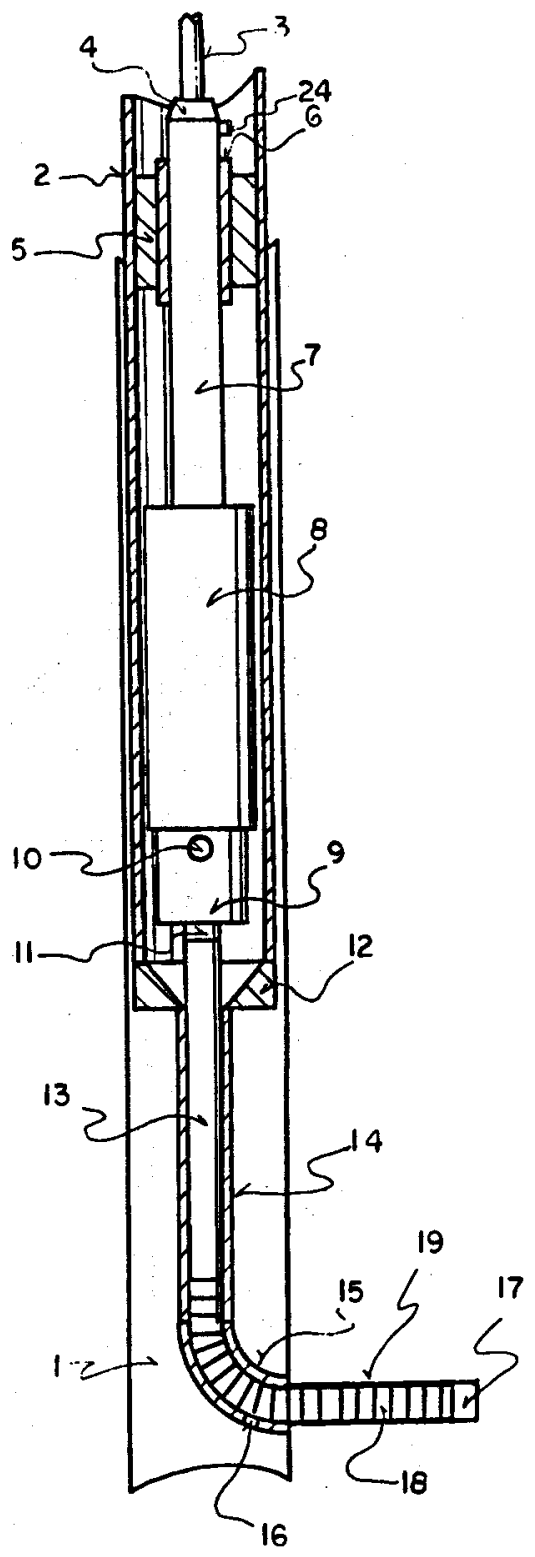

Patent No: 4,051,908

Date: October 4, 1977

Inventor: W. B. Driver

Assignee:

Title:

Downhole Drilling System 


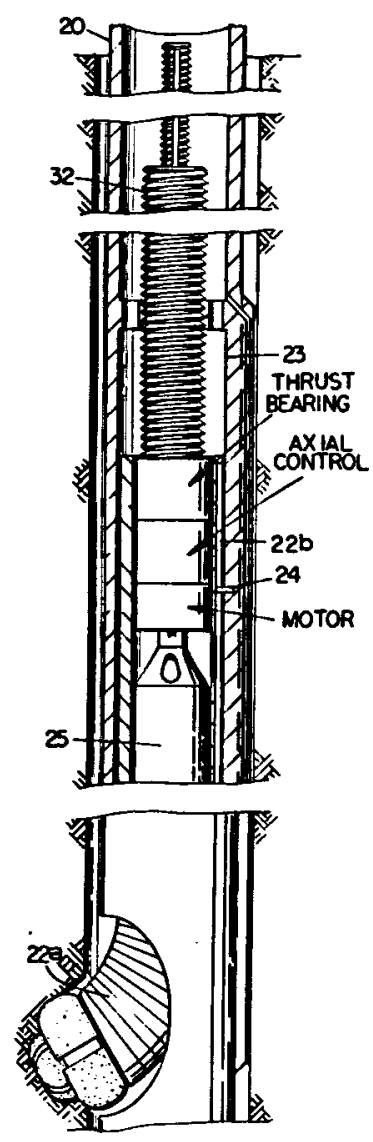

Patent No: $\quad 4,007,797$

Date: $\quad$ February 15, 1977

Inventor: John D. Jeter

Assignee: Texas Dynamatics Inc.

Title: $\quad$ Device for Drilling a Hole in the Side Wall of a Bore Hole 


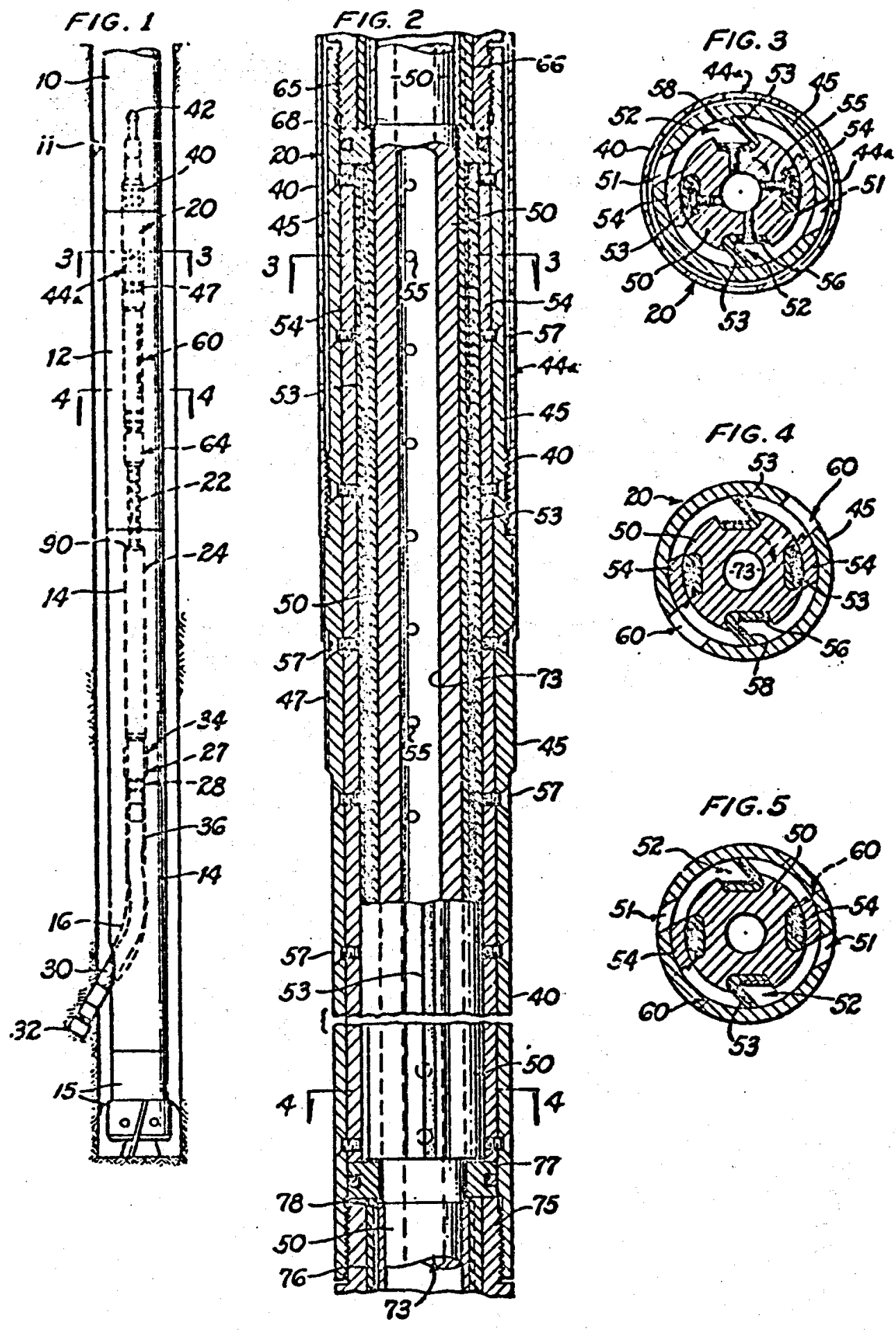

Patent No: $\quad 3,150,727$

Date: September 23, 1964

Inventor: M. A. Garrison

Assignee:

Title: Drill Stem Core Bit and Wall Sampler 


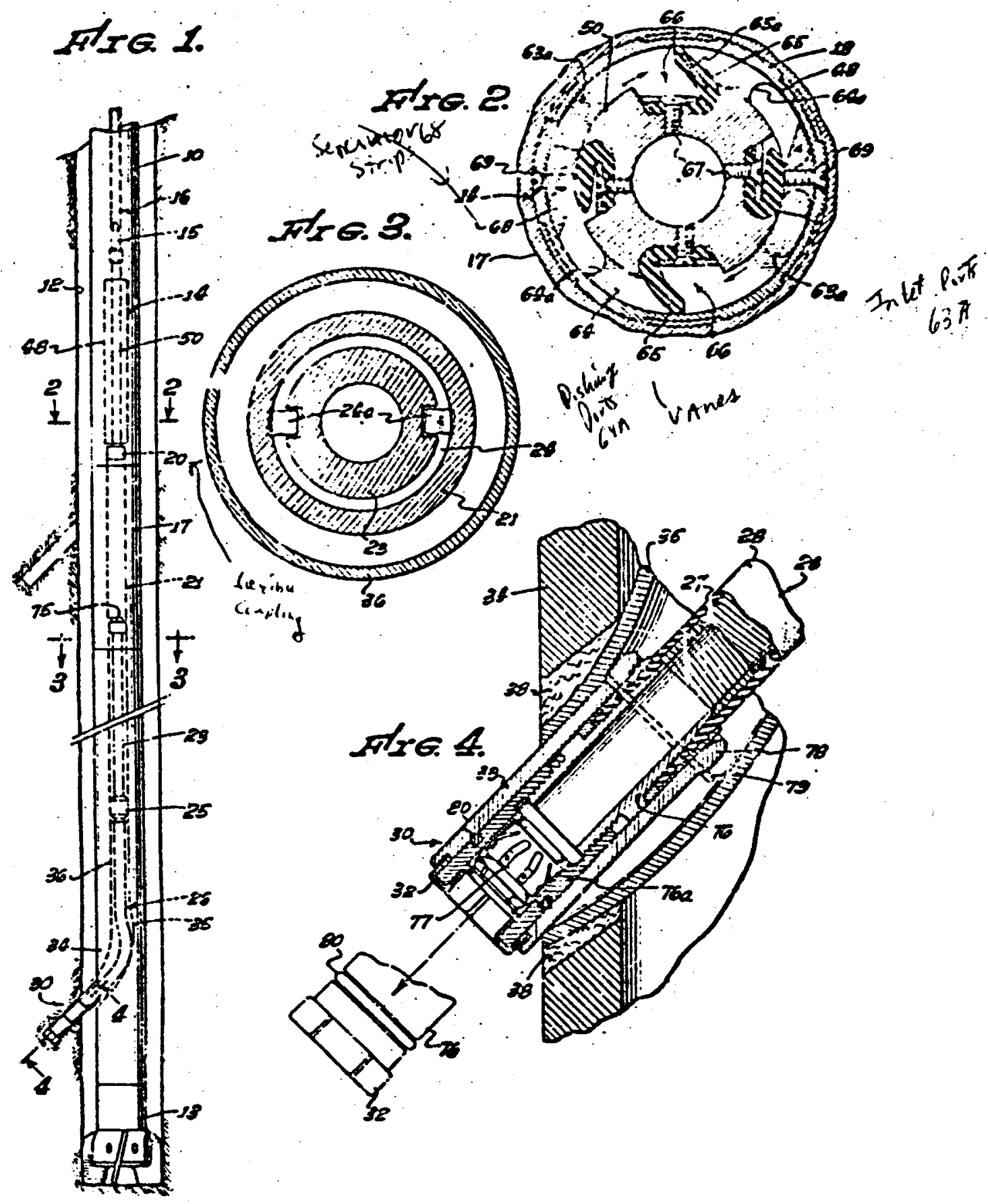

Patent No: $2,852,230$

Date: $\quad$ September 16, 1958

Inventor: M. A. Garrison

Assignee: Empire 0il Tool Company

Title: Side Wall Coring and Bottom Hole Drilling Tool 


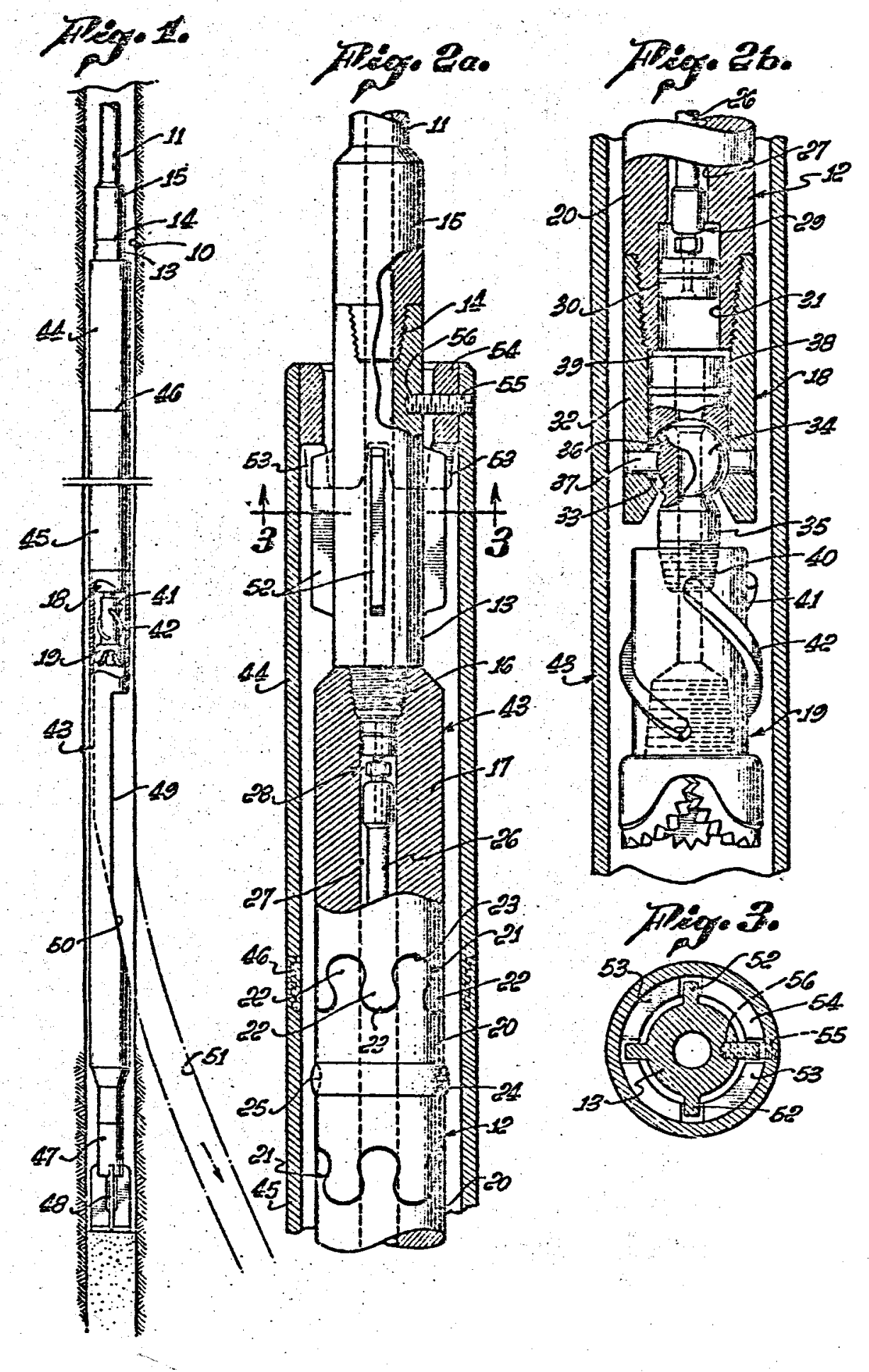

Patent No: $2,667,332$

Date: January 26, 1954

Inventor: J. S. McCune et al

Assignee: Oilwell Drain Hole Drilling Company

Title: Flexible Shaft Well Drilling Equipment 


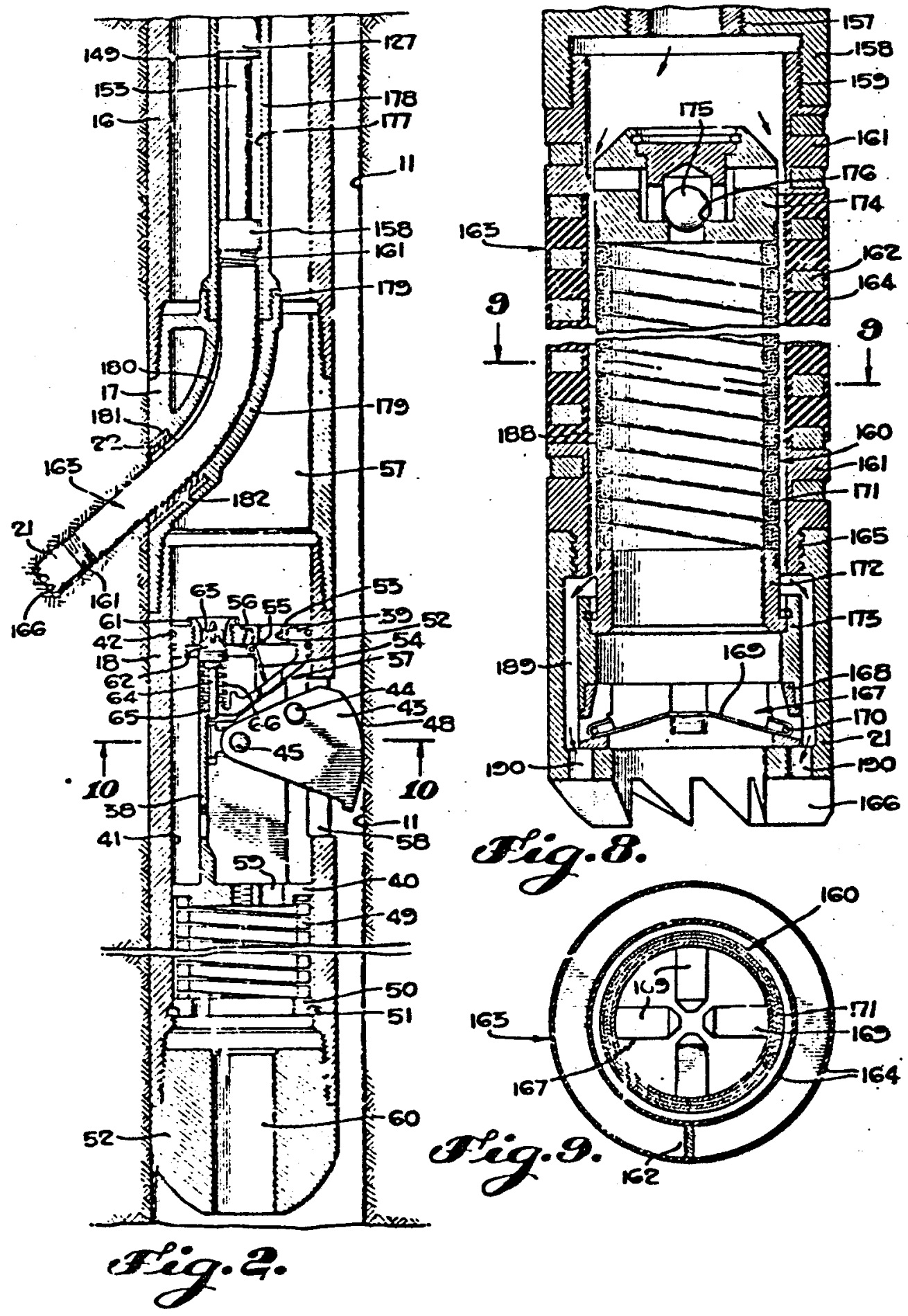

Patent No: $\quad 2,594,292$

Date: $\quad$ April 29, 1952

Inventor: $\quad$ P. D. Cornelius

Assignee: Byron Jackson Company

Title: Side Wall Sampler 


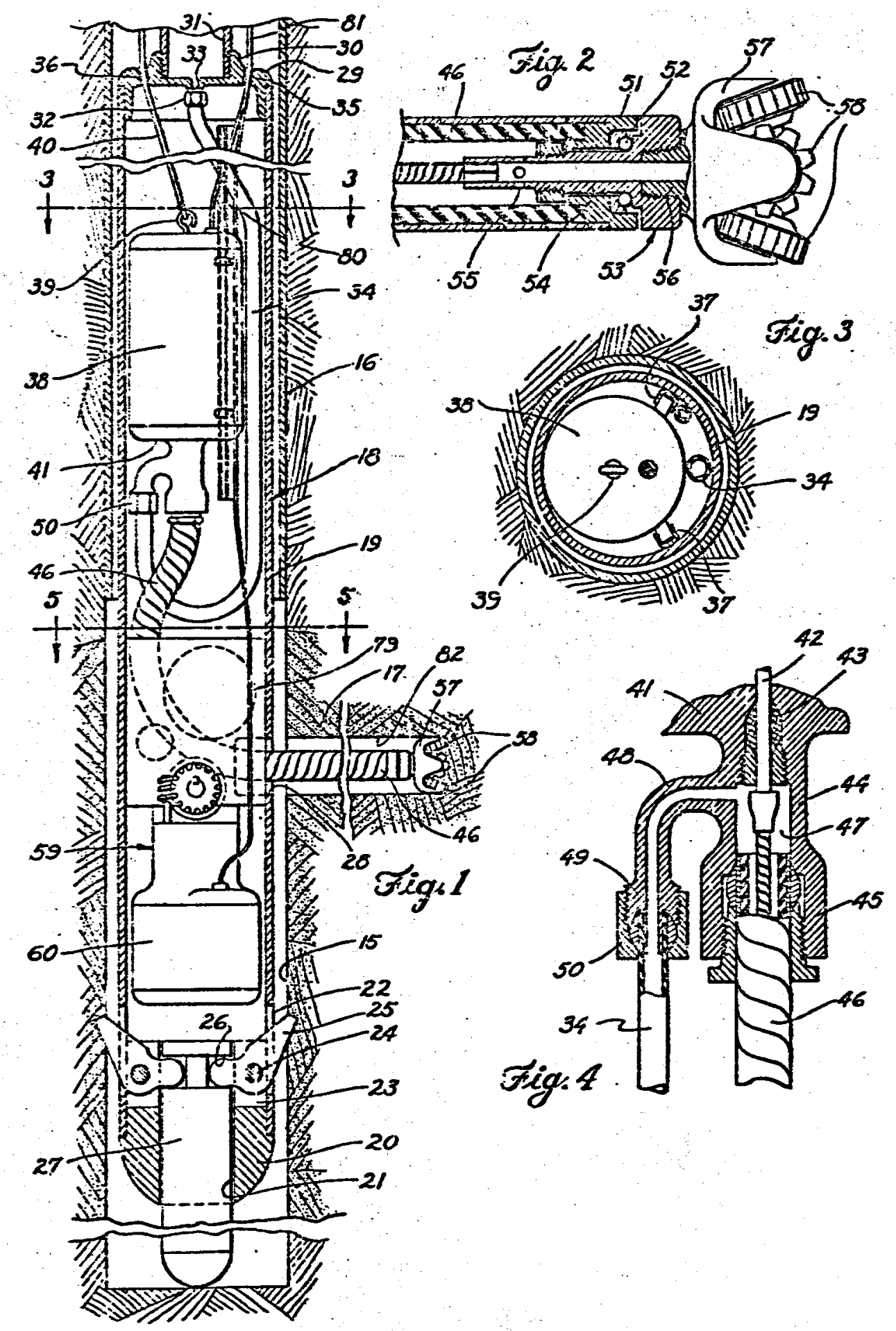

Patent No: $\quad 2,516,421$

Date: July 25, 1950

Inventor: J.B. Robertson

Assignee:

Title: Drilling Tool 

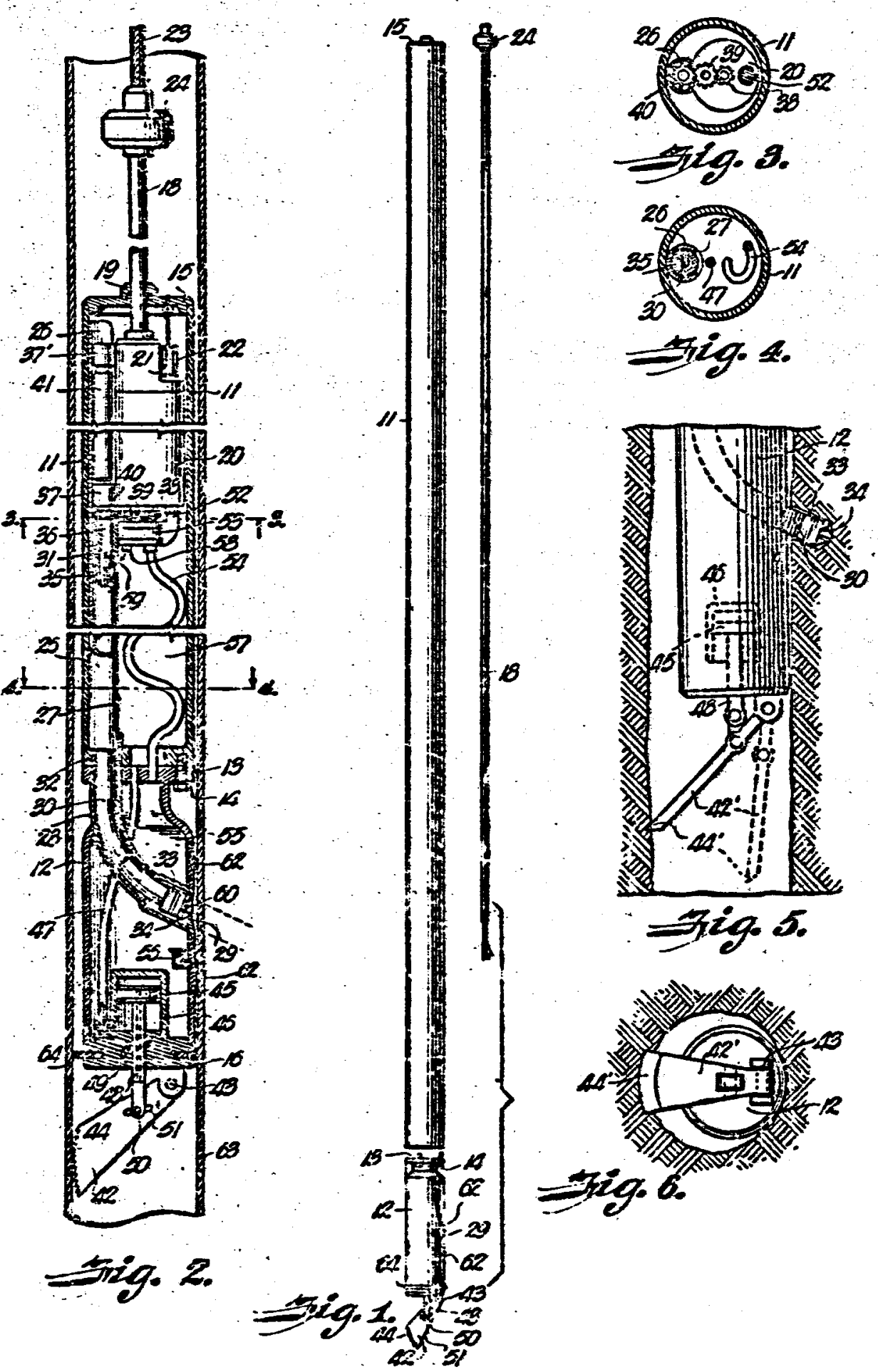

Patent No: $\quad 2,500,785$

Date: March 14, 1950

Inventor: A. Arutunoff

Assignee:

Title:

Side Drill with Slotted Guide Tube 


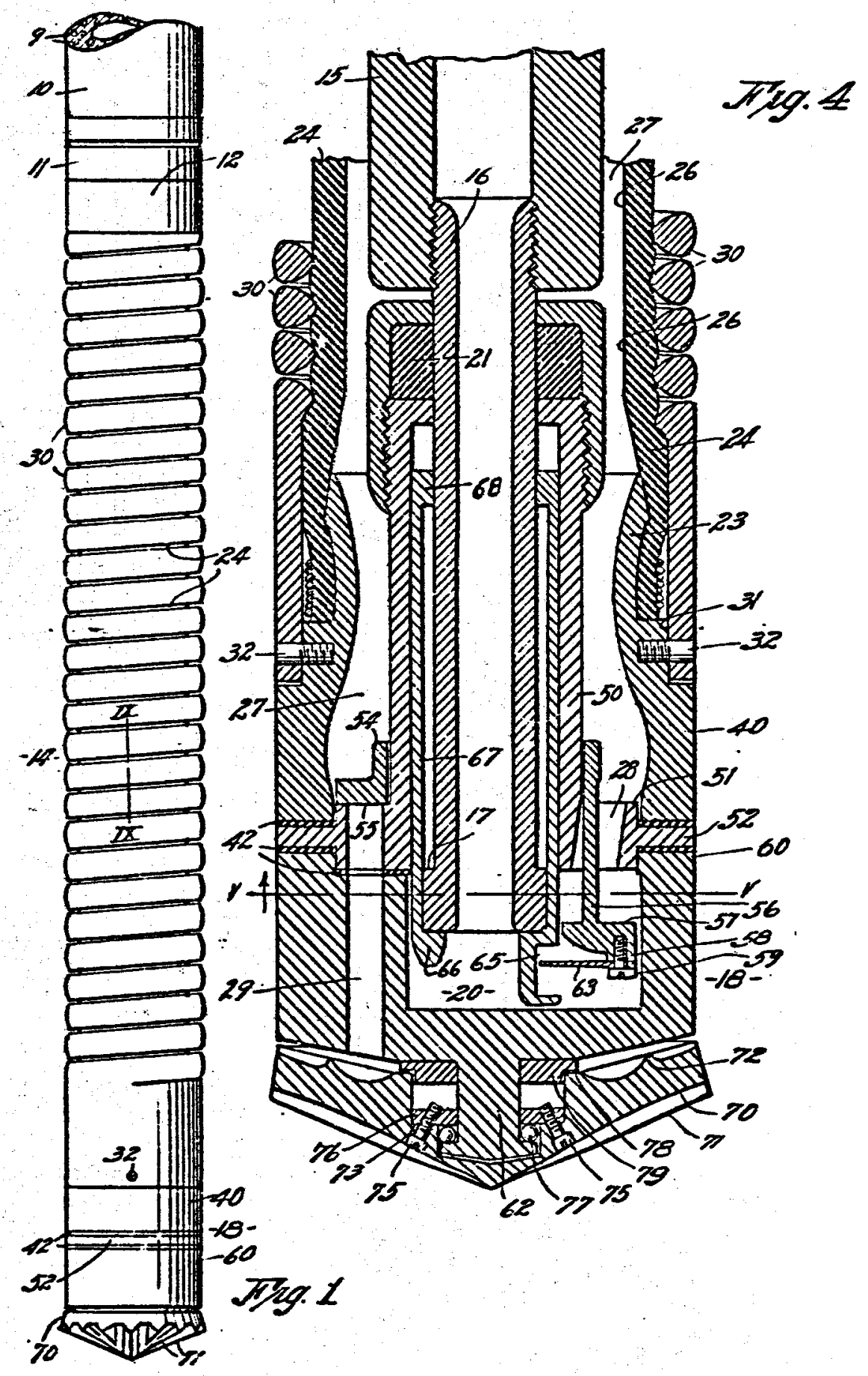

Patent No: $\quad 2,390,646$

Date: December 11, 1945

Inventor: R. R. Hays

Assignee:

Title:

Well Drilling Apparatus 


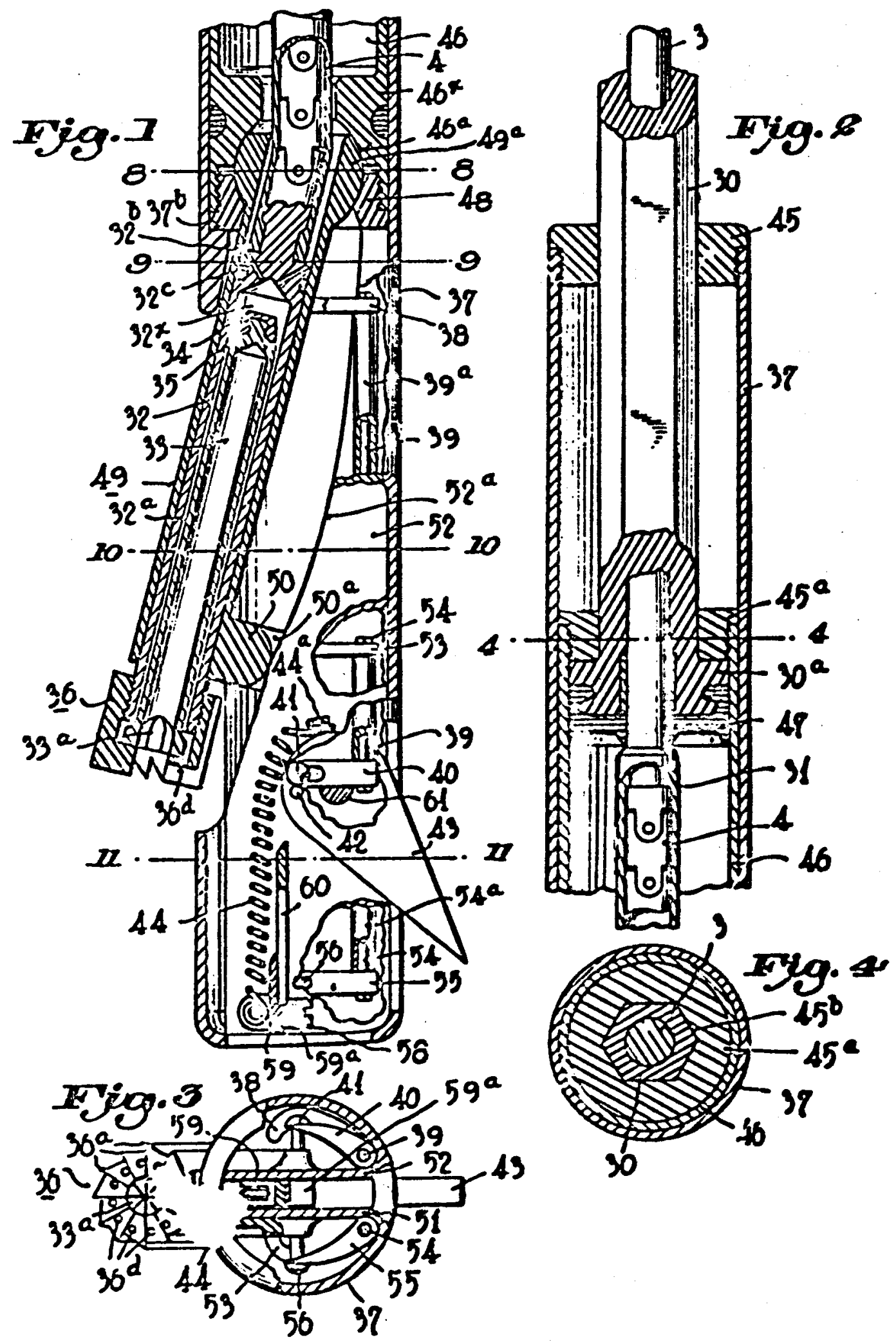

Patent No: $\quad 2,324,682$

Date: July 20, 1943

Inventor: R. De Long

Assignee: Fohs 0 il Company

Title:

side Wall Coring Tool 


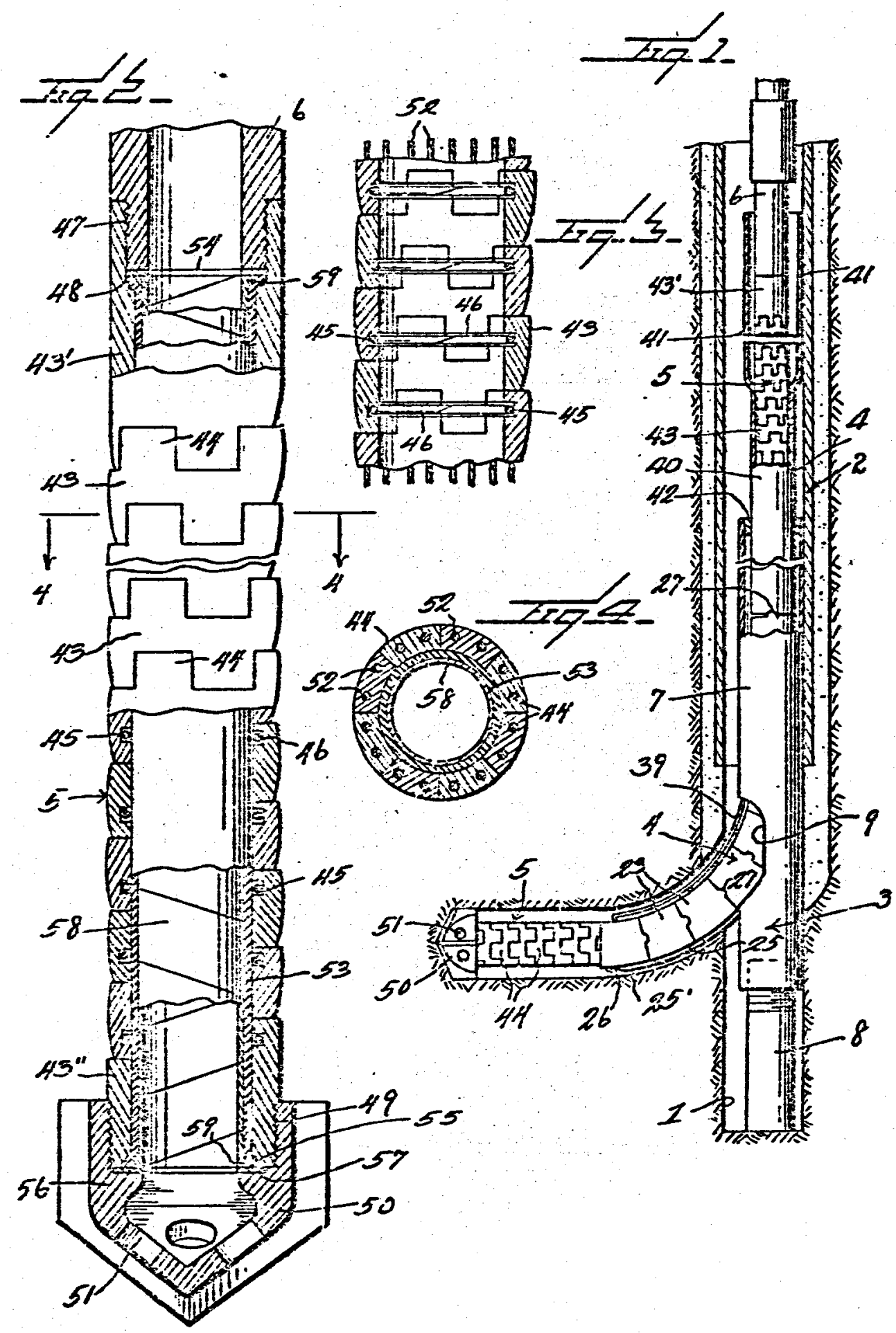

Patent No: $\quad 2,296,161$

Date: September 15, 1942

Inventor: J. D. Hall, Jr.

Assignee:

Title: Lateral Drill for Wells 

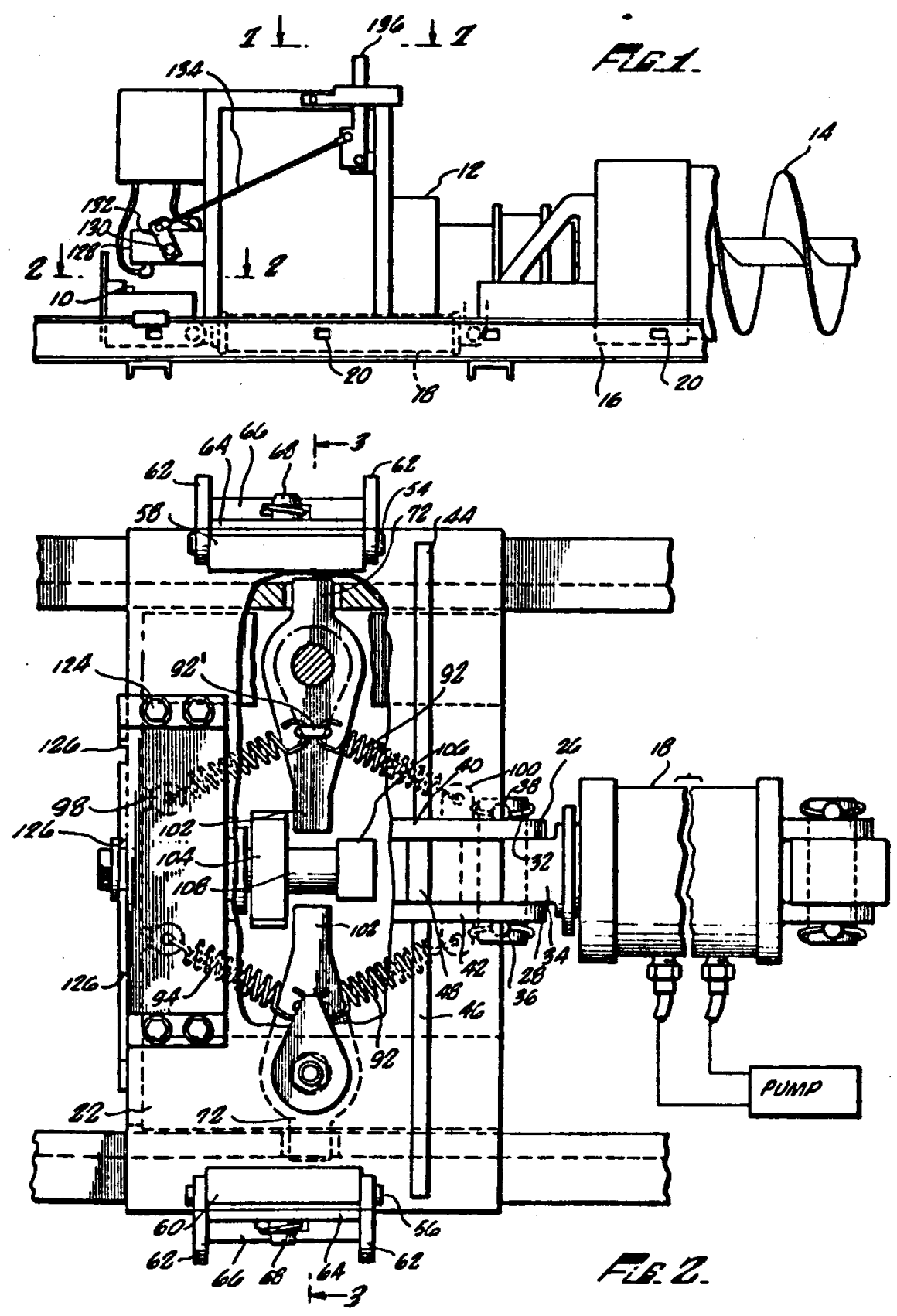

Patent No: 1449664 (British), 998701 (Canadian)

Date: $\quad$ September 15, 1976

Inventor: Allied Steel \& Tractor Products, Inc.

Assignee:

Title: Walking Beam 


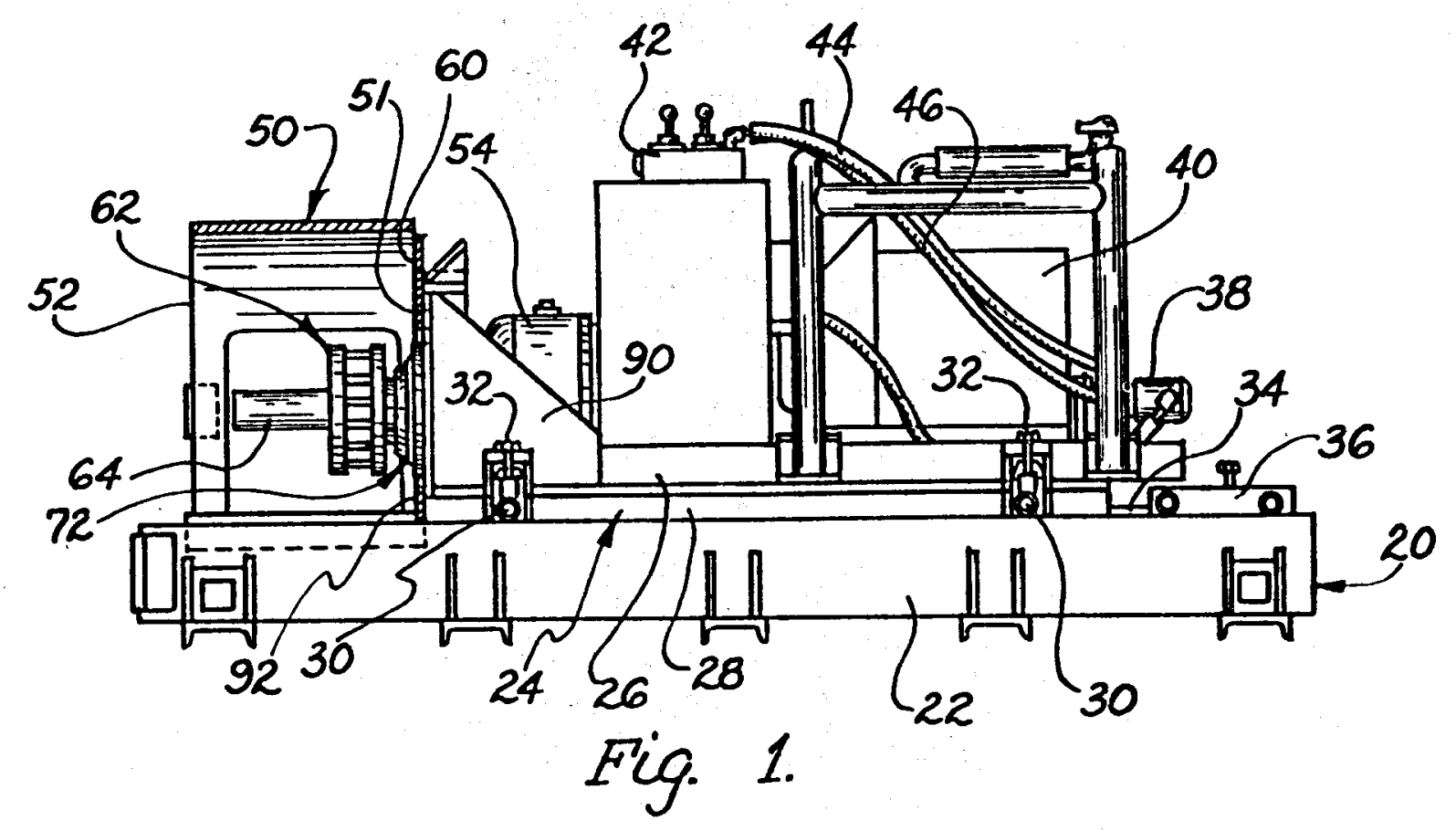

Patent No: 975349 (Canadian)

Date: September 30, 1975

Inventor: Albert R. Richmond

Assignee: Richmond Manufacturing Company

Title: $\quad$ Power Train for Horizontal Earth Boring Machine 


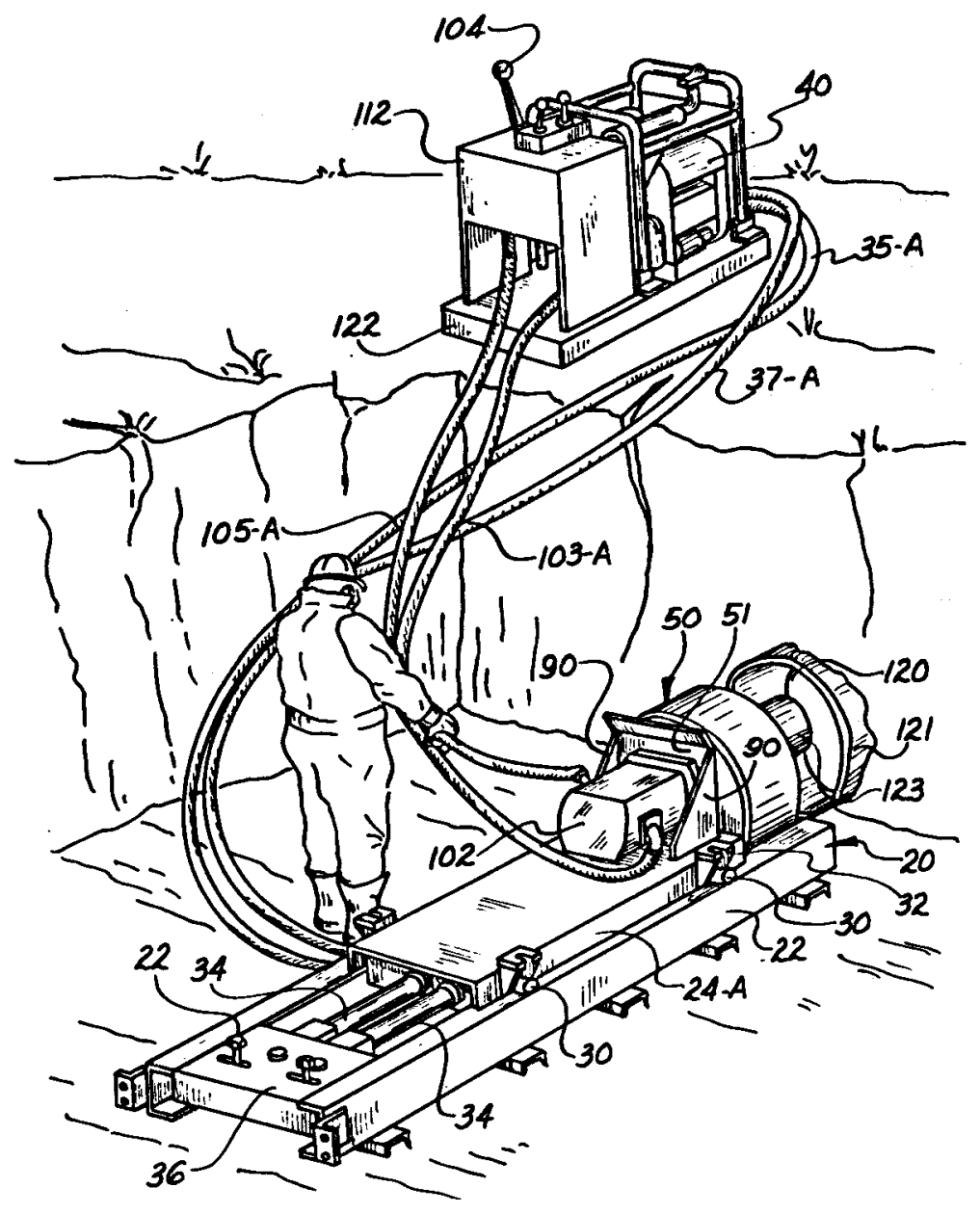

Patent No: $\quad 3,870,110$

Date: $\quad$ March 11, 1975

Inventor: Albert R. Richmond et al

Assignee: The Richmond Manufacturing Company

Title:

Power Train for Horizontal Earth Boring Machine 


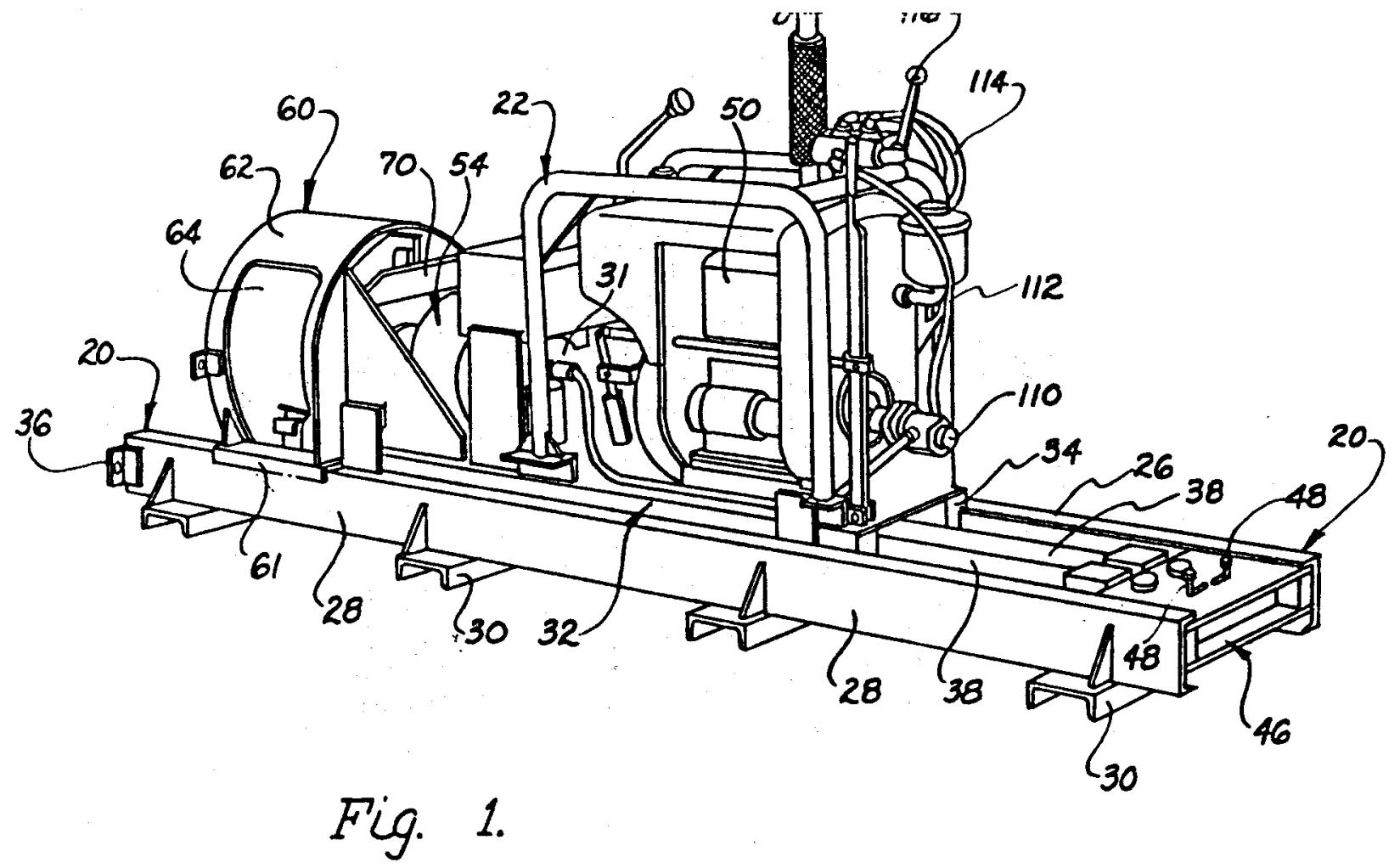

Patent No: 938798 (Canadian)

Date: December 25, 1973

Inventor: Albert R. Richmond

Assignee: Richmond Manufacturing Company

Title: : Earth Boring Machine 


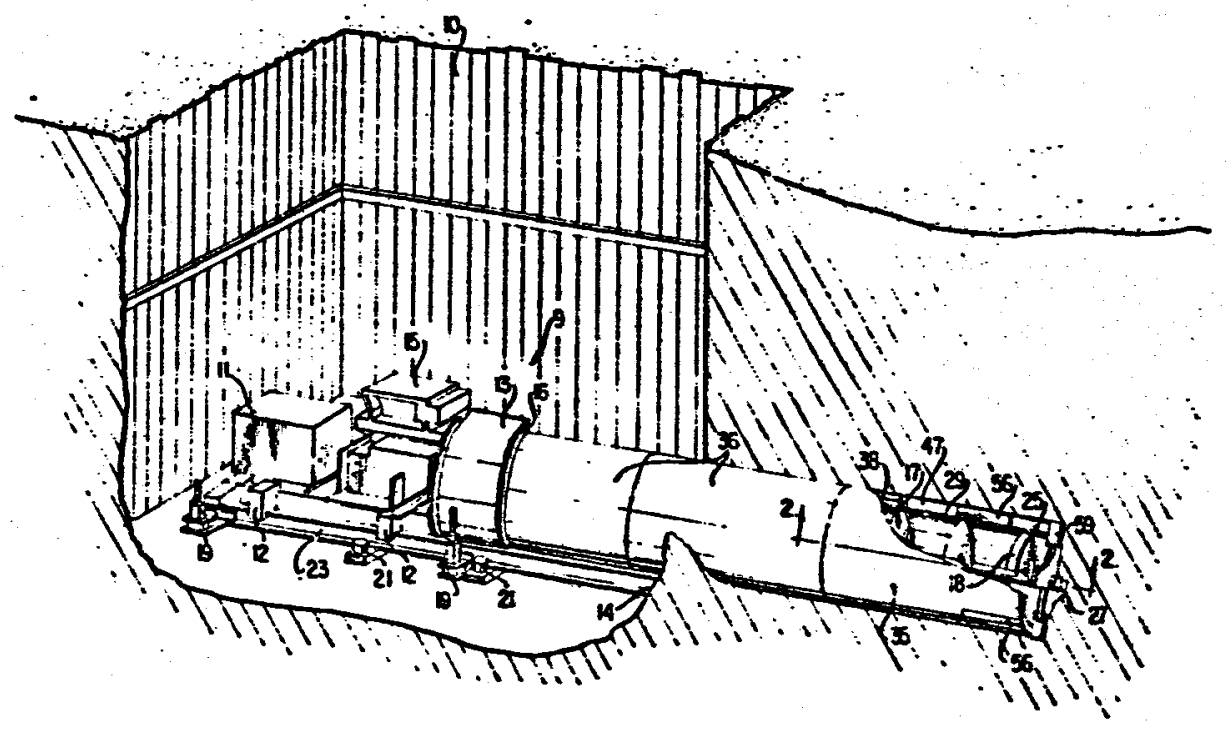

Patent No: $\quad 3,767,836$

Date: $\quad$ October 23, 1973

Inventor: Warren P. Geis et al

Assignee: Koehring Company

Title: $\quad$ Earth Boring Method and Apparatus 


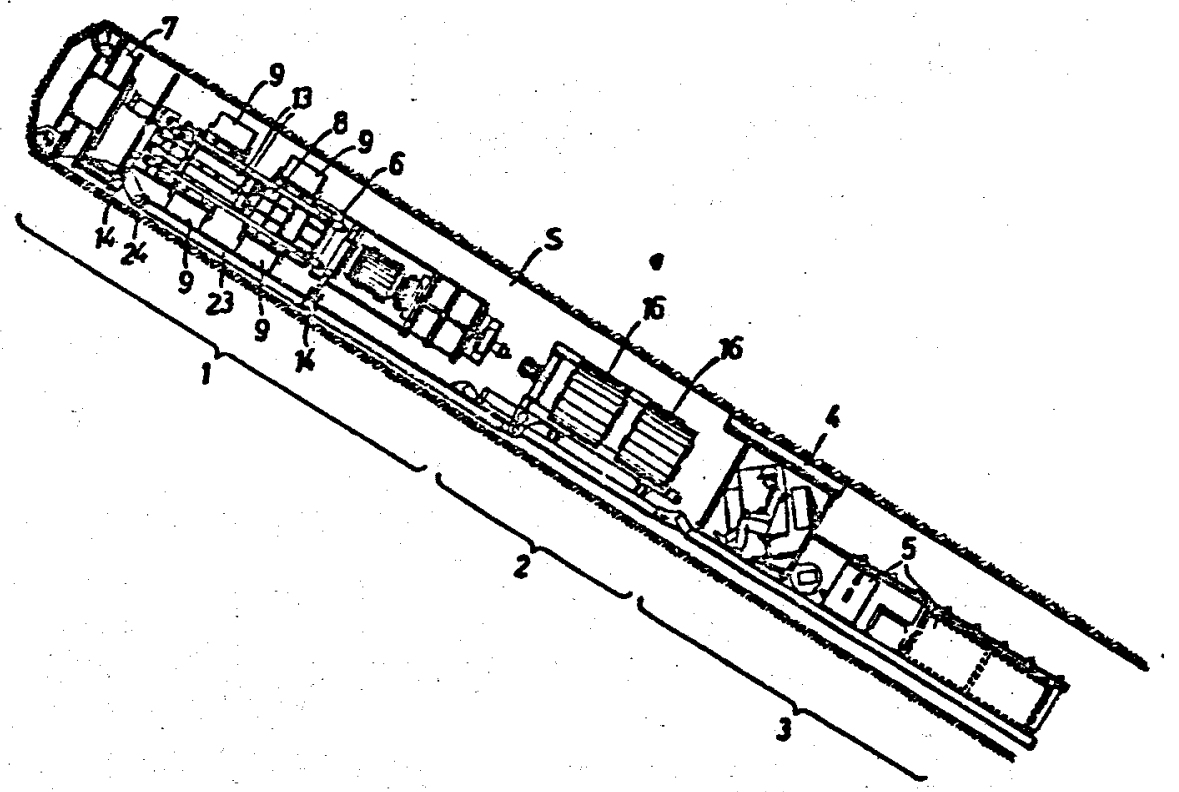

Patent No: $\quad 3,642,326$

Date: $\quad$ February 15, 1972

Inventor: Willi Steufmehl

Assignee: Maschimen- und Bohrgerate-Fabrik Alfred Wirth \& Co.

Title: Stepper Advancing Apparatus for Drilling Inclined Tunnels 
FIG.I
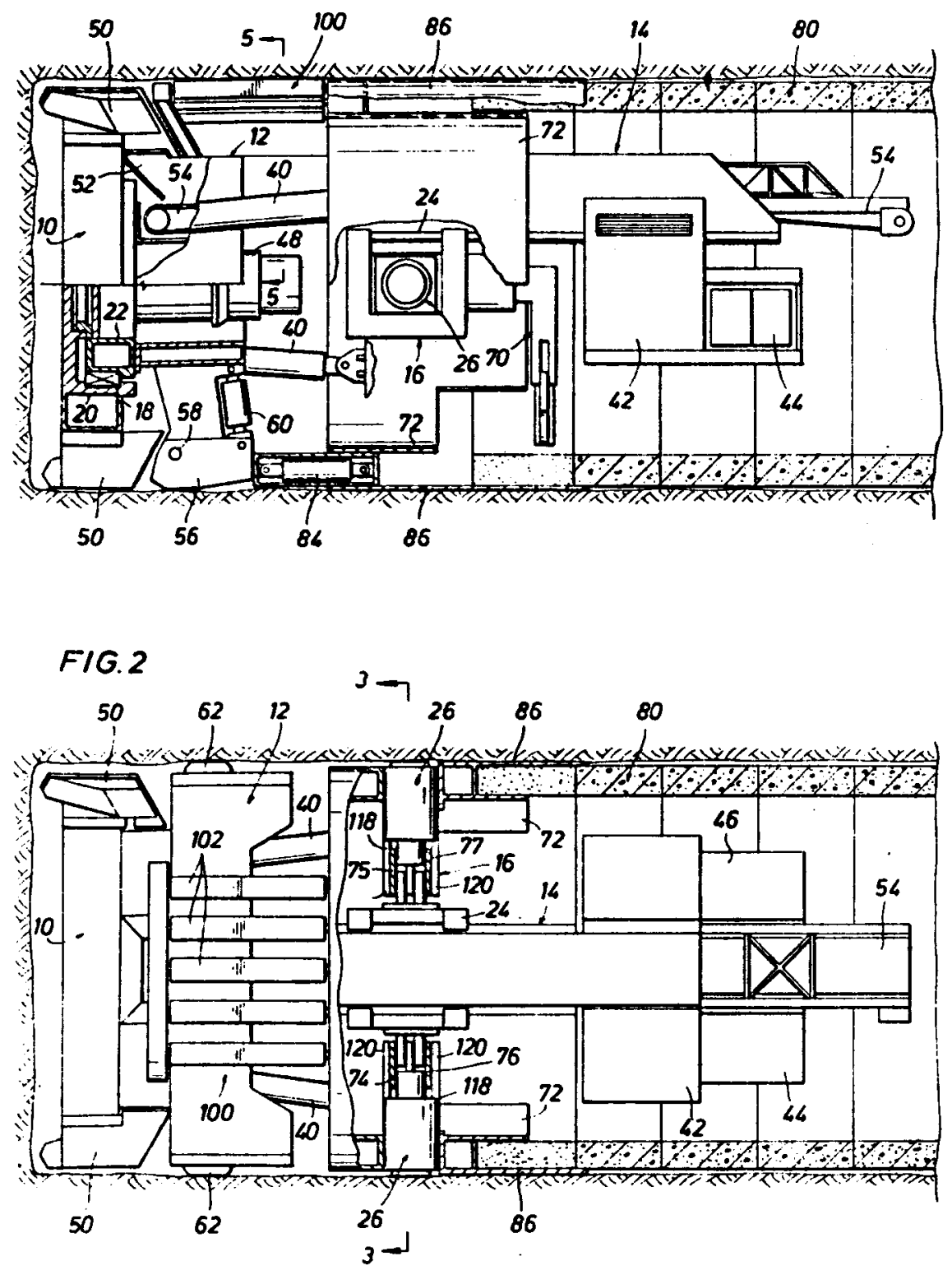

Patent No: 1212915 (British)

Date: November 18, 1970

Inventor: Howard Trethewen Edgecombe

Assignee:

Title:

Apparatus for Bore-Hole Drilling 


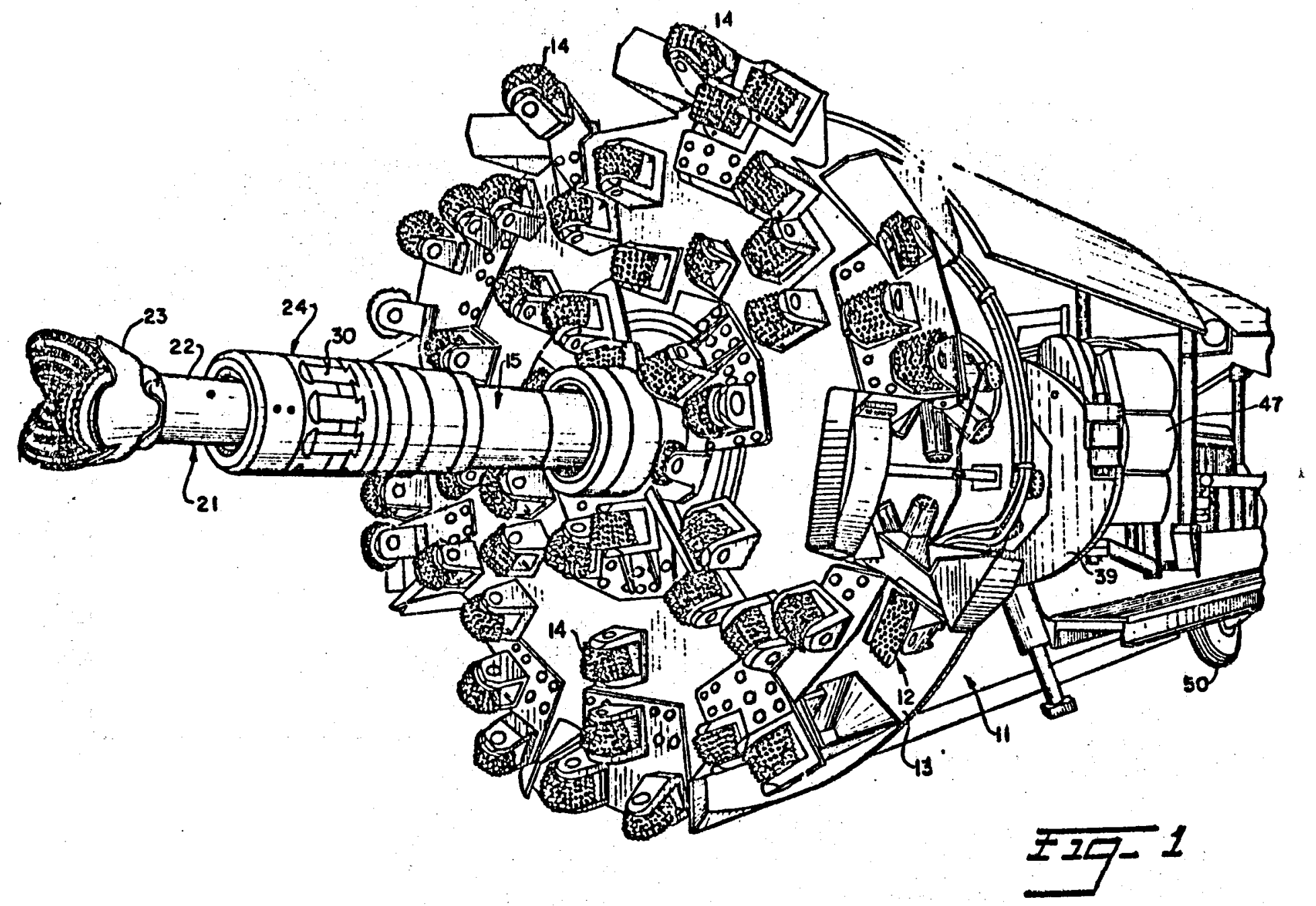

Patent No: $\quad 3,437,380$

Date: April 8, 1969

Inventor: J. C. Lawrence

Assignee: Alkirk, Inc.

Title: Steering Method and Apparatus 


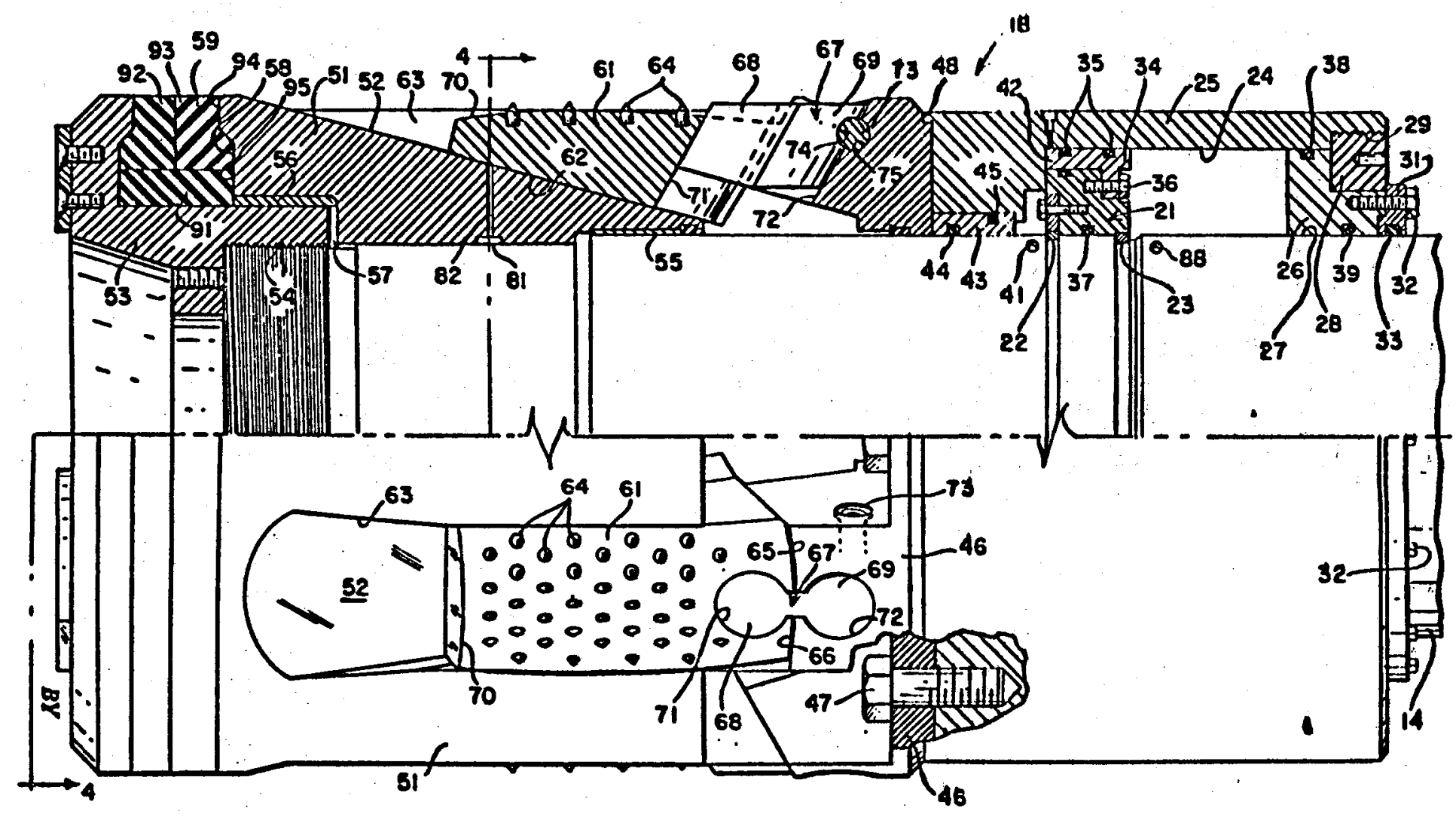

FIG. 2

\footnotetext{
Patent No: $\quad 3,386,520$

Date: June 4, 1968

Inventor: James C. Lawrence et al

Assignee: Alkirk, Inc.

Title: Apparatus for Anchoring the Pilot Member in a Pilot Bore
} 


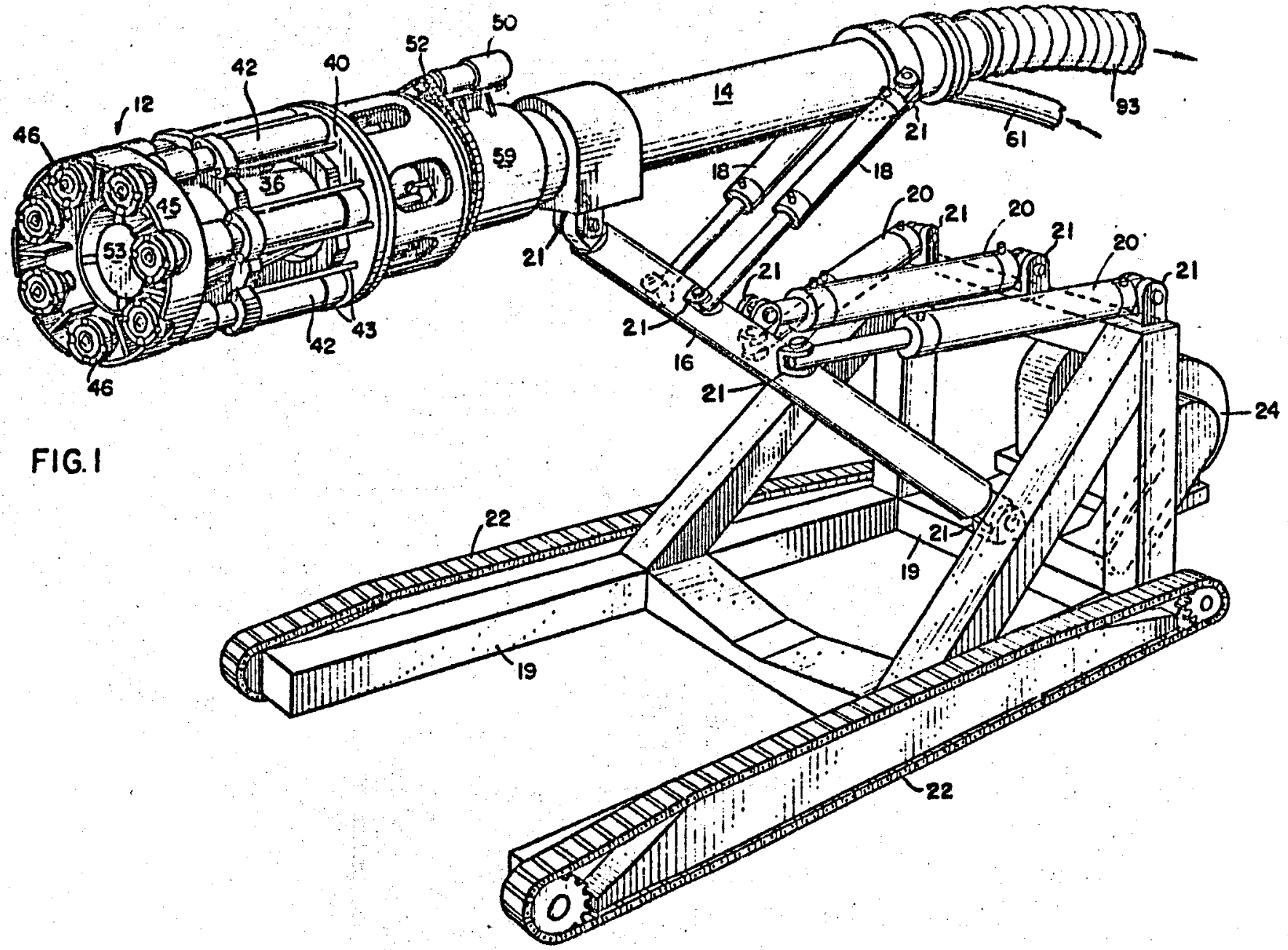

Patent No: $\quad 3,314,724$

Date: April 18, 1967

Inventor: William Tinlin

Assignee:

Title:

Tunneling Machine and Impact-Tool Cutting Head Therefore 

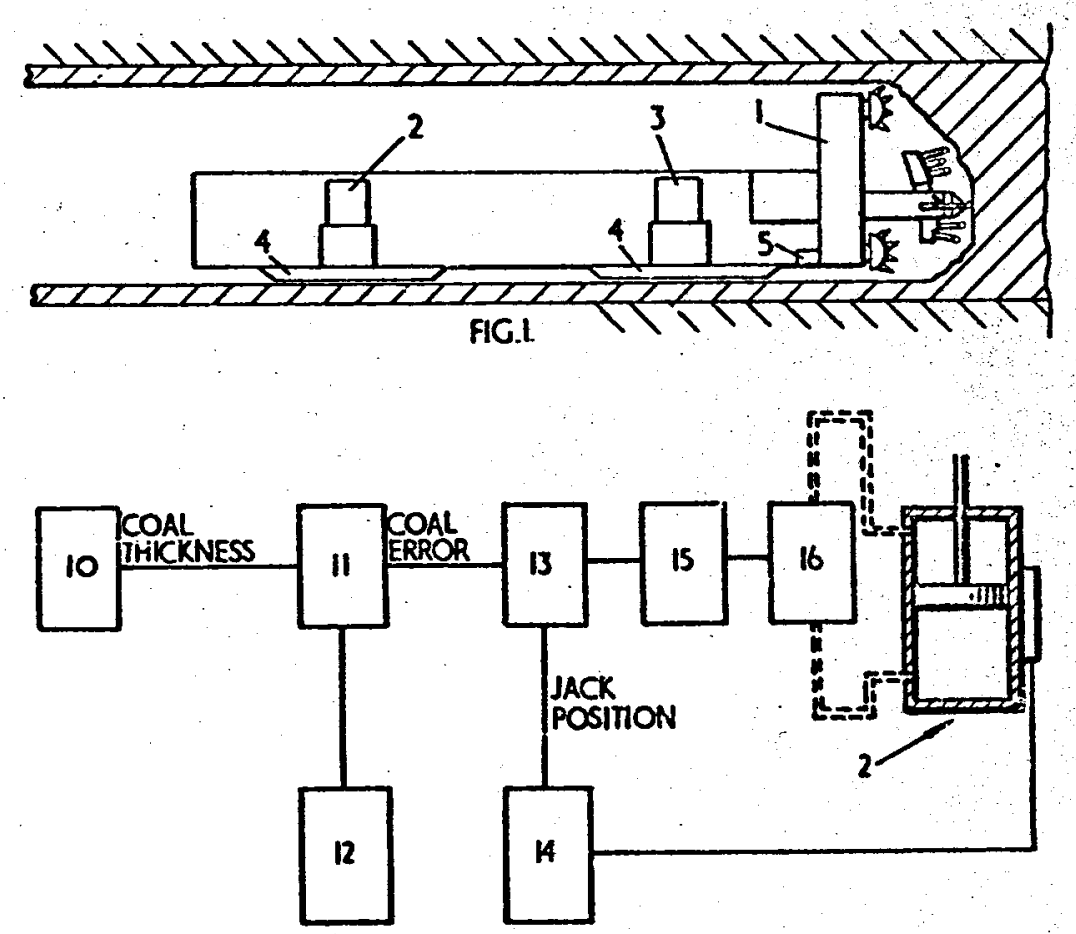

FIC. 2.

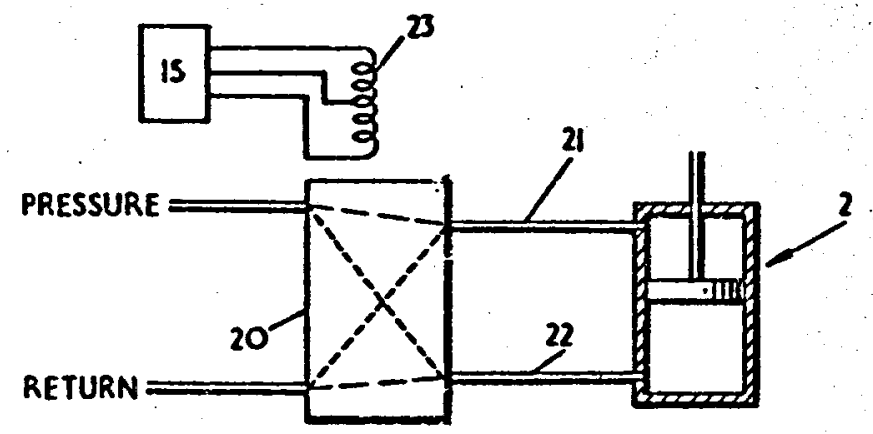

FIG. 3

Patent No: $\quad 3,294,449$

Date: December 27, 1966

Inventor: D. Hartley et al

Assignee: Coal Industry

Title: of a Mineral Mining Machine 


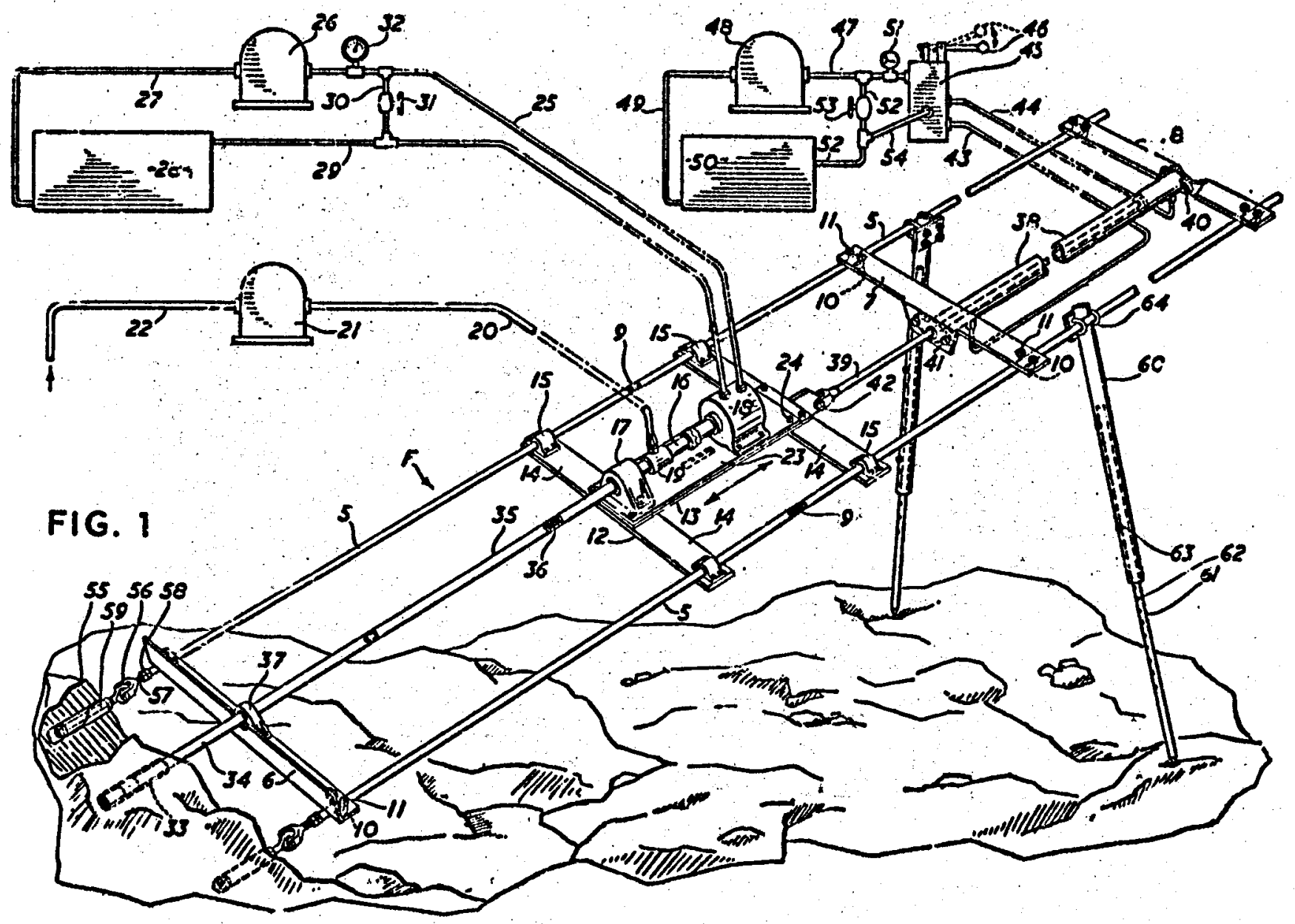

Patent No: $\quad 2,969,121$

Date: January 24, 1961

Inventor: J. G. Wallace

Assignee:

Title: Hydraulic Core Drill 


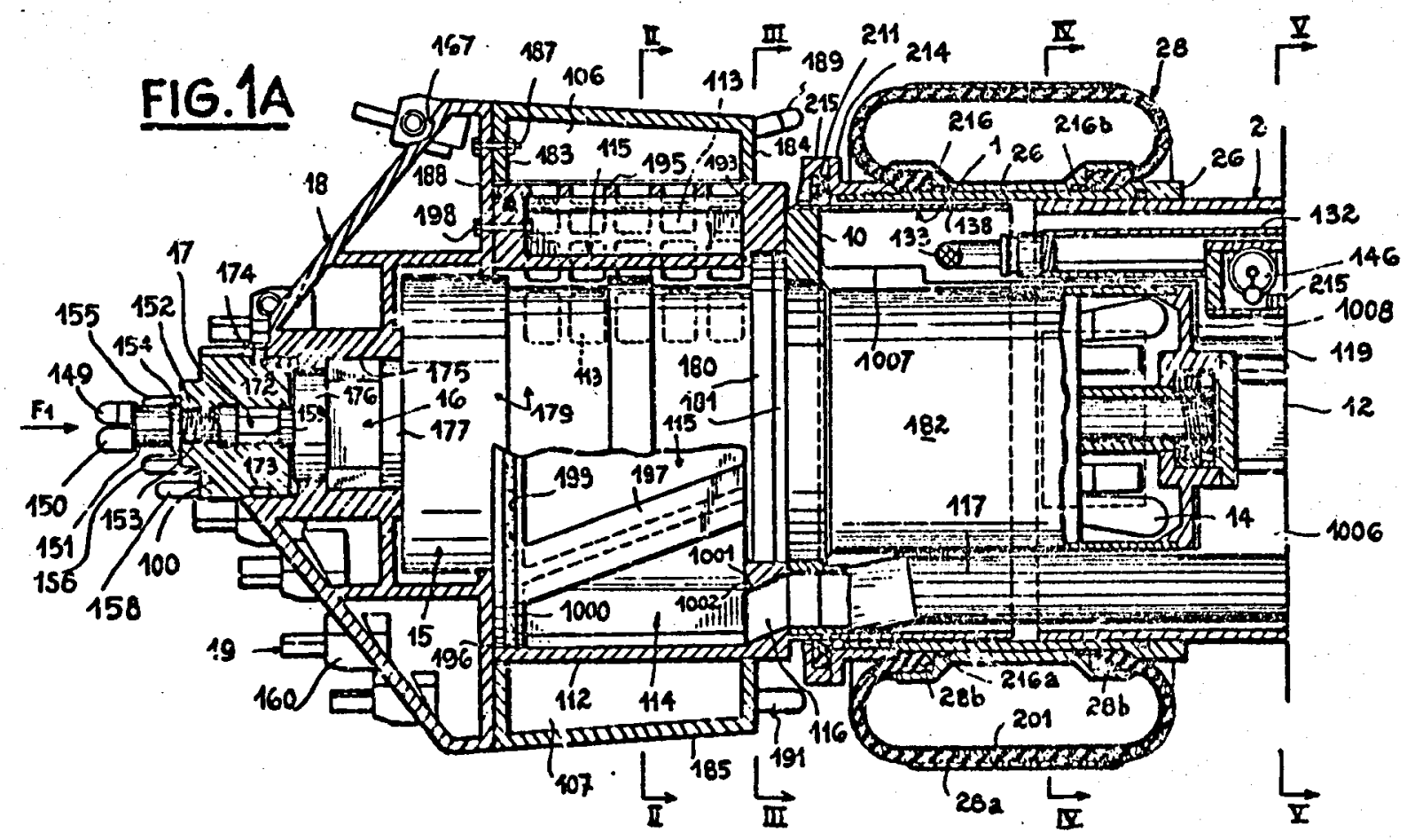

Patent No: $\quad 2,946,578$

Date: July 26, 1960

Inventor: A.'De Smaele

Assignee:

Title:

Excavator Apparatus Having Stepper Type Advancing Means 


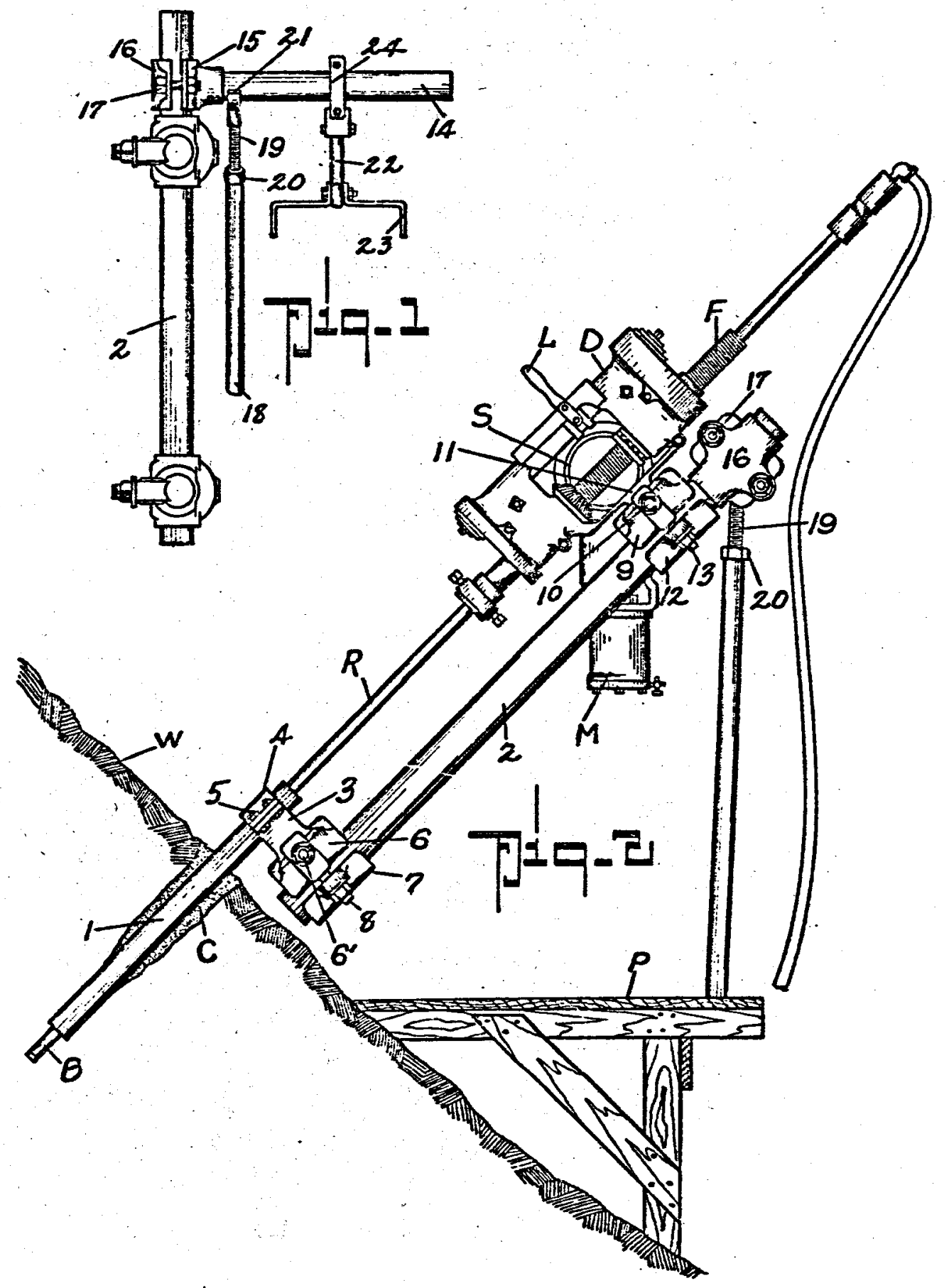

Patent No: $\quad 2,023,027$

Date: December 3, 1935

Inventor: W. J. Mitchell

Assignee: Chicago Pheumatic Tool Company

Title: Drill Rig 

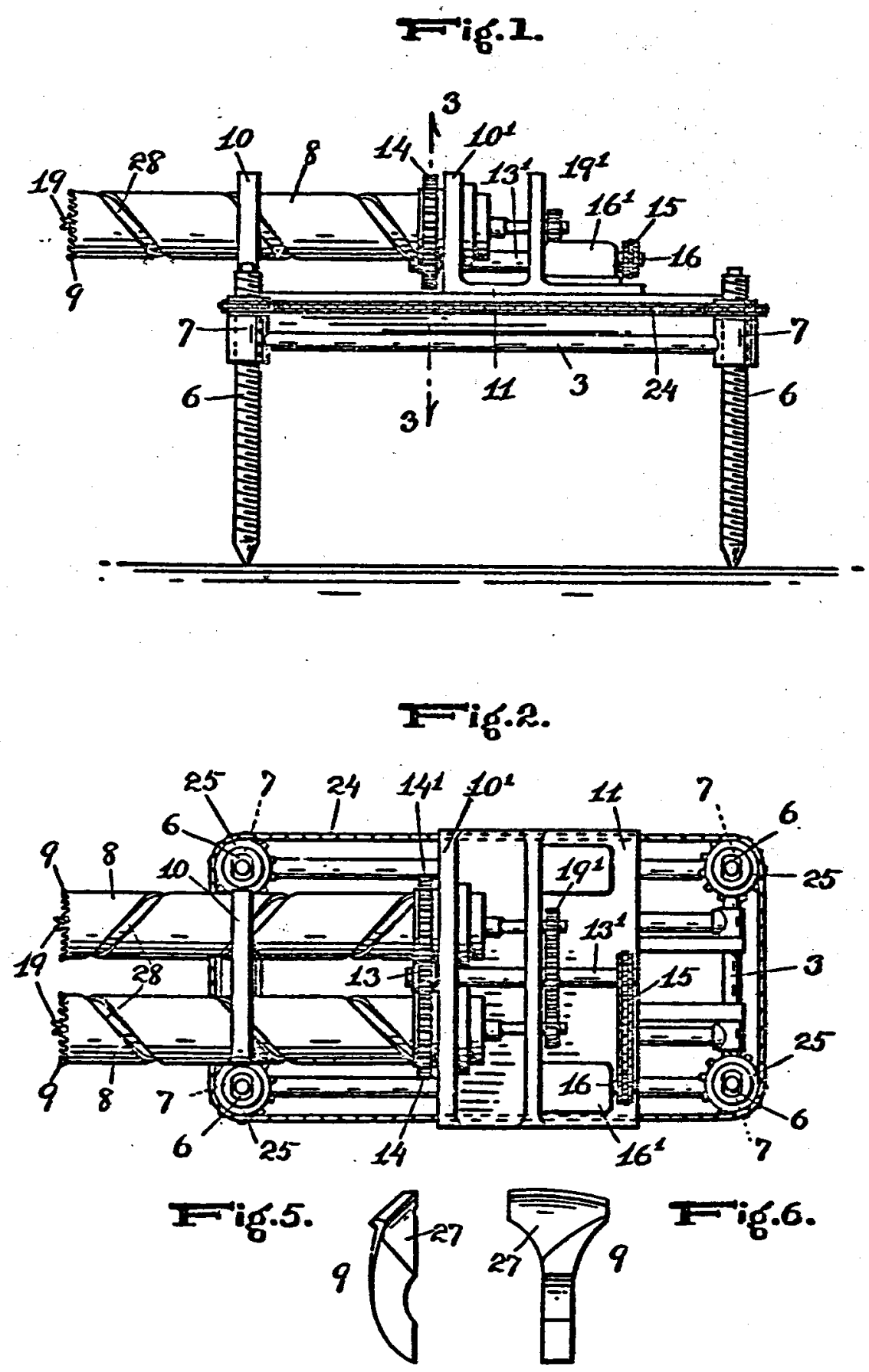

Patent No: $\quad 1,159,302$

Date: November 2, 1915

Inventor: J. S. Wallace

Assignee:

Title:

Coal Mining Machine 
Distribution:

TID-4500-R66 UC-66C

$\begin{aligned} 400 & \text { C. Winter } \\ 1000 & \text { G. A. Fow1er } \\ 1100 & \text { C. D. Broyles } \\ 2000 & \text { E. D. Reed } \\ 2300 & \text { J. C. King } \\ 2500 & \text { J. C. Crawford } \\ 4000 & \text { A. Narath } \\ 4200 & \text { G. Yonas } \\ 4300 & \text { R. L. Peurifoy, Jr. } \\ 4400 & \text { A. W. Snyder } \\ 4500 & \text { E. H. Beckner } \\ 4700 & \text { J. H. Scott } \\ 4710 & \text { G. E. Brandvo1d } \\ 4720 & \\ 4740 & \text { R. K. Traeger } \\ 4741 & \text { J. R. Ke1sey (25) } \\ 4742 & \text { A. F. Veneruso } \\ 4743 & \text { H. C. Hardee } \\ 4746 & \text { B. Granoff } \\ 4747 & \\ 4748 & \text { B. E. Bader } \\ 4750 & \text { V. L. Dugan } \\ 4751 & \text { J. R. Tillerson } \\ 4756 & \text { H. M. Dodd } \\ 5000 & \text { J. K. Ga1t } \\ 5600 & \text { D. B. Schuster. } \\ 5800 & \text { R. S. Claassen } \\ 3141 & \text { L. J. Erickson (5) } \\ 3151 & \text { W. L. Garner (3) } \\ 8214 & \text { M. A. Pound } \\ & \end{aligned}$

